Florida International University FIU Digital Commons

6-11-2018

\title{
The Investigation of Photocatalytic and Adsorptive Properties of Humic Acid Grafted Magnetite Nanoparticles for the Remediation of Arsenic, Selenium and Phosphorous from Water
}

Mohammad Mamunur Rashid

Florida International University, mrash008@fiu.edu

DOI: $10.25148 /$ etd.FIDC006892

Follow this and additional works at: https://digitalcommons.fiu.edu/etd

Part of the Analytical Chemistry Commons, Environmental Chemistry Commons, and the Materials Chemistry Commons

\section{Recommended Citation}

Rashid, Mohammad Mamunur, "The Investigation of Photocatalytic and Adsorptive Properties of Humic Acid Grafted Magnetite Nanoparticles for the Remediation of Arsenic, Selenium and Phosphorous from Water" (2018). FIU Electronic Theses and Dissertations. 3745.

https://digitalcommons.fiu.edu/etd/3745

This work is brought to you for free and open access by the University Graduate School at FIU Digital Commons. It has been accepted for inclusion in FIU Electronic Theses and Dissertations by an authorized administrator of FIU Digital Commons. For more information, please contact dcc@fiu.edu. 


\title{
FLORIDA INTERNATIONAL UNIVERSITY
}

Miami, Florida

\section{THE INVESTIGATION OF PHOTOCATALYTIC AND ADSORPTIVE PROPERTIES OF HUMIC ACID GRAFTED MAGNETITE NANOPARTICLES FOR THE REMEDIATION OF ARSENIC, SELENIUM AND PHOSPHOROUS FROM WATER}

\author{
A dissertation submitted in partial fulfillment of \\ the requirements for the degree of \\ DOCTOR OF PHILOSOPHY \\ in \\ CHEMISTRY \\ by
}

Mohammad Mamunur Rashid 
To: Dean Michael R. Heithaus

College of Arts, Sciences and Education

This dissertation, written by Mohammad Mamunur Rashid, and entitled The Investigation of Photocatalytic and Adsorptive Properties of Humic Acid Grafted Magnetite Nanoparticles for the Remediation of Arsenic, Selenium and Phosphorous from Water, having been approved in respect to style and intellectual content, is referred to you for judgment.

We have read this dissertation and recommend that it be approved.

$\begin{array}{r}\text { Yong Cai } \\ \hline \text { Raphael Raptis } \\ \hline \text { Alexander Mebel } \\ \hline \text { Kevin E. O'Shea, Major Professor Li }\end{array}$

Date of Defense: June 11, 2018

The dissertation of Mohammad Mamunur Rashid is approved.

Dean Michael R. Heithaus

College of Arts, Sciences and Education

Andrés G. Gil

Vice President for Research and Economic Development and Dean of the University Graduate School

Florida International University, 2018 
(C) Copyright 2018 by Mohammad Mamunur Rashid

All rights reserved. 


\section{DEDICATION}

I would like to dedicate this dissertation to my parents, Late Mohammad Ibrahim and Late Momtaz Begum and my wife Anika Samiha. Without their unconditional love, support and sacrifices, I would not be able to come this far to make my dream a reality. 


\section{ACKNOWLEDGMENTS}

Very firstly, I would like to thank my $\mathrm{PhD}$ advisor, Dr. Kevin O'Shea for mentoring and guiding me throughout my journey in the program with his ideas and advices, skills and expertise. I am really grateful to him for making my $\mathrm{PhD}$ life a memorable and enjoyable one. I want to extend my gratitude to my committee members Dr. Yong Cai, Dr. Raphael Raptis, Dr. Alexander Mebel and Dr. Wenzhi Li for their invaluable suggestions and comments that helps me to improve the quality of my research work and dissertation. Appreciations are extended to my research collaborators. I am thankful to Dr. Miguel Ángel Gracia Pinilla of Universidad Autónoma de Nuevo León, Mexico for doing some characterizations of my synthesized nanoparticles in his laboratory. I also love to acknowledge Dr. George Sterbinsky of Advanced Photon Source at Argonne National Laboratory, Illinois for helping me in doing different X-ray analysis of the nanoparticles during my visit in the facility. With great respect, I want to mention the name of Dr. Barry Rosen and Dr. Yoshinaga Masafumi of the Herbert Wertheim College of Medicine at FIU for giving me the permission to use their LC-ICPMS instrument for a prolonged period of time. Special thanks to Dr. Guangliang from Dr. Cai's lab for helping me with valuable research insights.

I also want to thank all the group members of Dr. O'Shea research group for being helpful and nice to me all the time. My sincere gratitude to University Graduate School of FIU for awarding me the Dissertation Year Fellowship (DYF) and Dissertation Evidence Acquisition (DEA) fellowship. Special acknowledgement to National Science Foundation (NSF) for their grant (ECS1710111) that helped fund my research project. Finally, big thanks to the Journals who published my papers and gave me the copyright permissions. 


\author{
ABSTRACT OF THE DISSERTATION \\ THE INVESTIGATION OF PHOTOCATALYTIC AND ADSORPTIVE PROPERTIES \\ OF HUMIC ACID GRAFTED MAGNETITE NANOPARTICLES FOR THE \\ REMEDIATION OF ARSENIC, SELENIUM AND PHOSPHOROUS FROM WATER
}

by

Mohammad Mamunur Rashid

Florida International University, 2018

Miami, Florida

Professor Kevin E. O’Shea, Major Professor

The crisis of freshwater has been a big concern worldwide. Water contamination that occurs through the discharge of toxic pollutants from different natural and anthropogenic sources have worsened the situation. Adsorption has emerged as a simple and economical water treatment procedure although the challenge is to find the right adsorbent that can efficiently remove the target contaminant followed by their easy recovery from the reaction vessel. In this dissertation, I have focused on the synthesis, characterizations and applications of environmentally compatible and magnetic humic acid coated magnetite nanoparticles (HA-MNP) as a potential adsorbent for water purification.

Phosphate is an essential nutrient for many plants and organisms in the environment. However, it can also cause water pollution when present in excess amounts. The adsorption experiments showed that the laboratory synthesized nanoparticles (HAMNP) can remove more than $90 \%$ of phosphate from water mainly through the mechanism of chemisorption. The overall removal process is spontaneous, endothermic and favorable. 
Water contamination by arsenic is considered one of the biggest natural disasters in human history. In the study, HA-MNP has been applied for the successful trapping and separation of two highly toxic inorganic As species, As(III) and As(V) from water. The removal of $\mathrm{As}(\mathrm{V})$ was faster than $\mathrm{As}(\mathrm{III})$ for the same initial arsenic concentration and HAMNP loading. The binding of As species is mainly attributed to three different phases, rapid surface association, intraparticle diffusion and equilibrium adsorption.

Selenium is a micronutrient for humans that can be toxic at modest concentrations. The remediation of toxic selenium species, $\mathrm{Se}(\mathrm{IV})$ and $\mathrm{Se}(\mathrm{VI})$ by using HA-MNP has been found effective under a variety of environmental conditions except at highly alkaline $\mathrm{pH}$ and the presence of sulfate and phosphate in aqueous solution. Selenite or Se(IV) forms strong inner sphere complexes while $\mathrm{Se}(\mathrm{VI})$ forms relatively weaker outer sphere complexes with the adsorbent sites.

The oxidation and adsorption of As(III) is explored by using the photocatalytic and adsorptive behavior of HA-MNP. The higher removal efficiency is attained through the reactive oxygen species mediated photo-conversion $\mathrm{As}(\mathrm{III})$ to $\mathrm{As}(\mathrm{V})$. Combination of oxygen and $350 \mathrm{~nm}$ light provides the best results. 


\section{TABLE OF CONTENTS}

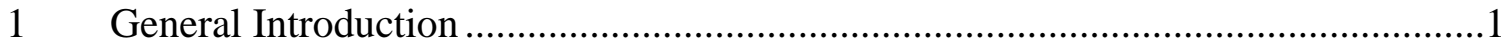

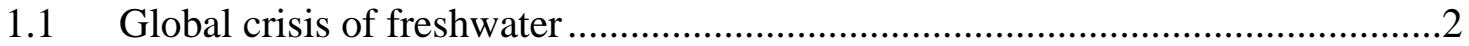

1.1.1 Water contamination by arsenic, selenium and phosphorous ........................2

1.2 Arsenic, selenium and phosphorous remediation by adsorption .........................6

1.2.1 Magnetic iron oxide nanoparticles ..............................................................

1.2.2 Natural organic matter coated iron oxide nanoparticles …………..................

1.2.3 Reactive oxygen species generation by HA-MNP.......................................10

1.3 General objective of dissertation ..............................................................11

2 Effective Removal of Phosphate from Aqueous Solution Using Humic Acid Coated Magnetite Nanoparticles.........................................................................13

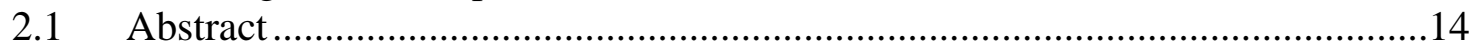

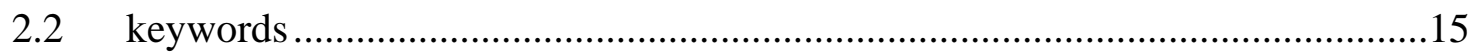

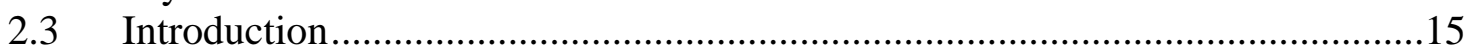

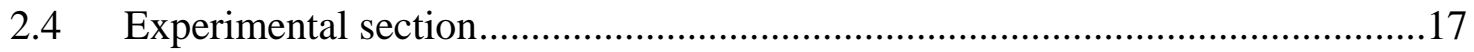

2.4.1 Materials ........................................................................................17

2.4.2 Synthesis of humic acid coated magnetite nanoparticles................................17

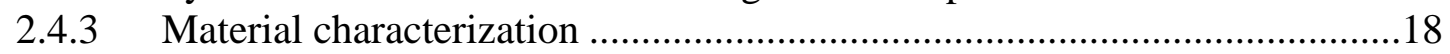

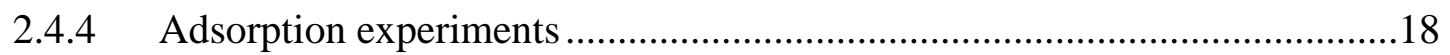

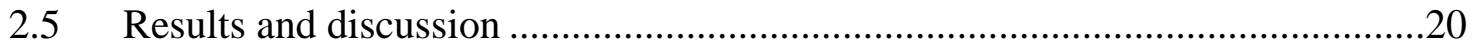

2.5.1 Characterization of the synthesized nanoparticles ......................................20

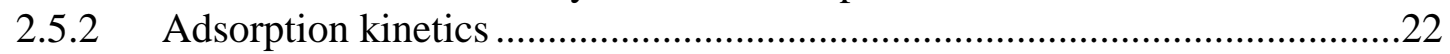

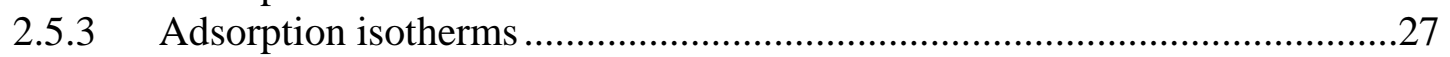

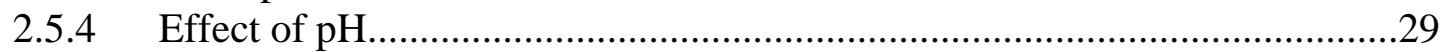

2.5.5 Effect of temperature …………............................................................

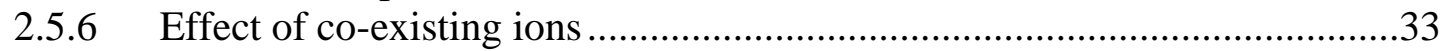

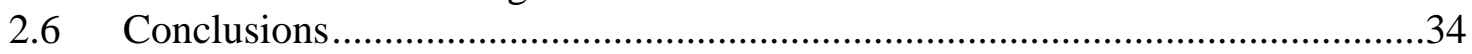

3 Kinetic and Mechanistic Evaluation of Inorganic Arsenic Species Adsorption onto Humic Acid Grafted Magnetite Nanoparticles ..................................................36

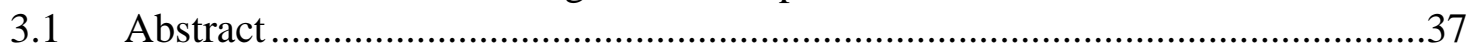

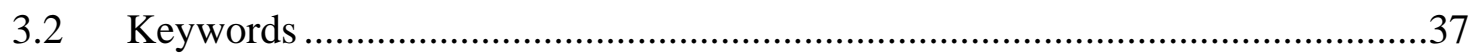

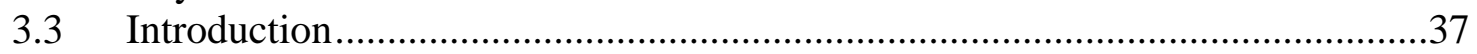

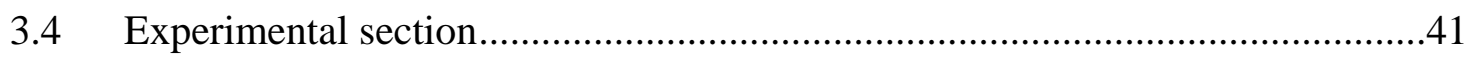

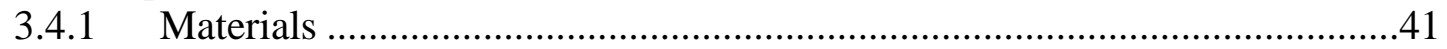

3.4.2 Synthesis and application of HA-MNP ....................................................

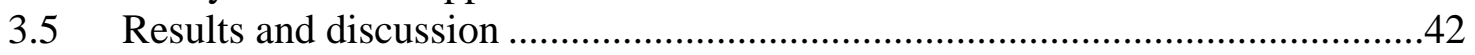

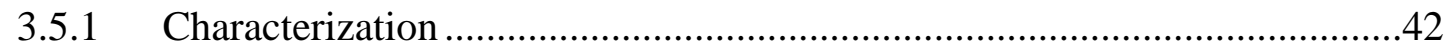

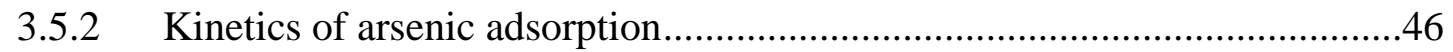

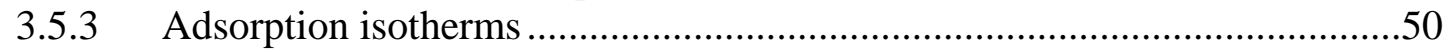

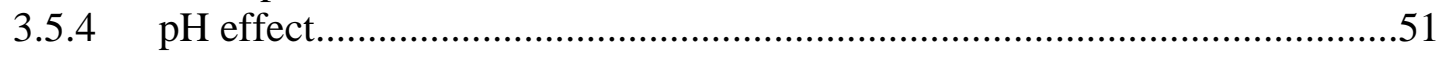




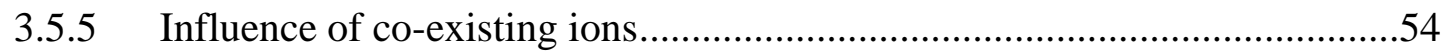

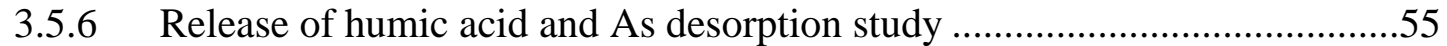

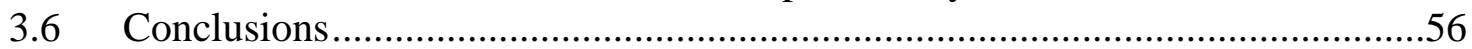

$4 \quad$ Study of the Sequestration of Toxic Selenium Species from Water by using

NOM Grafted Magnetic Iron Oxide Nanoparticles .............................................57

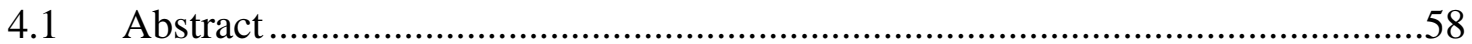

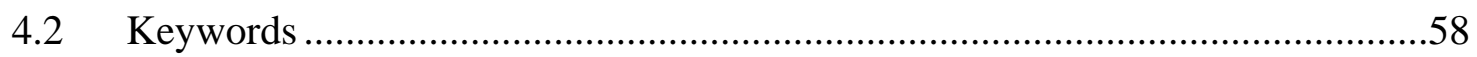

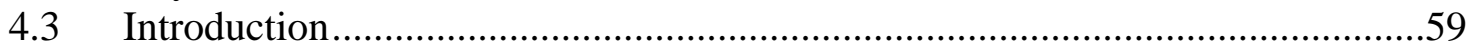

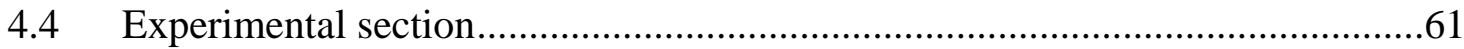

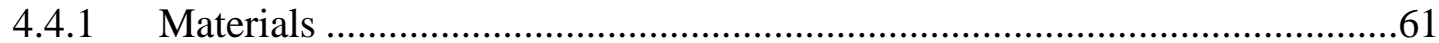

4.4.2 Synthesis and characterization of HA-MNP .........................................62

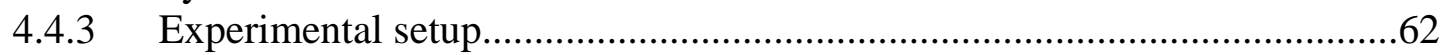

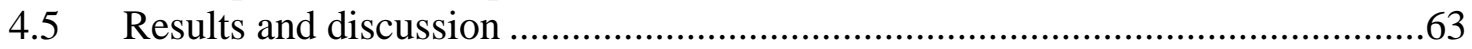

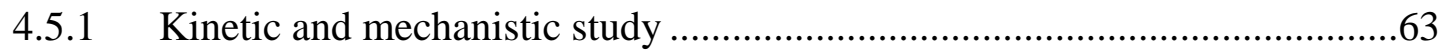

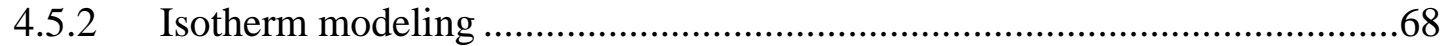

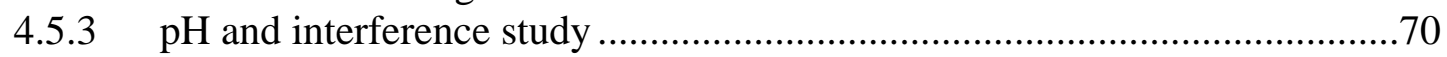

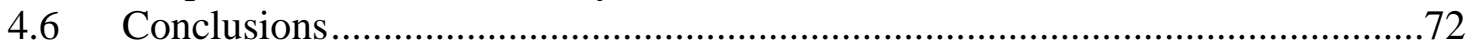

5 Efficient Removal of As(III) from Water by using the Photocatalytic and Adsorptive Properties of Humic Acid Coated Magnetic Nanoparticles ...................73

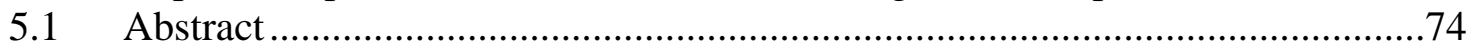

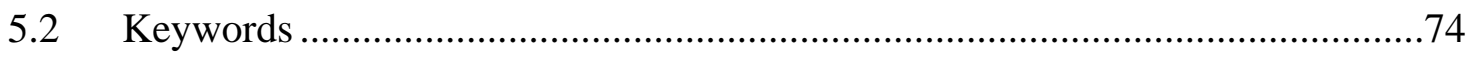

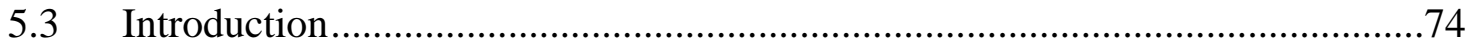

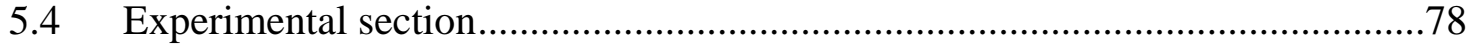

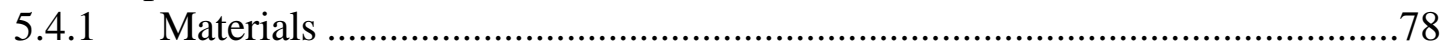

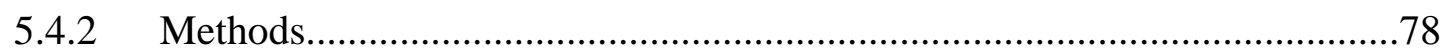

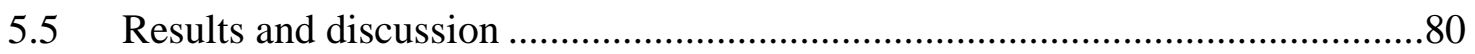

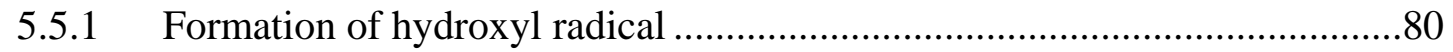

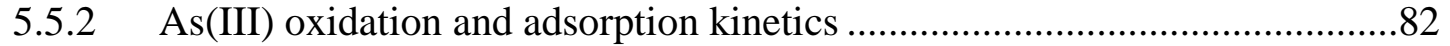

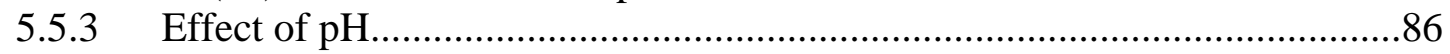

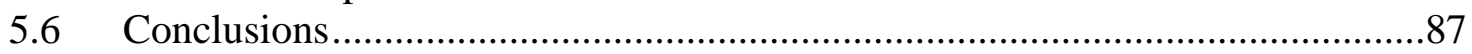

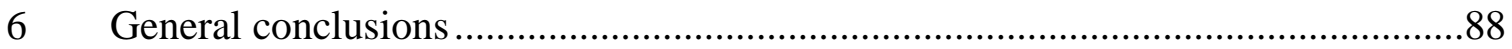

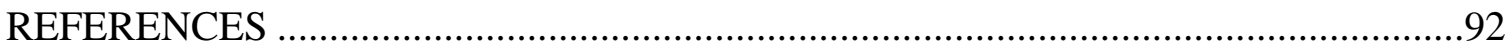

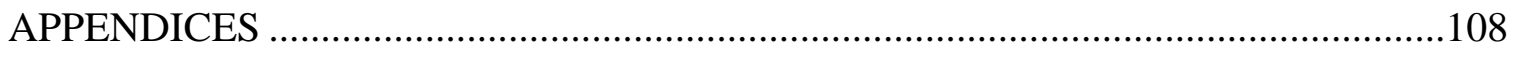

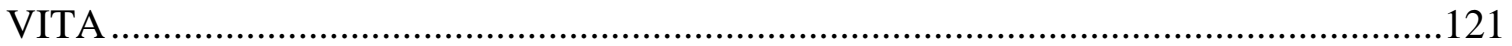




\section{LIST OF TABLES}

TABLE

PAGE

Table 1.1. Different arsenic compounds and their oxidation states ................................4

Table 2.1. Kinetic parameters for the adsorption of phosphate onto HA-MNP ..............25

Table 2.2. Langmuir and Freundlich parameters for the adsorption of phosphate onto

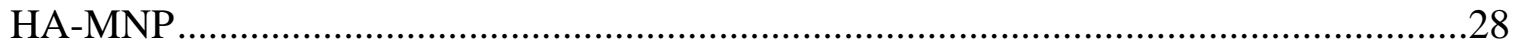

Table 2.3. Thermodynamic data for the adsorption of phosphate onto HA-MNP ...........33

Table 3.1. Kinetic parameters for the adsorption of arsenic onto HA-MNP ..................49

Table 3.2. Adsorption isotherm parameters for the binding of As(III) and As(V) onto

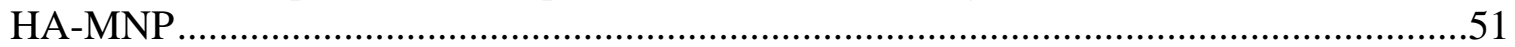

Table 4.1. Parameters for the kinetic modeling of selenium species adsorption by HA-MNP .66

Table 4.2. Parameters for the isotherm modeling of selenium species adsorption by HA-MNP

Table 5.1. Corrected concentration of 7-HC with respect to time

Table A1. Summary of the concentration of dissolved organic carbon (DOC) due to leaching of NOM from HA-MNP at different $\mathrm{pH}$ 108

Table B1. Effect of iron in the adsorption of arsenic species on HA-MNP

Table B2. Release of dissolved organic carbon from HA-MNP before and after arsenic adsorption 


\section{LIST OF FIGURES}

FIGURE

PAGE

Figure 1.1. Speciation and $\mathrm{pK}_{\mathrm{a}}$ values for arsenic and selenium ................................5

Figure 1.2. Empirical structure of humic acid (HA) .................................................

Figure 2.1. TEM images of HA-MNP. (a) low resolution TEM image, the red lines show the humic acid coating on MNP (b) HRTEM images shows a high crystalline structure of magnetite core in HA-MNPs

Figure 2.2. STEM-HAADF images of HA-MNP, (a) High resolution STEM-HAADF image (detail of high porosity). (b) low magnification STEM-HAADF image of HA-MNP clearly shows the high porosity in the surface of MNP, (c) EDS spectra of HA-MNP.

Figure 2.3. Adsorption kinetics of phosphate on HA-MNP. Initial phosphate (P) concentration $=2$ to $10 \mathrm{mg} / \mathrm{L}(\mathrm{ppm}), \mathrm{pH}=6.6, \mathrm{HA}-\mathrm{MNP}$ dose $=1.0 \mathrm{~g} / \mathrm{L}$, temperature $=298 \mathrm{~K}$, contact time $=3$ hours

Figure 2.4. Phosphate adsorption modeling of the kinetic data with Weber-Morris intraparticle diffusion plot. Series 1 (point 1-4, 0 to 10 minutes): external adsorption, series 2 (point 4-6, 10 to 60 minutes): intraparticle diffusion, series3 (point 6-9, 60 to 180 minutes): equilibrium adsorption. Initial phosphate $(\mathrm{P})$ concentration $=5 \mathrm{mg} / \mathrm{L}$, $\mathrm{pH}=6.6, \mathrm{HA}-\mathrm{MNP}$ dose $=1.0 \mathrm{~g} / \mathrm{L}$, temperature $=298 \mathrm{~K}$, contact time $=3$ hours

Figure 2.5. Effect of initial $\mathrm{pH}$ for the adsorption of phosphate onto HA-MNP. Initial phosphate concentration $=5 \mathrm{mg} / \mathrm{L}, \mathrm{HA}-\mathrm{MNP}$ dose $=1.0 \mathrm{~g} / \mathrm{L}$, temperature $=$ $298 \mathrm{~K}$, contact time $=1$ hour

Figure 2.6. Effect of temperature for the adsorption of phosphate onto HA-MNP. Initial phosphate concentration $=5 \mathrm{mg} / \mathrm{L}, \mathrm{pH}=6.6, \mathrm{HA}-\mathrm{MNP}$ dose $=1.0 \mathrm{~g} / \mathrm{L}$, contact time $=1$ hour

Figure 2.7. Arrhenius plot of lnk vs $1 / \mathrm{T}$ to determine activation energy

Figure 2.8. Effect of coexisting ions for the adsorption of phosphate onto HA-MNP. Initial phosphate concentration $=5 \mathrm{mg} / \mathrm{L}$, concentration of each of the anions $=1 \mathrm{mM}$, $\mathrm{pH}=6.6, \mathrm{HA}-\mathrm{MNP}$ dose $=1.0 \mathrm{~g} / \mathrm{L}$, temperature $=298 \mathrm{~K}$, contact time $=3$ hours

Figure 3.1. (a) Low resolution TEM image of HA-MNP (b) STEM-HAADF image of As(III)-HA-MNP (c) HRTEM image of As(III)-HA-MNP and (d) EDS spectra of As(III)-HA-MNP

Figure 3.2. Raman spectra of HA-MNP and As(III)-HA-MNP 
Figure 3.3. Comparison of adsorption kinetics of As(III) and As(V) on HA-MNP. $[\mathrm{As}(\mathrm{III})]_{0}=200 \mathrm{ppb},[\mathrm{As}(\mathrm{V})]_{0}=200 \mathrm{ppb}, \mathrm{pH}=6.6, \mathrm{HA}-\mathrm{MNP} \operatorname{dose}=0.2 \mathrm{~g} / \mathrm{L}$, temperature $=25^{\circ} \mathrm{C}$

Figure 3.4. Weber-Morris intraparticle diffusion plot of As(III) and As(V) adsorption kinetic data. $[\mathrm{As}(\mathrm{III})]_{0}=200 \mathrm{ppb},[\mathrm{As}(\mathrm{V})]_{0}=200 \mathrm{ppb}, \mathrm{pH}=6.6$, HA-MNP dose $=0.2 \mathrm{~g} / \mathrm{L}$, temperature $=25^{\circ} \mathrm{C}$

Figure 4.1. Adsorption kinetics of Se(IV) and Se(VI). [Se(IV)]0 = $500 \mathrm{ppb}$, $[\mathrm{Se}(\mathrm{VI})]_{0}=500 \mathrm{ppb},[\mathrm{HA}-\mathrm{MNP}]=0.5 \mathrm{~g} / \mathrm{L}$ for $\mathrm{Se}(\mathrm{IV})$ and $1.0 \mathrm{~g} / \mathrm{L}$ for $\mathrm{Se}(\mathrm{VI})$

Figure 4.2. Competitive adsorption of $\mathrm{Se}(\mathrm{IV})$ and $\mathrm{Se}(\mathrm{VI})$ by HA-MNP from the same solution. $[\mathrm{Se}(\mathrm{IV})]_{0}=500 \mathrm{ppb},[\mathrm{Se}(\mathrm{VI})]_{0}=500 \mathrm{ppb},[\mathrm{HA}-\mathrm{MNP}]=1.0 \mathrm{~g} / \mathrm{L}$

Figure 4.3. Weber-Morris intraparticle diffusion model for the adsorption of Se(IV) and $\mathrm{Se}(\mathrm{VI})$ by HA-MNP....

Figure 4.4. Effect of ionic strength on Se adsorption by HA-MNP. [Se(IV) $]_{0}=500$ $\mathrm{ppb},[\mathrm{Se}(\mathrm{VI})]_{0}=500 \mathrm{ppb},[\mathrm{HA}-\mathrm{MNP}]=0.5 \mathrm{~g} / \mathrm{L}$ for $\mathrm{Se}(\mathrm{IV})$ and $1.0 \mathrm{~g} / \mathrm{L}$ for $\mathrm{Se}(\mathrm{VI})$

Figure 4.5. Effect of solution $\mathrm{pH}$ on Se adsorption by HA-MNP. [Se(IV) $]_{0}=500$ $\mathrm{ppb},[\mathrm{Se}(\mathrm{VI})]_{0}=500 \mathrm{ppb},[\mathrm{HA}-\mathrm{MNP}]=0.5 \mathrm{~g} / \mathrm{L}$ for $\mathrm{Se}(\mathrm{IV})$ and $1.0 \mathrm{~g} / \mathrm{L}$ for $\mathrm{Se}(\mathrm{VI})$

Figure 4.6. Effect of co-existing ions on Se adsorption by HA-MNP. [Se(IV) $]_{0}=500$ $\mathrm{ppb},[\mathrm{Se}(\mathrm{VI})]_{0}=500 \mathrm{ppb},[\mathrm{HA}-\mathrm{MNP}]=0.5 \mathrm{~g} / \mathrm{L}$ for $\mathrm{Se}(\mathrm{IV})$ and $1.0 \mathrm{~g} / \mathrm{L}$ for $\mathrm{Se}(\mathrm{VI}) \ldots \ldots . . .72$

Figure 5.1. Chromophoric part of humic acid (HA)

Figure 5.2. Photogeneration of different ROS via charge transfer from HA interaction with $\mathrm{O}_{2}$

Figure 5.3. Fluorescence intensity of 7-HC generated from the reaction between coumarin and hydroxyl radical. [coumarin $]_{0}=125 \mu \mathrm{M},[\mathrm{HA}-\mathrm{MNP}]=1.0 \mathrm{~g} / \mathrm{L}$, Total lamps $=14$, Light wavelength $=350 \mathrm{~nm}$

Figure 5.4. Concentration of 7-HC generated from the reaction between coumarin and hydroxyl radical. [coumarin $]_{0}=125 \mu \mathrm{M},[\mathrm{HA}-\mathrm{MNP}]=1.0 \mathrm{~g} / \mathrm{L}$, Total lamps $=$ 14, Light wavelength $=350 \mathrm{~nm}$

Figure 5.5. Concentration of 7-HC generated from the reaction between coumarin and hydroxyl radical in absence of light. [coumarin $]_{0}=125 \mu \mathrm{M}$, [HA-MNP] $=$ $1.0 \mathrm{~g} / \mathrm{L}$

Figure 5.6. Formation kinetics of 7-HC after the correction of concentration in dark condition 
Figure 5.7. Photo-oxidation and adsorption of As(III) by HA-MNP in presence of $\mathrm{O}_{2}$. $[\mathrm{As}(\mathrm{III})]_{0}=200 \mathrm{ppb},[\mathrm{HA}-\mathrm{MNP}]=0.2 \mathrm{~g} / \mathrm{L}$, total lamps $=14$, light wavelength $=$ $350 \mathrm{~nm}$

Figure 5.8. Oxidation and adsorption of As(III) by HA-MNP in presence of $\mathrm{O}_{2}$ and without light. $[\mathrm{As}(\mathrm{III})]_{0}=200 \mathrm{ppb},[\mathrm{HA}-\mathrm{MNP}]=0.2 \mathrm{~g} / \mathrm{L}$

Figure 5.9. Photo-oxidation and adsorption of As(III) by HA-MNP in presence of argon. $[\mathrm{As}(\mathrm{III})]_{0}=200 \mathrm{ppb},[\mathrm{HA}-\mathrm{MNP}]=0.2 \mathrm{~g} / \mathrm{L}$, total lamps $=14$, light wavelength $=350 \mathrm{~nm}$.

Figure 5.10. Oxidation and adsorption of As(III) by HA-MNP in presence of argon and without light. $[\mathrm{As}(\mathrm{III})]_{0}=200 \mathrm{ppb},[\mathrm{HA}-\mathrm{MNP}]=0.2 \mathrm{~g} / \mathrm{L}$

Figure 5.11. Effect of $\mathrm{pH}$ for the oxidation and adsorption of As(III) in presence of light and $\mathrm{O}_{2} .[\mathrm{As}(\mathrm{III})]_{0}=200 \mathrm{ppb},[\mathrm{HA}-\mathrm{MNP}]=0.2 \mathrm{~g} / \mathrm{L}$, total lamps $=14$, light wavelength $=350 \mathrm{~nm}$

Figure A1: Synthesized humic acid coated magnetite nanoparticles (HA-MNP) in presence of a handheld magnet a) before adsorption of phosphate b) after adsorption of phosphate

Figure A2: FTIR spectra of humic acid (HA) and humic acid coated magnetite nanoparticles (HA-MNP)

Figure B1: FTIR spectra of the synthesized HA-MNP before and after the adsorption of arsenic species

Figure B2: Size distribution of HA-MNP from TEM measurement

Figure B3: Adsorption and conversion of As(III) using HA-MNP and $\mathrm{O} 2$ under dark condition. Initial As(III) concentration $=200 \mathrm{ppb}, \mathrm{HA}-\mathrm{MNP}$ dose $=0.2 \mathrm{~g} / \mathrm{L}$

Figure B4: a) Wide scan XPS spectra of HA-MNP. Deconvolution of the XPS spectra of (b) C 1s, (c) O 1s and (d) Fe 2p respectively

Figure B5: Fe K-edge (a) XANES and (b) EXAFS spectra of bare magnetite and HA-MNP

Figure B6: (a) Arsenic K-edge XANES spectra of As(III) standard, As(V) standard and As(III)-HA-MNP at different $\mathrm{pH}$ (b) arsenic K-edge XANES spectra of As(III) standard, $\mathrm{As}(\mathrm{V})$ standard and $\mathrm{As}(\mathrm{V})-\mathrm{HA}-\mathrm{MNP}$ at different $\mathrm{pH}$ 118

Figure B7: XANES spectra time profile of HA-MNP treated As(III) at pH 6.1 
Figure B8: Competition between As(III) and As(V) for HA-MNP when present in the same solution. $[\mathrm{As}(\mathrm{III})]_{0}=200 \mathrm{ppb},[\mathrm{As}(\mathrm{V})]_{0}=200 \mathrm{ppb}, \mathrm{pH}=6.6$, HA-MNP dose $=0.2 \mathrm{~g} / \mathrm{L}$

Figure B9: Effect of initial $\mathrm{pH}$ for the adsorption of As(III) and As(V) on HA-MNP. Initial As(III) concentration $=200 \mathrm{ppb}$, initial As(V) concentration $=200 \mathrm{ppb}$, HA-MNP dose $=0.2 \mathrm{~g} / \mathrm{L}$, temperature $=25^{\circ} \mathrm{C}$, MCL stands for Maximum Contaminant Level (in drinking water).

Figure B10: Effect of coexisting ions for the adsorption of arsenic species on HA-MNP. Initial As(III) concentration $=200 \mathrm{ppb}$, initial As $(\mathrm{V})$ concentration $=$ $200 \mathrm{ppb}, \mathrm{HA}-\mathrm{MNP}$ dose $=0.2 \mathrm{~g} / \mathrm{L}$, temperature $=25^{\circ} \mathrm{C}$ 


\section{CHAPTER 1}

General Introduction 


\subsection{Global crisis of freshwater}

The lack of access to freshwater is a serious problem putting the health and livelihood of millions of people around the world at risk. Only $~ 2.5 \%$ of all water on earth is freshwater and less than $0.26 \%$ of the global fresh water reserve is available for human consumption (Postel, Daily, \& Ehrlich, 1996). The stress on freshwater resources is increasing daily with population growth, urbanization and industrialization (Zimmerman et al., 2008). Close to two-thirds of the world's population currently live under severe water shortages for at least one month in any given year (M.Mekonnen and Hoekstra, 2016). Release of toxic chemicals from different natural and anthropogenic sources have aggravated the freshwater crisis (Polizzotto et al., 2008; Schwarzenbach et al., 2006). In addition to an extensive number of organic pollutants and heavy metals, the presence of inorganic contaminants such as arsenic, selenium, phosphorous in drinking water sources pose a serious threat to human health and ecological balance (Hamilton, 2004; Nickson et al., 1998; Stoddard et al., 2016). The development of a sustainable and eco-friendly water treatment methods is therefore critical for the effective remediation of these problematic water pollutants. The focus of this dissertation is on the development and demonstration of humic acid coated nanomaterials as an adsorbent for the remediation of arsenic, selenium and phosphorous.

\subsubsection{Water contamination by arsenic, selenium and phosphorous}

The presence of elevated levels of arsenic, selenium and phosphorous species in freshwater is a serious environmental and health concern. Arsenic (As) is a metalloid that belongs to group 15 in the periodic table directly below phosphorous and adjacent to 
selenium. Arsenic occurs in the earth's crust and is mobilized through volcanic eruption, mineral weathering, microbial assisted redox transformation, and a range of anthropogenic activities (A. K. Katja Amstaetter, Thomas Borch, Philip Larese-Casanova, 2010; Smedley and Kinniburgh, 2000). Human exposure to arsenic takes place mainly through consumption of contaminated water and food where arsenic exists in many different forms as shown in Table. 1.1 (Sharma et al., 2014). The toxicity of arsenic species generally follows the order of MMA(III) $>\operatorname{As}(\mathrm{III})>\operatorname{As}(\mathrm{V})>\operatorname{DMA}(\mathrm{V})>\mathrm{MMA}(\mathrm{V})$ (Sharma et al., 2014). However, in aqueous media, arsenic predominantly exists in its inorganic form as arsenite, $\mathrm{As}(\mathrm{III})$ and arsenate, $\mathrm{As}(\mathrm{V})$, with the former being more toxic and mobile than the latter. Groundwater contamination by arsenic has impacted the health of $\sim 150$ million people globally in more than 70 countries where the concentration of total arsenic varies from $0.5-5000 \mu \mathrm{g} / \mathrm{L}$ (Brammer and Ravenscroft, 2009; Sharma et al., 2014). The International Agency for Research on Cancer (IARC) classified inorganic arsenic in Group 1 as a proven carcinogen. Long term intake of this colorless, tasteless and odorless poison containing water can cause skin, lung and kidney cancer, cardiovascular disease, diabetes, birth defects and other health problems (Cheng et al., 2015; Naujokas et al., 2013). The adverse health effects of arsenic has led the United States Environmental Protection Agency (US EPA) and World Health Organization (WHO) to set $10 \mu \mathrm{g} / \mathrm{L}$ (ppb) as the maximum contaminant level (MCL) of arsenic in drinking water (Smedley and Kinniburgh, 2000).

Selenium (Se) is a naturally occurring trace element that is present in group 16 in the periodic table. Selenium is unique, functioning as an essential nutrient for humans at 
trace levels ( $<40 \mu \mathrm{g} / \mathrm{day})$ while considered toxic element at modest concentrations ( $>400$ $\mu \mathrm{g}$ /day) (Conde and Sanz Alaejos, 1997).

Table 1.1. Different arsenic compounds and their oxidation states

\begin{tabular}{|c|c|c|}
\hline Compound name & Detected media & Structure \\
\hline $\begin{array}{l}\text { Arsenous acid } \\
\qquad[\mathrm{As}(\mathrm{III})]\end{array}$ & Water & 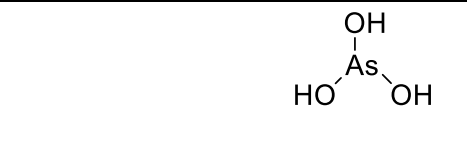 \\
\hline Arsenic acid $[\mathrm{As}(\mathrm{V})]$ & Water & \\
\hline $\begin{array}{l}\text { Monomethylarsonic } \\
\text { acid }[\mathrm{MMA}(\mathrm{V})]\end{array}$ & & 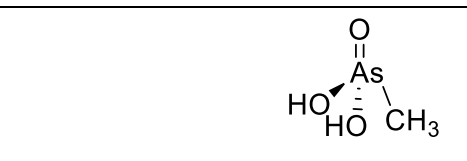 \\
\hline $\begin{array}{c}\text { Dimethylarsinic acid } \\
\qquad[\mathrm{DMA}(\mathrm{V})]\end{array}$ & $\begin{array}{l}\text { Metabolites in } \\
\text { urine }\end{array}$ & 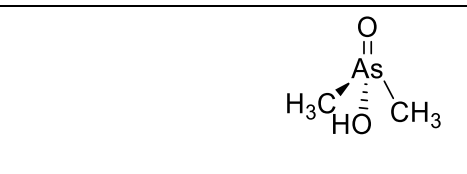 \\
\hline $\begin{array}{l}\text { Monomethylarsonous } \\
\text { acid [MMA(III)] }\end{array}$ & & 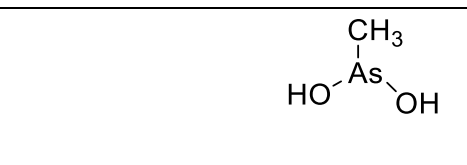 \\
\hline $\begin{array}{l}\text { Dimethylarsinous } \\
\text { acid [DMA(III)] }\end{array}$ & & 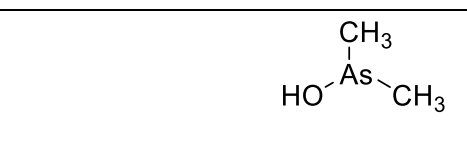 \\
\hline $\begin{array}{c}\text { Arsenobetaine } \\
\text { [As(V)] }\end{array}$ & Seafood & $\begin{array}{r}\mathrm{CH}_{2} \mathrm{COO}^{-} \\
\mathrm{H}_{3} \mathrm{C}-\mathrm{As}^{+}-\mathrm{CH}_{3} \\
\mathrm{CH}_{3}\end{array}$ \\
\hline Arsenolipids $[\mathrm{As}(\mathrm{V})]$ & Fatty fish & 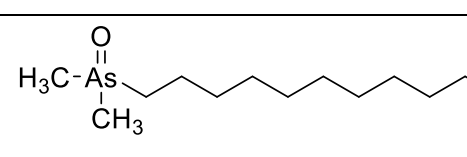 \\
\hline
\end{tabular}


The deficiency of selenium can lead to health-related issues in human body such as fatigue, heart disease, immune system dysfunction, reproductive problem among others, while the excessive intake may result in selenosis e. g., hair loss, fingernail brittleness, abnormal functioning of nervous system, gastrointestinal problems (Fordyce, 2013; Goldhaber, 2003). In animals, high concentrations of selenium are reported to cause deformities and death in bird and fish species; alkali disease and blind staggers are observed in cattle and horses (Hamilton, 2004; Tinggi, 2003). One of the entry routes of selenium into the human body is the consumption of drinking water with high levels of selenium. To protect public health from selenium toxicity, US EPA and WHO has set 50 and $40 \mathrm{ppb}$ as the maximum acceptable limit of selenium in drinking water, respectively (Fu et al., 2014). The main source of selenium in the water system is its uncontrolled discharge from coal and mining operations, thermal power stations, oil refineries, glass and metal processing industries, agricultural runoff, petrochemical and solar batteries (Lemly, 2004; Yamani et al., 2014; Zelmanov and Semiat, 2013). Among different oxidation states $(-\mathrm{II}, 0,+\mathrm{IV}$ and $+\mathrm{VI})$, the most prevalent form of selenium in aqueous media is the two highly toxic forms, selenite, $\mathrm{Se}(\mathrm{IV})$ and selenate, $\mathrm{Se}(\mathrm{VI})$. Selenite is found to be more toxic than $\mathrm{Se}(\mathrm{VI})$. For both $\mathrm{As}$ and $\mathrm{Se}$, the redox environment and solution $\mathrm{pH}$ greatly influence the speciation of the toxic species in the

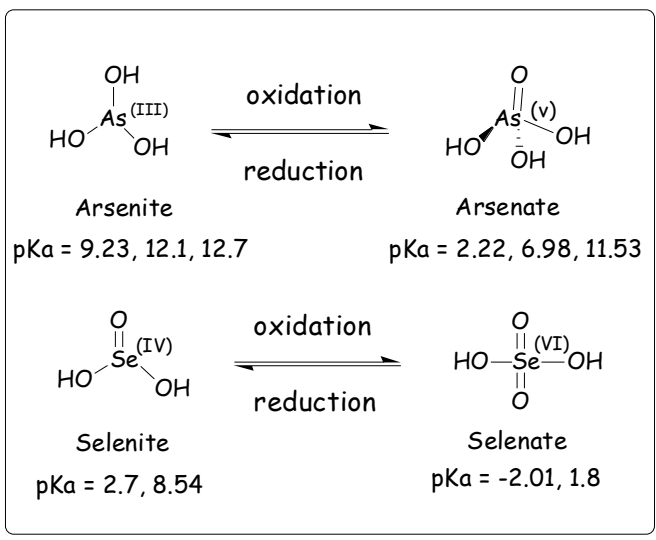

Figure 1.1. Speciation and $\mathrm{pK}_{\mathrm{a}}$ values for arsenic and selenium environment (Fig. 1.1). 
Phosphorous $(\mathrm{P})$ is also a group 15 element of the periodic table that exists mostly as orthophosphate, polyphosphate and organic phosphate in aqueous environment (Mezenner and Bensmaili, 2009). A primary nutrient, phosphorous, is required for the essential functioning of plants and organisms in the ecosystem (Almeelbi and Bezbaruah, 2012). However, excessive discharge of phosphate effluent from agricultural, industrial and household activities causes eutrophication in the aquatic system which is detrimental to the environmental and water quality (Huang et al., 2008). Notably eutrophication is responsible for the bloom of toxic cyanobacteria and the decline of aquatic habitat through the depletion of dissolved oxygen (Chouyyok et al., 2010).

\subsection{Arsenic, selenium and phosphorous remediation by adsorption}

There are number of different methods available for the removal of toxic arsenic, selenium and phosphorous including precipitation (Geoffroy and Demopoulos, 2011; Harper and Kingham, 1992), ion exchange (Blaney et al., 2007; Kim and Benjamin, 2004; Nishimura et al., 2007), reverse osmosis (Ning, 2002), solvent extraction (Bidari et al., 2007), and biological treatment (Y. Zhang et al., 2008). Although each of the methods has advantages, they also suffer from a number of inherent limitations inhibiting their real-life applications, e. g., toxic sludge, byproduct generation, poor removal efficiency, long treatment time, high operational cost, species specific removal, complex or inconvenient water treatment procedure (Yamani et al., 2014; Zelmanov and Semiat, 2013). Recently, adsorption has emerged as a promising alternative to conventional treatment methods because of its simplicity, low cost, trace amount removal capability and point-of-use compatibility (Santos et al., 2015). In the adsorption process, a material or solute (known 
as adsorbate) accumulates on a solid surface (known as adsorbent) from its liquid or gaseous surroundings (Gupta et al., 2009). The accumulation of adsorbate on the adsorbent surface can occur through a weak van der Walls force of attraction, known as physisorption or through a strong chemical interaction, known as chemisorption. Activated carbon, alumina, chitosan, iron oxides and hydroxides, and binary metal oxides are common adsorbents employed for removal of toxins from drinking water (Dou et al., 2010; Gang et al., 2010; Yamani et al., 2014; Yoon et al., 2016; G. Zhang et al., 2009). Although these adsorbents may have limitations like $\mathrm{pH}$ and temperature dependence, low surface area, poor selectivity and regeneration costs, the benefits of adsorption processes generally outweigh the limitations and thus are considered among the most viable techniques for wastewater treatment.

\subsubsection{Magnetic iron oxide nanoparticles}

The use of nanomaterials as adsorbents has received significant attention for water purification because of their fast dissolution, tunable pore size, high surface-to-volume ratio and high surface energy, all of which lead to greater adsorption efficiency and faster removal rates than traditional adsorbents (Hua et al., 2012; Pradeep and Anshup, 2009; Qu et al., 2013). One of the primary challenges associated with the use of nanoadsorbents (or adsorbents) is the recovery of the materials after the treatment process. The development of magnetic nanoparticles has allowed for easy adsorbent recovery by simply employing a magnetic field. Iron oxide magnetic nanoparticles are widely chosen for such applications because they are easy to prepare, readily available and economical (Jiang et al., 2014). For example, nanoparticles of magnetite $\left(\mathrm{Fe}_{3} \mathrm{O}_{4}\right)$, the most magnetic among all naturally 
occurring minerals, can be easily synthesized (Eq. 1.1) in the laboratory using two iron salts in alkaline media following the co-precipitation method (Maity and Agrawal, 2007).

$\mathrm{Fe}^{2+}+2 \mathrm{Fe}^{3+}+8 \mathrm{OH}^{-}=\mathrm{Fe}_{3} \mathrm{O}_{4}+4 \mathrm{H}_{2} \mathrm{O}$

Although the use of bare iron oxide nanoparticle for the removal of toxic water contaminants have been successfully explored in the laboratory, the particles are not stable enough for large scale commercial applications because of agglomeration and loss of magnetism through natural auto-oxidative processes (J. Liu et al., 2008). A thin film coating of organic substrate on the surface of bare iron oxide nanoparticles can prevent the agglomeration and inhibit auto-oxidation of the iron oxide nanoparticles such that the magnetic properties of the iron oxide core are maintained for extended periods of time.

\subsubsection{Natural organic matter coated iron oxide nanoparticles}

Natural organic matter (NOM) is naturally occurring macromolecule that are ubiquitous in nature. It is a complex, heterogeneous mixture of polyfunctional organic compounds derived from the decomposition of plant and animal residues through a series of biological and chemical processes (Chen et al., 2002). In the environment, NOM plays an important role in determining the fate, biogeochemical cycling and mobility of different metal oxides, organic and inorganic pollutants (Aiken et al., 2011; Chin et al., 1994; De Paolis and Kukkonen, 1997). The sources, age of materials and the medium that degrades the plant and animal residue greatly determine the size and physico-chemical properties of NOM ((Chen et al., 2002). Humic substances (HS) are a large portion of NOM found in the soil and aquatic environment (Zhou et al., 2005). A significant amount of HS is also detected in the effluents discharged from wastewater treatment plants (Tang et al., 2014). 
The large molecular weight fraction of HS is called humic acid (HA). A simplified empirical structure of HA is shown in Fig. 1.2. Humic acid has relatively higher carbon content, lower oxygen content and is usually more hydrophobic than fluvic acid (FA), another fraction of HS (De Paolis and Kukkonen, 1997; Lubal et al., 1998).

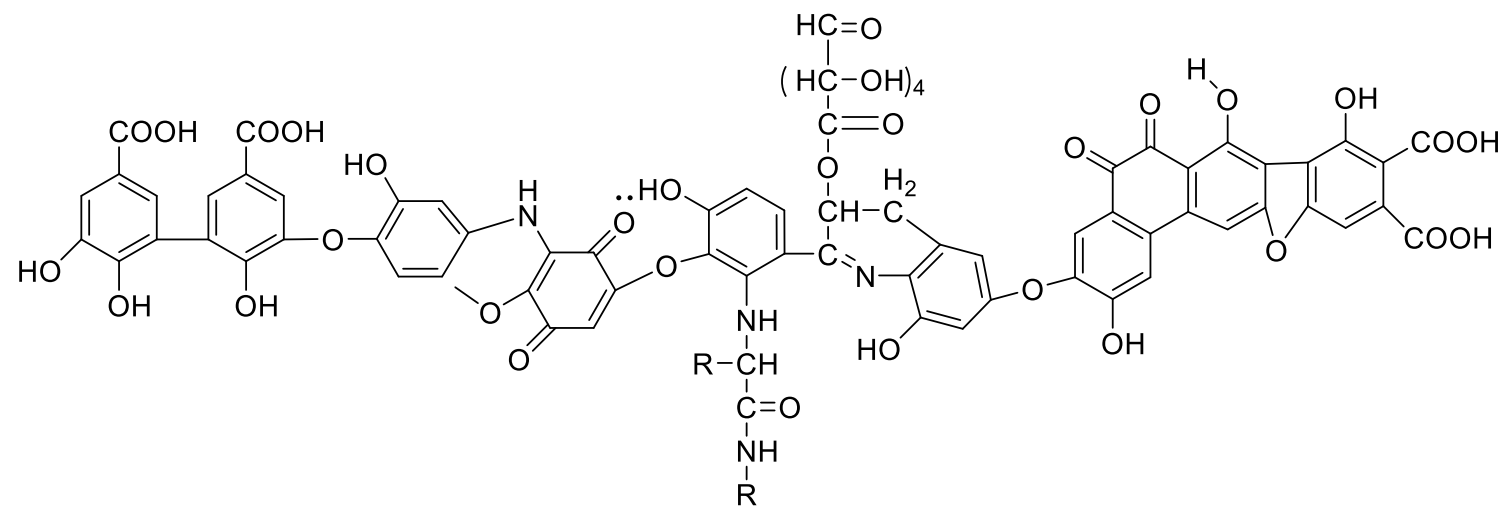

Figure 1.2. Representative structure of humic acid (HA)

The polyanionic character of HA helps it to bind strongly with metal and metal oxides (Tombácz et al., 2013). Humic acid shows high affinity to iron oxides, forming a stabilizing layer on the surface (Eq. 1.2 - 1.5) probably through ligand exchange-chemical complexation reactions (Gu et al., 1994). The diverse acidic functional groups of humic acid bind with iron oxide such as magnetite, and thus form a thin layer on the surface. The coating of humic acid on magnetite nanoparticles can prevent the agglomeration and toxicity toxicity to a significant extent. It also addresses the auto-oxidation problem of bare magnetite nanoparticles. 


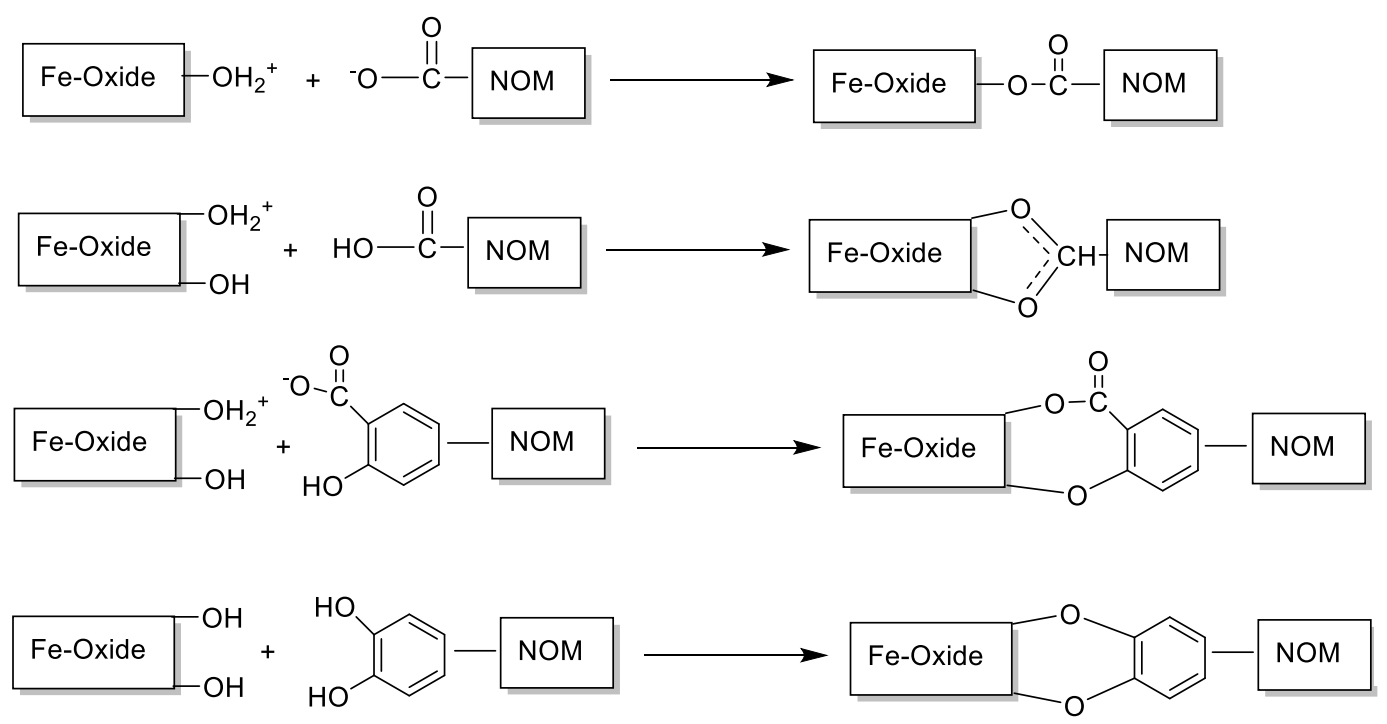

Humic acid coated magnetite nanoparticles (HA-MNP) are robust in nature and highly stable even under extreme conditions (Illés and Tombácz, 2006; J. Liu et al., 2008). The nanoparticles have been found effective for the removal of different toxic metal cations and other pollutants from water (J. Liu et al., 2008; Peng et al., 2012; Zhang et al., 2013). However, very few studies have been carried out until this point to assess the efficacy of the materials for the remediation of poisonous inorganic oxyanions from the aqueous system (Jiang et al., 2014).

\subsubsection{Reactive oxygen species generation by HA-MNP}

The presence of dissolved HS in aquatic media plays an important role in the photoprocesses of surface waters since part of the HS interacts with light (Cooper et al., 1988). Upon irradiation, HS can act as a photosensitizer to generate reactive intermediates and reactive oxygen species (ROS) such as singlet oxygen $\left({ }^{1} \mathrm{O}_{2}\right)$, superoxide anion radical $\left(\mathrm{O}_{2}{ }^{-}\right.$ •) and others. The ROS production from the absorption of light followed by intersystem crossing (ISC) of HS are shown in eq. 1.6 - 1.10 (Cooper et al., 1988). The significance of 
HS photochemistry is that the ROS and excited triplet state of HS can lead to the degradation of water pollutants. The ROS can also influence the redox cycling of environmentally critical metals like Fe and Hg (Dalrymple et al., 2010).

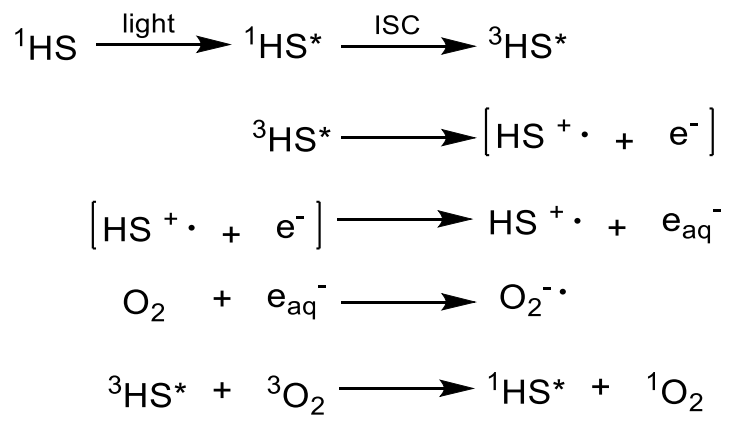

The hydroxyl radical $\left(\mathrm{OH}^{*}\right)$ is another ROS, the production mechanism of which is not well-defined. Apart from the photolysis of $\mathrm{H}_{2} \mathrm{O}_{2}$, photo-Fenton processes and photolysis of nitrite and nitrate, the hydrogen abstraction from the quinone functionality of HS during irradiation is proposed as another plausible pathway for the generation of $\mathrm{OH}^{*}$ (Blough, 1998; TAKEDA et al., 2004).

As a fraction of HS, HA also exhibits photochemical properties. The generation of ROS by HA (and HS) depends heavily on the source, season and age. However, study shows that the humic acid coated magnetite nanoparticles (HA-MNP) can generate the ROS of nearly same quantum yield as free HA (Carlos et al., 2012). Hence, for water treatment applications, the photochemical properties of HA-MNP is a promising feature in addition to the adsorptive and magnetic properties.

\subsection{General objective of dissertation}

The focus of the dissertation project is to investigate the adsorptive and photochemical properties of laboratory synthesized HA-MNP for the efficient remediation of toxic 
arsenic, selenium and phosphorous species from aqueous media. Detail characterizations of the nanoparticles before and after the adsorption of target contaminant were carried out. Kinetic and thermodynamic studies were conducted under different environmentally relevant conditions (temperature, $\mathrm{pH}$, co-existing ions etc.) to assess the method versatility and to understand the mechanistic insights of the removal process. 


\section{CHAPTER TWO}

Effective Removal of Phosphate from Aqueous Solution Using Humic Acid Coated Magnetite Nanoparticles 


\subsection{Abstract}

Effective removal of excess phosphate from water is critical to counteract eutrophication and restore water quality. In this study, low cost, environmentally friendly humic acid coated magnetite nanoparticles (HA-MNP) were synthesized and applied for the remediation of phosphate from aqueous media. The HA-MNPs, characterized by FTIR, TEM and HAADF-STEM showed the extensive coating of humic acid on the magnetite surface. The magnetic nanoparticles with diameter of 7-12 nm could be easily separated from the reaction mixture by using a simple handheld magnet. Adsorption studies demonstrate the fast and effective separation of phosphate with maximum adsorption capacity of $28.9 \mathrm{mg} / \mathrm{g}$ at $\mathrm{pH}$ 6.6. The adsorption behavior follows the Freundlich isotherm suggesting the formation of non-uniform multilayers of phosphate on the heterogeneous surface of HA-MNP. The adsorption kinetic fits the pseudo-second order model well with rate constants of $0.206 \pm 0.003,0.073 \pm 0.002$ and $0.061 \pm 0.003 \mathrm{~g} \mathrm{mg}^{-1} \mathrm{~min}^{-1}$ for phosphate (P) concentration of 2,5 and $10 \mathrm{mg} / \mathrm{L}$ respectively. The removal of phosphate was found higher at acidic and neutral $\mathrm{pH}$ compared to basic conditions. The nanoparticles exhibit good selectivity and adsorption efficiency for phosphate in presence of co-existing ions such as $\mathrm{Cl}^{-}, \mathrm{SO}_{4}{ }^{2-}$ and $\mathrm{NO}_{3}{ }^{-}$with some inhibition effect by $\mathrm{CO}_{3}{ }^{2-}$. The effect of temperature on the adsorption reveals that the process is endothermic and spontaneous. HA-MNPs are promising, simple, environmentally friendly materials for the removal of phosphate from aqueous media. 


\section{$2.2 \quad$ Keywords}

Humic acid coated magnetite nanoparticles, adsorption, magnetic separation, phosphate

\subsection{Introduction}

Phosphate is a primary nutrient required for the normal functioning of many organisms in the ecosystem (Zeng et al., 2004). However, presence of excess phosphate into the aquatic systems leads to eutrophication which can promote harmful algal growth and decrease the amount of dissolved oxygen in water (Chouyyok et al., 2010; Pan et al., 2014; Yan et al., 2010). Recent study shows the significant rise of lakes and streams length containing higher amounts of total phosphorous (TP) which exacerbate the concern about the deterioration of water quality and overall ecological balance (Stoddard et al., 2016). Municipal and industrial wastewaters are the major point sources for phosphate discharges while agricultural run-off is considered the dominant non-point source (Almeelbi and Bezbaruah, 2012; Karageorgiou et al., 2007). The commonly used methods to remove phosphates from water include biological treatment (Oehmen et al., 2007), chemical precipitation (De-Bashan and Bashan, 2004), reverse osmosis (Kumar et al., 2007), adsorption (Almeelbi and Bezbaruah, 2012; H. Liu et al., 2008; Seida and Nakano, 2002) etc. Among these, adsorption is the most widely accepted method for phosphate removal because of its high efficiency, minimum cost, easy and simple operation and applicability at lower concentrations (G. Zhang et al., 2009). In this study, we have used adsorption to remove phosphate from the aqueous solutions using humic acid coated magnetic iron oxide (magnetite) nanoparticles as adsorbent. 
In recent years, iron based nanoparticles have been widely applied for environmental remediation. The strong magnetic properties of such nanoparticles enables separation of adsorbent and adsorbate by using a simple magnet (Qu et al., 2013; Xu et al., 2012). Magnetite, an iron $\left(\mathrm{Fe}_{3} \mathrm{O}_{4}\right)$ material shows the highest magnetism among all the naturally available minerals (Harrison et al., 2002). Application of bare magnetite nanoparticles (MNP) for the removal of toxic water contaminants have been reported into the literature (Mayo et al., 2007). However, the susceptibility to auto-oxidation, tendency to agglomeration and concerns over toxicity are the main challenges for the real life water treatment applications of bare MNP (Huang et al., 2016; J. Liu et al., 2008; Maity and Agrawal, 2007). The coating of natural organic matter (NOM) on the bare MNP surface has been found useful in making the nanoparticles less toxic and more environmental friendly. Such thin coatings can also inhibit the agglomeration and auto-oxidation, the primary drawbacks associated with the use of bare MNP. Furthermore, the coating with NOM can potentially increase the adsorption capacity and selectivity of the nanoparticles.

Humic acid (HA), a ubiquitous natural organic matter (NOM), is derived from plants and microbial residues. HA possesses a number of organic functional groups including carboxylic acids, carbonyl groups and phenolic hydroxyl groups which can promote its complexation with a variety of metal oxides (Hankins et al., 2006). HA has a high affinity for magnetite $\left(\mathrm{Fe}_{3} \mathrm{O}_{4}\right)$ and effectively coats bare MNP most likely through the surface complexation ligand exchange reactions (Gu et al., 1994; Illés and Tombácz, 2003). Limited studies have been reported on the removal of water contaminants using HA-MNP with primary focus on the removal of metal cations (J. Liu et al., 2008; Yang et al., 2012). However, our research group recently demonstrated the potential use of HA-MNP to 
successfully remove a metal oxyanions (chromate) from the aqueous media (Jiang et al., 2014). Herein, we report the application of the nanoparticles (HA-MNP) for the efficient removal of anionic phosphate from water. The natural protective coating of humic acid plays a crucial role in the phosphate-HA-MNP complexation while preserving the magnetic property of magnetite imperative for the final separation step in the treatment process.

\subsection{Experimental Section}

\subsubsection{Materials}

Di-potassium hydrogen phosphate (>99.9\%), ammonium hydroxide (29.15\%), sulfuric acid (>95.6\%), ferric chloride hexahydrate $(98.8 \%)$, sodium carbonate $(100.4 \%)$ and sodium bicarbonate $(99.7 \%$ ) were purchased from Fisher. Humic acid sodium salt and ferrous chloride tetrahydrate $(\geq 99.0 \%)$ were obtained from Sigma. In all cases, Millipore filtered water (18 M $\Omega . \mathrm{cm})$ was used to prepare the solutions.

\subsubsection{Synthesis of humic acid coated magnetite nanoparticles}

An established method (Jiang et al., 2014) was followed to prepare the humic acid coated magnetite nanoparticles (HA-MNP). Briefly, $3.0 \mathrm{~g}$ of ferrous chloride tetrahydrate $\left(\mathrm{FeCl}_{2} .4 \mathrm{H}_{2} \mathrm{O}\right)$ and $6.0 \mathrm{~g}$ of ferric chloride hexahydrate $\left(\mathrm{FeCl}_{3} .6 \mathrm{H}_{2} 0\right)$ were dissolved in 100 $\mathrm{mL}$ of water in a three-neck round bottom flask connected with a reflux condenser. The mixture was then heated with magnetic stirring until the temperature reached to $90{ }^{\circ} \mathrm{C}$. At this temperature, $10 \mathrm{~mL}$ of $25 \%$ ammonium hydroxide and $50 \mathrm{~mL}$ of $1 \%$ humic acid sodium salt were added simultaneously into the reaction mixture and kept at $90 \pm 5{ }^{\circ} \mathrm{C}$ for additional 30 minutes. The solution was then allowed to cool, washed with water several 
times to separate the nanoparticles from the free iron and humic acid. Finally, the dried (in a vacuum oven at $40{ }^{\circ} \mathrm{C}$ ), ground magnetic nanoparticles [Fig. A1(a)] were stored in a desiccator.

\subsubsection{Material characterization}

Fourier transform infrared spectroscopy (FTIR) was performed at room temperature using PerkinElmer FTIR 100. Spectral scans of the synthesized nanoparticles

were obtained from 550-4000 $\mathrm{cm}^{-1}$ (64 scans per spectrum). Transmission electron microscopy (TEM) and high angular annual dark field (HAADF-STEM) images were collected to determine the surface morphology and microstructure of the HA-MNP. The samples were sonicated for 30 minutes prior to dipping onto a silicone monoxide substrate grids, dried at room temperature and then analyzed using a FEI TITAN G2 80-300 instrument operated at $300 \mathrm{kV}$. The leaching of HA was determined by measuring total organic carbon (TOC) in solutions at different $\mathrm{pH}$ after the separations of the synthesized. Shimadzu TOC-VCSH analyzer was used for TOC analysis.

\subsubsection{Adsorption experiments}

Stock solution of phosphate $(\mathrm{P})$ with concentration of $1000 \mathrm{mg}$ of $\mathrm{P} / \mathrm{L}(\mathrm{ppm})$ was prepared from di-potassium hydrogen phosphate $\left(\mathrm{K}_{2} \mathrm{HPO}_{4}\right)$. A series of standard and working solutions with concentrations ranging from 0.05 to $100 \mathrm{mg} / \mathrm{L}$ were prepared by dilution of the stock solution. The adsorption studies were carried out in capped plastic bottles with $50 \mathrm{~mL}$ of phosphate solution as adsorbate and $0.05 \mathrm{~g}$ of HA-MNP $(1.0 \mathrm{~g} / \mathrm{L})$ as adsorbent. To ensure efficient mixing and proper mass transfer, the samples were placed in the orbit shaker (Lab-line instrument Inc., model 3520) and shaken at $250 \mathrm{rpm}$ for a 
specific time period. All the experiments were conducted at room temperature $(298 \mathrm{~K})$ with a $\mathrm{pH} 6.6 \pm 0.1$ except the studies investigating the temperature and $\mathrm{pH}$ effects. For the $\mathrm{pH}$ experiments, $0.1 \mathrm{M} \mathrm{NaOH}$ and $0.1 \mathrm{M} \mathrm{HCl}$ were used to adjust the initial solution $\mathrm{pH}$, confirmed in the $\mathrm{pH}$ meter (Mettler Toledo, model: SevenEasy). In case of thermodynamic study, sample solutions were placed in the thermostated waterbath (Lauda-Brinkman, model: RM20) to maintain the desired temperature. In all instances, the sample solutions were separated from the adsorbent nanoparticles using a simple handheld magnet [Fig. A1(b)]. To determine the residual concentration of phosphate, the magnetically separated solutions were filtered further using $0.45 \mu \mathrm{m}$ syringe filter (to insure removal of any trace amount of suspended particles from the solution) and the filtrates were analyzed in the ion chromatography (761 Metrohm compact IC) equipped with a compact auto sampler (model: 813). The equilibrium of phosphate adsorption was calculated by using the following equation,

$$
Q_{e}=\frac{\left(C_{o}-C_{e}\right)}{m} V
$$

Where $\mathrm{Q}_{\mathrm{e}}$ is the amount of phosphate adsorbed $(\mathrm{mg} / \mathrm{g})$ at equilibrium, $\mathrm{C}_{0}$ and $\mathrm{C}_{\mathrm{e}}$ corresponds to the initial and equilibrium concentration of phosphate in solution respectively, expressed in $\mathrm{mg} / \mathrm{L}$; $\mathrm{m}$ is the mass $(\mathrm{g})$ of the adsorbent $(\mathrm{HA}-\mathrm{MNP})$ and $\mathrm{V}$ is the total volume $(\mathrm{L})$ of the solution. Reproducibility of the collected data were ensured by taking the average of triplicate run of the experiments with accepted standard deviation not more than $5 \%$. 


\subsection{Results and discussion}

\subsubsection{Characterization of the synthesized nanoparticles}

From FTIR spectra (Fig. A2), the band at $1598 \mathrm{~cm}^{-1}$ in HA-MNP corresponds to the $\mathrm{C}=\mathrm{O}$ stretching of carboxylate anion of $\mathrm{HA}$ due to its interaction with the iron oxide surface of magnetite (Jiang et al., 2014). The same band appears at $1638 \mathrm{~cm}^{-1}$ in humic acid (Fig. A2) along with the band for amide $\mathrm{C}=\mathrm{O}$ stretch at $1564 \mathrm{~cm}^{-1}$. The appearance of another strong band in the synthesized HA-MNP at $1398 \mathrm{~cm}^{-1}$ can be assigned to the scissoring of $-\mathrm{CH}_{2}$ group of $\mathrm{HA}$. The band at $3331 \mathrm{~cm}^{-1}$ in $\mathrm{HA}$ is attributed to $\mathrm{O}-\mathrm{H}$ stretching of alcohol and/or phenol which largely disappeared in HA-MNP indicating the complexation between the magnetite core and the humic acid shell. The band at 1090 and $1009 \mathrm{~cm}^{-1}$ in $\mathrm{HA}$ can be ascribed to the $\mathrm{C}-\mathrm{O}$ stretching of $\mathrm{COO}^{-}$and deformation vibration of C-H bond of benzene ring respectively (Peng et al., 2012; Yang et al., 2012). The TEM and HRTEM images of HA-MNP showed high crystallinity of magnetite nanoparticles inside $\left(\mathrm{Fe}_{3} \mathrm{O}_{4}\right.$ core) and disordered structure outside which is due to the coating of humic acid on the surface of iron oxide nanoparticles (Fig. 2.1). The observed lattice distance of 2.6 A corresponds to the crystallographic plane of magnetite (311) core. Further analysis of the TEM images showed the narrow size distribution of HA-MNP in the range of 7-12 nm with quasi-spherical geometry. 


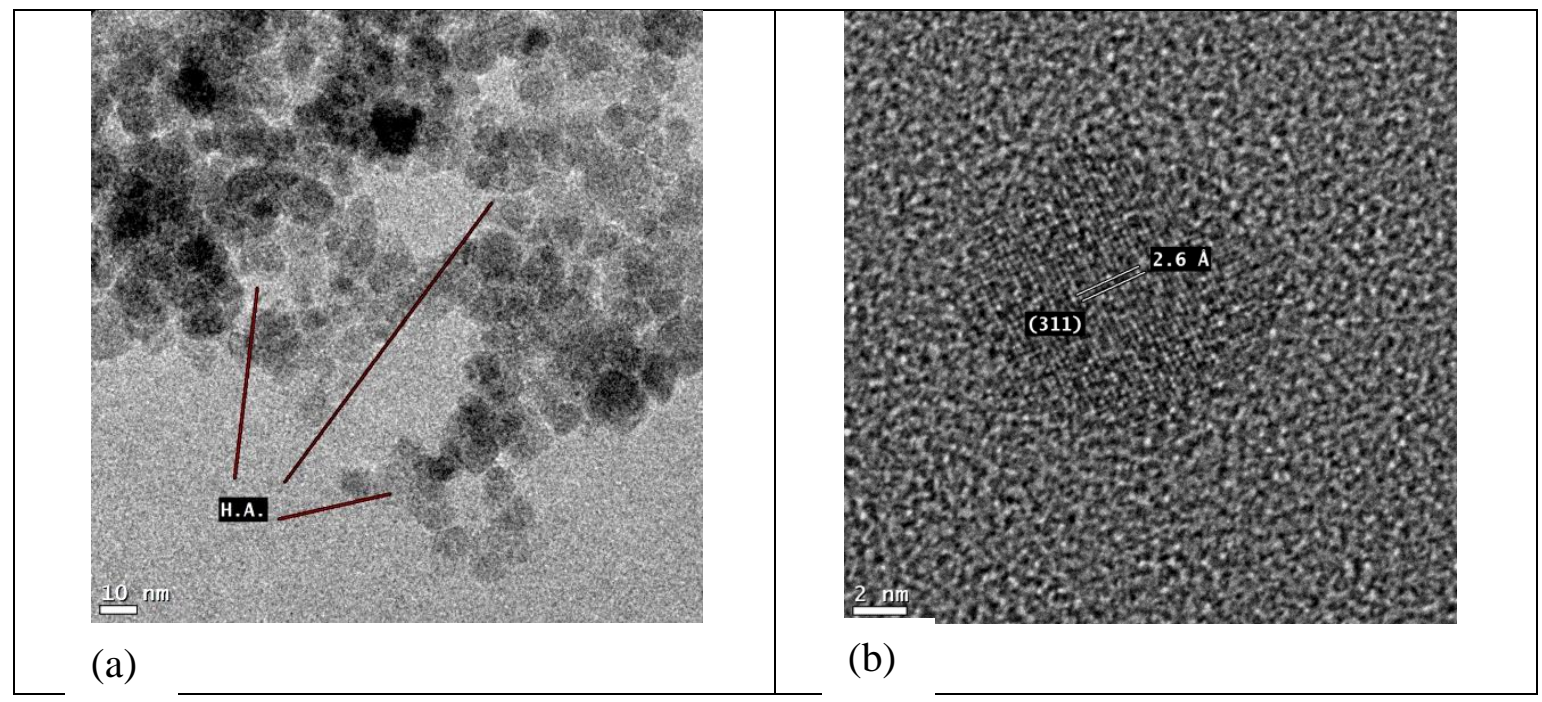

Figure 2.1. TEM images of HA-MNP. (a) low resolution TEM image, the red lines show the humic acid coating on MNP (b) HRTEM images shows a high crystalline structure of magnetite core in HA-MNPs

The micrographs of STEM-HAADF are shown in Fig. 2.2(a, b) where we note hexagonal packing with little agglomeration of HA-MNP. Chemical analysis of this agglomerant by energy dispersive spectroscopy (EDS) yields [Fig. 2.2(c)] the elements as carbon, iron, oxygen, and silicon (silicon appeared from the TEM grids). The results confirm the composition of the HA-MNP. High resolution of STEM-HAADF shown in Fig. 2.2(a), demonstrates HA-MNP have diameters of approximately $10 \mathrm{~nm}$. The space between HA and MNP, the distance between HA film and MNP is approximately $1 \mathrm{~nm}$, corresponding to the film on the shell of HA. 


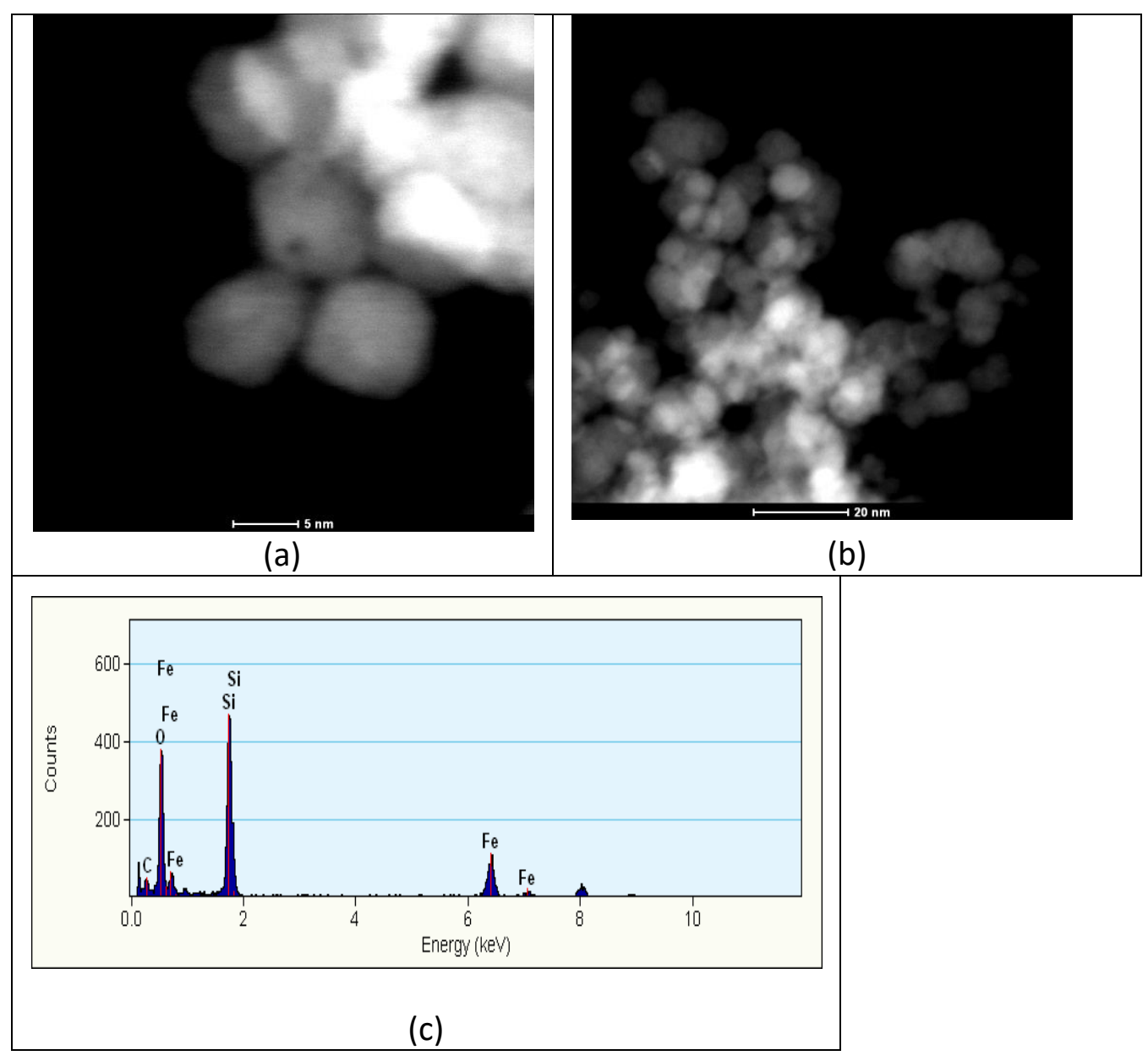

Figure 2.2. STEM-HAADF images of HA-MNP, (a) High resolution STEM-HAADF image (detail of high porosity). (b) low magnification STEM-HAADF image of HA-MNP clearly shows the high porosity in the surface of MNP, (c) EDS spectra of HA-MNP

\subsubsection{Adsorption kinetics}

An adsorption kinetic study was achieved by separately adding $50 \mathrm{mg}$ of HAMNP in $50 \mathrm{~mL}$ of 2 to $10 \mathrm{ppm}$ phosphate $(\mathrm{P})$ at $298 \mathrm{~K}$. The initial experiment was carried out in the orbit shaker for a total of 3 hours to ensure that the adsorption equilibrium is completed. The samples collected at different time intervals were filtered to separate HAMNP and the filtrates were analyzed by IC to measure phosphate in solution. Data from IC showed that the adsorption of phosphate on HA-MNP surface increased with time and 
reached adsorption equilibrium within 60 minutes with $>90 \%$ of phosphate removed from the solution in 3 hours for an initial phosphate concentration of 2 ppm (Fig. 2.3). Surface saturation occurs at higher initial phosphate concentration and the adsorption rate became slower (Fig. 2.3).

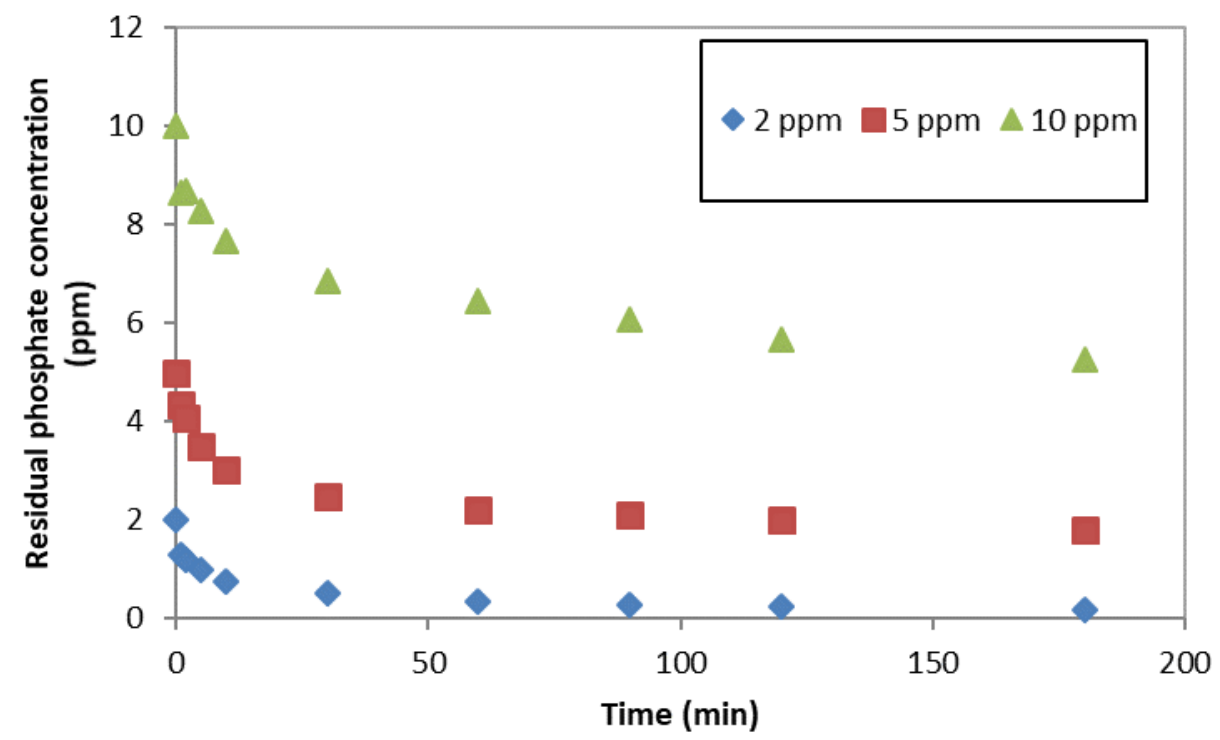

Figure 2.3. Adsorption kinetics of phosphate on HA-MNP. Initial phosphate (P) concentration $=2$ to $10 \mathrm{mg} / \mathrm{L}(\mathrm{ppm}), \mathrm{pH}=6.6, \mathrm{HA}-\mathrm{MNP}$ dose $=1.0 \mathrm{~g} / \mathrm{L}$, temperature $=$ $298 \mathrm{~K}$, contact time $=3$ hours

The kinetic data were fit to both pseudo-first order and pseudo-second order kinetic models (equation 2 and 3 respectively) and compared, to provide insights of adsorption mechanisms such as mass transfer and chemical reaction. It is well established that the pseudo-first order kinetic model fits better in the initial stage of reaction processes especially those with rapid adsorption (Ho and McKay, 1998), whereas the pseudo-second order model (Ho and McKay, 1999) considers adsorption behavior over longer contact times with chemisorption as the rate controlling process (Bhattacharyya and Sharma, 2004; Bulut et al., 2008; Crini et al., 2007). 


$$
\begin{aligned}
& \log \left(Q_{e}-Q_{t}\right)=\log Q_{e}-k_{1} t / 2.303 \\
& \frac{t}{Q_{t}}=\frac{1}{k_{2} Q_{e}^{2}}+\frac{1}{Q_{e}} t
\end{aligned}
$$

Where $\mathrm{Q}_{\mathrm{t}}$ and $\mathrm{Q}_{\mathrm{e}}$ are the amount of solute adsorbed on the adsorbent surface $(\mathrm{mg} / \mathrm{g})$ at time $\mathrm{t}$ and at equilibrium respectively. $\mathrm{k}_{1}$ and $\mathrm{k}_{2}$ are the rate constants of the pseudo-first order and pseudo-second order rate equation respectively. In both cases, $\mathrm{t}$ is the time in minutes. From the derived kinetic parameters of equation $2 \& 3$ (see Table 2.1), the adsorption of phosphate is found to follow the pseudo-second order kinetic model with good linearity $\left(\mathrm{R}^{2}>0.99\right)$ and a good agreement between the experimental and calculated Qe values. The rate constants $\left(\mathrm{k}_{2}\right)$ are calculated with standard error as $0.206 \pm 0.003$, $0.073 \pm 0.002$ and $0.061 \pm 0.003 \mathrm{~g} \mathrm{mg}^{-1} \mathrm{~min}^{-1}$, for 2,5 and $10 \mathrm{ppm}$ phosphate solutions, respectively. These results illustrate that the adsorption of phosphate on HA-MNP likely occurs through chemisorption where sharing or exchange of electron takes place between phosphate and the functional groups of humic acids of HA-MNP (Gücek et al., 2005). In the typical pseudo-second order process, an initial surface reaction occurs until all the surface sites are occupied; subsequently diffusion and molecular reorganization can take place at the surface for additional complexation (Xie et al., 2014). 
Table 2.1. Kinetic parameters for the adsorption of phosphate onto HA-MNP

\begin{tabular}{llllllll}
\hline & \multicolumn{5}{c}{ Pseudo-first order kinetics } & \multicolumn{3}{c}{ Pseudo-second order kinetics } \\
\cline { 3 - 8 } Initial & $\mathrm{Q}_{\mathrm{e}}$, & $\mathrm{Q}$, & $\mathrm{k} 1$ & & $\mathrm{Q}$, & $\mathrm{k} 2$ & \\
Conc. & expt. & calc. & $\left(\mathrm{min}^{-1}\right)$ & $\mathrm{R}^{2}$ & $\mathrm{calc}$. & $\left(\mathrm{g} \mathrm{mg}^{-1} \mathrm{~min}^{-1}\right)$ & $\mathrm{R}^{2}$ \\
$(\mathrm{mg} / \mathrm{L})$ & $(\mathrm{mg} / \mathrm{g})$ & $(\mathrm{mg} / \mathrm{g})$ & & & $(\mathrm{mg} / \mathrm{g})$ & & \\
\hline 2 & 1.66 & 0.95 & $0.056 \pm 0.002$ & 0.97 & 1.71 & $0.206 \pm 0.003$ & 0.99 \\
5 & 2.81 & 1.34 & $0.066 \pm 0.003$ & 0.96 & 2.99 & $0.073 \pm 0.002$ & 0.99 \\
10 & 3.55 & 1.46 & $0.061 \pm 0.002$ & 0.99 & 3.75 & $0.061 \pm 0.003$ & 0.99
\end{tabular}

Under our experimental conditions, the pseudo-first order kinetic model also exhibits a good correlation after fitting the experimental data; however, significant deviation was observed between the two $Q_{e}$ values indicating that this model is not consistent with the observed phosphate adsorption in our system.

To further explore the adsorption process, the kinetic data were also examined using the Weber and Morris intraparticle diffusion model that expresses the fraction of solute adsorbed as a function of square root of time,

$$
Q_{t}=k_{i d} t^{1 / 2}+c
$$

Where $\mathrm{Q}_{\mathrm{t}}$ is the amount of phosphate adsorbed at time $\mathrm{t}$ (minute), $\mathrm{k}_{\mathrm{id}}$ is the intraparticle diffusion rate constant and $\mathrm{c}$ is the intercept. The kinetic data of 5 ppm phosphate is used for this model to probe the existence of different phases in the adsorption process. A plot of $\mathrm{Q}_{\mathrm{t}} \mathrm{vs} \mathrm{t}^{1 / 2}$ yielded a linear relationship which did not pass through the origin (Fig. 2.4). The results suggest that intraparticle diffusion is involved in the overall adsorption process although it is not the rate limiting step (Hamayun et al., 2014; Jacukowicz-sobala and Ocin, 
2013). Additionally, the observed multilinearity can be attributed to the involvement of two or more steps in the adsorption process (Wu et al., 2001).

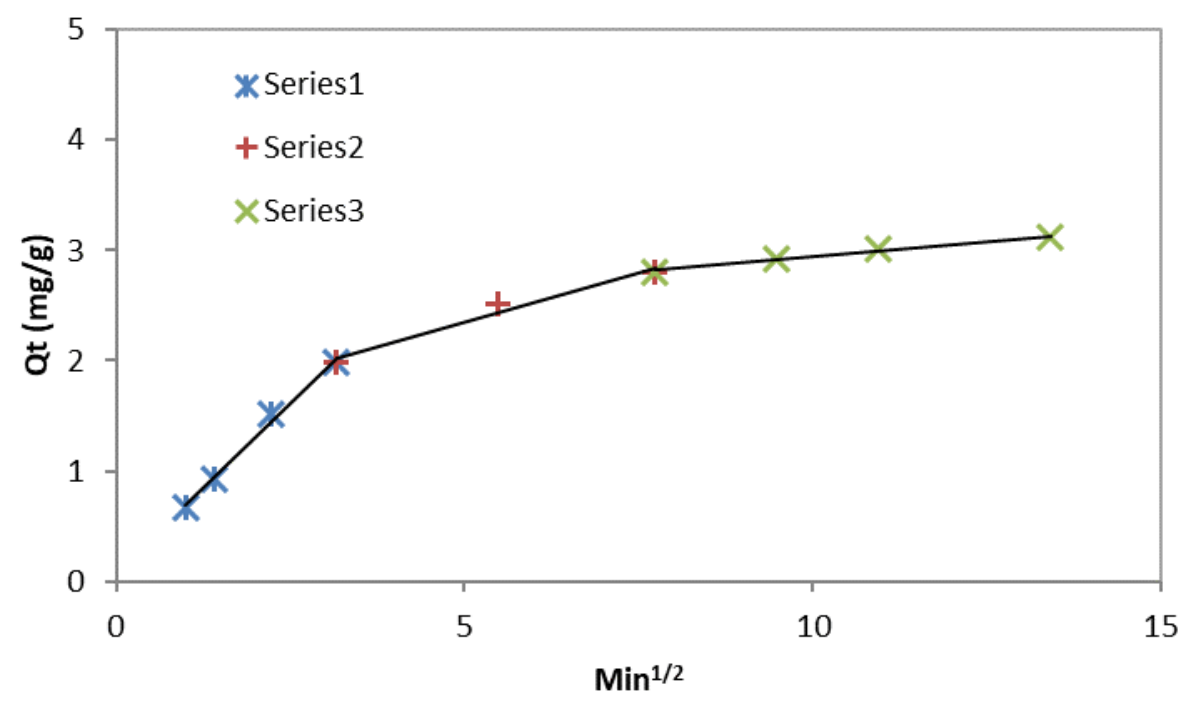

Figure 2.4. Phosphate adsorption modeling of the kinetic data with Weber-Morris intraparticle diffusion plot. Series1 (point 1-4, 0 to 10 minutes): external adsorption, series2 (point 4-6, 10 to 60 minutes): intraparticle diffusion, series3 (point 6-9, 60 to 180 minutes): equilibrium adsorption. Initial phosphate $(\mathrm{P})$ concentration $=5 \mathrm{mg} / \mathrm{L}, \mathrm{pH}=6.6$, HA-MNP dose $=1.0 \mathrm{~g} / \mathrm{L}$, temperature $=298 \mathrm{~K}$, contact time $=3$ hours

The external adsorption process is assumed to be the fastest and instantaneous where a significant concentration of initial phosphate was adsorbed in the HA-MNP surface within 10 minutes (first four points of Fig. 2.4). The second stage of adsorption was controlled by intraparticle diffusion mechanism over a period of approximately 60 minutes (middle region of Fig. 2.4). The final stage is the equilibrium adsorption (last four points of Fig. 2.4) where intraparticle diffusion no longer dominates due to low phosphate concentration and the process approaches the equilibrium (Crini et al., 2007). 


\subsubsection{Adsorption isotherms}

The adsorption isotherm describes the adsorbent-adsorbate relationship at equilibrium critical for determining optimal parameters for the application of the adsorbent. A range of concentrations ( 5 to $100 \mathrm{mg} / \mathrm{L}$ ) of phosphate were mixed with a fixed amount of HA-MNP ( $1 \mathrm{~g} / \mathrm{L})$. The experiment was carried out for 3 hours in the orbit shaker at temperature $298 \mathrm{~K}, \mathrm{pH} 6.6$ and a mixing speed of $250 \mathrm{rpm}$. The concentrations of phosphate obtained from IC were plotted as adsorption isotherms and fit to Langmuir and Freundlich models to determine the equilibrium adsorption and the maximum adsorption capacity. The Langmuir isotherm assumes that monolayer adsorption occurs on homogeneous adsorbent surface and there is no interaction between the adsorbate molecules (Tahir and Rauf, 2006). The linear form of Langmuir adsorption isotherm is represented below, Eq. 2.5,

$$
\frac{C_{e}}{Q_{e}}=\frac{1}{b Q_{\max }}+\frac{C_{e}}{Q_{\max }}
$$

Where, $C_{e}$ is the concentration of phosphate $(\mathrm{mg} / \mathrm{L})$ in solution at equilibrium, $\mathrm{Q}_{\mathrm{e}}$ is the amount of phosphate adsorbed $(\mathrm{mg} / \mathrm{g})$ on the adsorbent surface at equilibrium, $\mathrm{Q}_{\max }$ is the maximum adsorption capacity $(\mathrm{mg} / \mathrm{g})$ and $\mathrm{b}$ is the Langmuir constant related to adsorption free energy $(\mathrm{L} / \mathrm{mg})$. The Freundlich isotherm, on the other hand, describes the heterogeneity of the adsorbent surface (Yoon et al., 2016) with non-uniform distribution of adsorption heat and affinities as well as the formation of multilayer during the adsorption process. The mathematical expression of Freundlich isotherm is represented below, (Eq.

$$
\log Q_{e}=\log K_{f}+\frac{1}{n} \log C_{e}
$$


Where $\mathrm{Q}_{\mathrm{e}}$ and $\mathrm{C}_{\mathrm{e}}$ represent the same parameter as in Langmuir isotherm, $\mathrm{K}_{\mathrm{f}}$ denotes the adsorption capacity and $1 / \mathrm{n}$ indicates adsorption intensity (dimensionless). The value of $\mathrm{K}_{\mathrm{f}}$ is linearly proportional to adsorption capacity while a $1 / \mathrm{n}$ value of less than 1 indicates greater adsorption strength through chemisorption. Individual adsorption parameters and the correlation coefficients were obtained by plotting the experimental data in the two different isotherm models, presented in Table 2.2.

Table 2.2. Langmuir and Freundlich parameters for the adsorption of phosphate onto HAMNP

\begin{tabular}{llllcc}
\hline \multicolumn{2}{l}{ Langmuir isotherm } & \multicolumn{5}{l}{ Freundlich isotherm } \\
\hline $\mathrm{Q}_{\max }(\mathrm{mg} / \mathrm{g})$ & $\mathrm{b}(\mathrm{L} / \mathrm{mg})$ & $\mathrm{R}^{2}$ & $\mathrm{~K}_{\mathrm{f}}$ & $1 / \mathrm{n}$ & $\mathrm{R}^{2}$ \\
\hline 28.9 & 0.03 & 0.80 & 12.4 & 0.48 & 0.93
\end{tabular}

The theoretical maximum adsorption capacity for phosphate was calculated to be $28.9 \mathrm{mg} / \mathrm{g}(\mathrm{P})$ which is comparable to other similar types of adsorbents used for phosphate removal, e.g., $1.5 \mathrm{mg} / \mathrm{g}\left(\mathrm{PO}_{4}{ }^{3-}\right)$ by synthetic iron oxide coated sand at $\mathrm{pH} 5,7.9 \mathrm{mg} / \mathrm{g}(\mathrm{P})$ by lanthanum doped activated carbon fiber ( $\mathrm{pH}$ not reported), $11.2 \mathrm{mg} / \mathrm{g}(\mathrm{P})$ by hydroxyiron pillared bentonites at $\mathrm{pH} 3,36.5 \mathrm{mg} / \mathrm{g}(\mathrm{P})$ by Fe-Mn binary oxide at $\mathrm{pH} 5.6$ (Boujelben et al., 2008; Liu et al., 2011; Yan et al., 2010; G. Zhang et al., 2009). The results also showed that the Freundlich isotherm model explains $\left(\mathrm{R}^{2}>0.93\right)$ the adsorption process better than the Langmuir isotherm $\left(\mathrm{R}^{2} \approx 0.80\right)$ and thus indicative of the formation of multilayer adsorption and heterogeneous surface sites. The value of $1 / \mathrm{n}$ was found to be less than unity (0.48) which corresponds to an adsorption mechanism involving chemisorption, supported by our kinetic study presented earlier. 


\subsubsection{Effect of $\mathrm{pH}$}

Solution $\mathrm{pH}$ can have a pronounced effect on adsorption since the adsorbent surface charge strongly influence the adsorption of charged phosphate species. The leaching of humic acid from the HA-MNP surface is also affected by solution $\mathrm{pH}$. With this in mind, the adsorption of phosphate was studied as a function of initial solution $\mathrm{pH}$ from acidic to alkaline range. The amount of phosphate removal decreases noticeably with the increase of $\mathrm{pH}$ values as depicted in Fig. 2.5. The lower adsorption at basic $\mathrm{pH}$ can be explained by considering the phosphate speciation in aqueous medium. Phosphate is polyacidic $\left(\mathrm{pK}_{1}=\right.$ 2.12, $\mathrm{pK}_{2}=7.21$, and $\left.\mathrm{pK}_{3}=12.67\right)$ prevail as $\mathrm{H}_{3} \mathrm{PO}_{4}, \mathrm{H}_{2} \mathrm{PO}_{4}{ }^{-}, \mathrm{HPO}_{4}{ }^{2-}$ and $\mathrm{PO}_{4}{ }^{3-}$ in water. At lower $\mathrm{pH}$, sorbent surface will be positively charged while the phosphate species will be predominantly monoanionic i.e. $\mathrm{H}_{2} \mathrm{PO}_{4}^{-}$. Thus, electrostatic attraction between $\mathrm{H}_{2} \mathrm{PO}_{4}{ }^{-}$ and HA-MNP- $\mathrm{H}^{+}$results in higher adsorption of phosphate on HA-MNP. As the $\mathrm{pH}$ increases, more hydroxyl ion exists in the solution which might compete with phosphate species for the sorbent site. Another possibility is that, at higher $\mathrm{pH}$, the sorbent surface and the phosphate species becomes more negative which introduces greater repulsion and as a consequence, the adsorption of phosphate decreases. In summary, the $\mathrm{pH}$ study demonstrates that HA-MNP can be applied in neutral or acidic water (or wastewaters) for the effective removal of phosphate. 


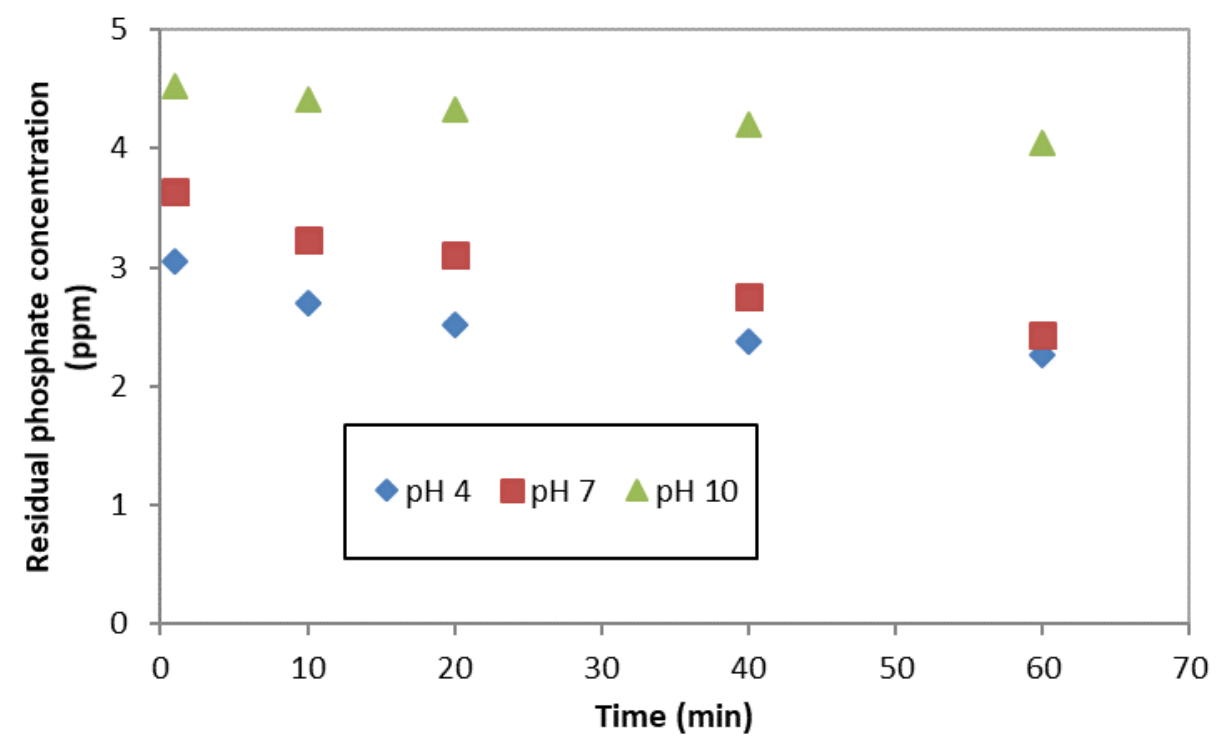

Figure 2.5. Effect of initial $\mathrm{pH}$ for the adsorption of phosphate onto HA-MNP. Initial phosphate concentration $=5 \mathrm{mg} / \mathrm{L}, \mathrm{HA}-\mathrm{MNP}$ dose $=1.0 \mathrm{~g} / \mathrm{L}$, temperature $=298 \mathrm{~K}$, contact time $=1$ hour

The leaching of humic acid was measured by preparing a mixture of $100 \mathrm{ppm}$ water dispersed HA-MNP at different $\mathrm{pH}(4,7 \& 10)$. The mixture was placed in the orbit shaker (250 rpm) at room temperature for 3 hours to mimic the originally followed adsorption experiment environment, filtered using $0.45 \mu \mathrm{m}$ filter and finally analyzed in the TOC analyzer. The concentration of dissolved organic carbon (DOC) was found in the range of 0.02 to $0.08 \mathrm{ppm}$ (Table A1) for the studied $\mathrm{pH}$ values which is lower than the DOC concentration reported into the literature for the same materials (J. Liu et al., 2008). This implies the robustness of the coating of humic acid on magnetite surface and further shows the promise of the nanoparticles to be used under different environmental conditions. 


\subsubsection{Effect of temperature}

Thermodynamic study of phosphate adsorption was conducted by measuring the adsorption at different temperatures ranging from 25 to $65^{\circ} \mathrm{C}$ ( 298 to $338 \mathrm{~K}$ ) with an initial concentration of $5 \mathrm{ppm}$ of phosphate and $1 \mathrm{~g} / \mathrm{L}$ of HA-MNP. The reaction time was 1 hour. By fitting each of these temperature data into the pseudo second order model (Fig. 2.6), different rate constants were obtained for different temperatures.

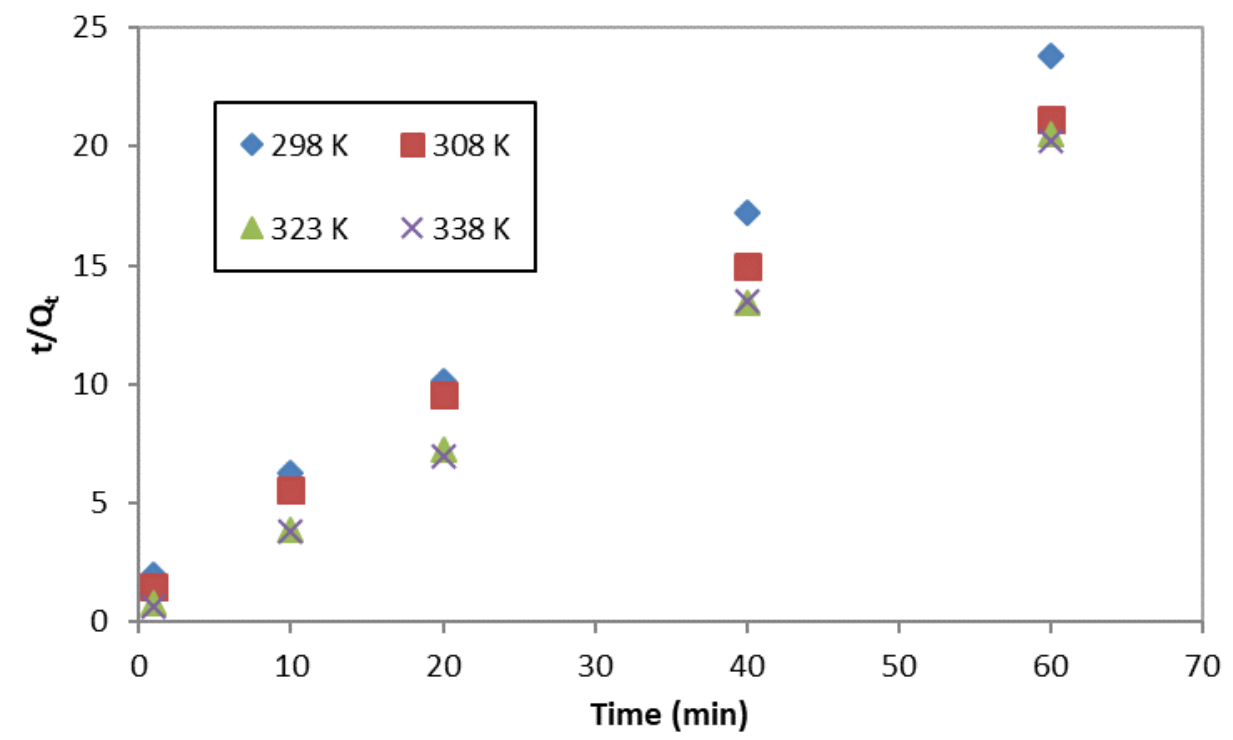

Figure 2.6. Effect of temperature for the adsorption of phosphate onto HA-MNP. Initial phosphate concentration $=5 \mathrm{mg} / \mathrm{L}, \mathrm{pH}=6.6, \mathrm{HA}-\mathrm{MNP}$ dose $=1.0 \mathrm{~g} / \mathrm{L}$, contact time $=1$ hour

A plot of lnk versus $1 / \mathrm{T}$ was used to determine the activation energy (Ea) based on Arrhenius equation,

$$
\ln k=\ln K_{0}-\frac{E_{a}}{R T}
$$

Where $E_{a}$ is the activation energy $(\mathrm{kJ} / \mathrm{mol}), \mathrm{K}_{0}$ is the temperature independent factor, $\mathrm{R}$ is the ideal gas constant $(8.314 \mathrm{~J} / \mathrm{K} \mathrm{mol})$ and $\mathrm{T}$ is the temperature in Kelvin. The 
plot gives a straight line (Fig. 2.7) from where the value of Ea is calculated to be $\approx 27 \mathrm{~kJ} / \mathrm{mol}$ which also suggests that the adsorption process is mostly driven by the mechanism of chemisorption (Chen et al., 2011; Liu et al., 2011).

Other important thermodynamic parameters were calculated by using the following equations-

$$
\begin{aligned}
& \log \frac{Q e}{C e}=\frac{\Delta S^{\circ}}{2.303 R}-\frac{\Delta H^{\circ}}{2.303 R T} \\
& \Delta G^{\circ}=\Delta H^{\circ}-T \Delta S^{\circ}
\end{aligned}
$$

Where $\Delta \mathrm{G}^{\circ}, \Delta \mathrm{H}^{\circ}$ and $\Delta \mathrm{S}^{\circ}$ are the standard free energy, enthalpy and entropy for the adsorption process respectively, $\mathrm{Q}_{\mathrm{e}}$ is the amount of phosphate adsorbed at equilibrium $(\mathrm{mg} / \mathrm{g}), \mathrm{C}_{\mathrm{e}}$ is the equilibrium concentration $(\mathrm{mg} / \mathrm{L})$ of phosphate in solution and $\mathrm{T}$ is the temperature $(\mathrm{K})$. The calculated values of the thermodynamic parameters are listed in Table 2.3. The positive value of $\Delta \mathrm{H}^{\circ}$ indicate that the process is endothermic i.e. adsorption increases with the increase of temperature which might result from the fact that rising temperature increases the adsorbent pore size and/or favor the mass transport by reducing the reaction energy barrier between the phosphate ions and the HA-MNP. 


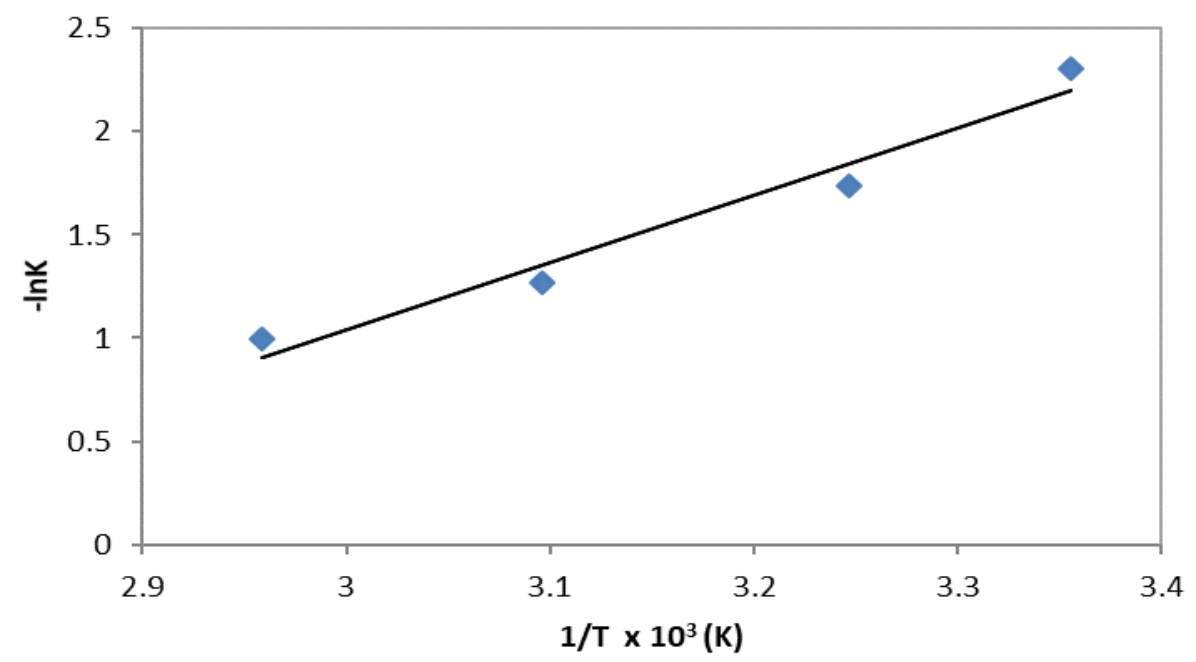

Figure 2.7. Arrhenius plot of lnk vs $1 / \mathrm{T}$ to determine activation energy

The positive value of $\Delta \mathrm{S}^{\circ}$ implies that randomness of the system increases at the solid-solution interface which helps the adsorption of phosphate onto the surface of HAMNP. The negative value of $\Delta \mathrm{G}^{\circ}$ indicates that the overall adsorption process is spontaneous and therefore, thermodynamically favorable at all the investigated temperatures.

Table 2.3. Thermodynamic data for the adsorption of phosphate onto HA-MNP

\begin{tabular}{|c|c|c|c|c|c|c|}
\hline \multirow{2}{*}{$\begin{array}{l}\text { Concentration } \\
\text { of phosphate } \\
\text { (ppm) }\end{array}$} & \multirow{2}{*}{$\begin{array}{l}\mathrm{Ea} \\
(\mathrm{kJ} / \mathrm{mol})\end{array}$} & \multirow{2}{*}{$\begin{array}{l}\Delta \mathrm{S}^{\circ}(\mathrm{J} / \mathrm{mol} \\
\mathrm{K})\end{array}$} & \multirow{2}{*}{$\begin{array}{l}\Delta \mathrm{H}^{\circ} \\
(\mathrm{kJ} / \mathrm{mol})\end{array}$} & \multicolumn{3}{|l|}{$\Delta \mathrm{G}^{\circ}(\mathrm{J} / \mathrm{mol} \mathrm{K})$} \\
\hline & & & & $298 \mathrm{~K} \quad 308 \mathrm{~K}$ & $323 \mathrm{~K}$ & $338 \mathrm{~K}$ \\
\hline 5 & 27.03 & 15.32 & 4.08 & -0.48 & -0.86 & -1.09 \\
\hline
\end{tabular}

\subsubsection{Effect of co-existing ions}

In groundwater and wastewater, anions such as sulfate, nitrate, chloride and carbonate often co-exist along with phosphate, so the effect of coexisting ions was also 
studied by separately adding $1 \mathrm{mM}$ of each of the anions into the reaction mixtures containing $5 \mathrm{ppm}$ of phosphate $(\mathrm{P})$ and $1 \mathrm{~g} / \mathrm{L}$ of HA-MNP. The reaction was continued for 3 hours. Results from the analysis of the competition ions effect are shown in Fig. 2.8. Except carbonate, no noticeable effect in the adsorption efficiency was observed due to the presence of any other anions in the solution. The addition of carbonate $\left(\mathrm{CO}_{3}{ }^{2-}\right)$ made the overall phosphate solution alkaline by changing the $\mathrm{pH}$ from the initial 6.6 to 10.1 . This higher $\mathrm{pH}$ might be the reason for the decrease of phosphate uptake by HA-MNP as we observed the similar trend in our $\mathrm{pH}$ effect study section.

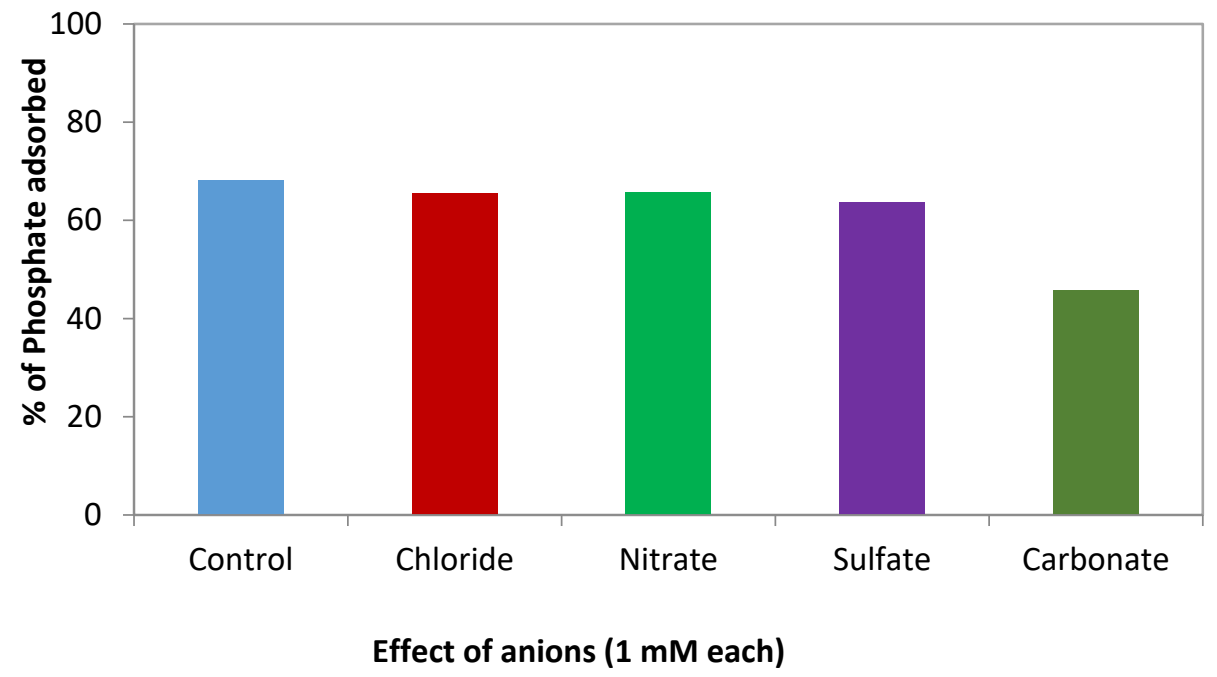

Figure 2.8. Effect of coexisting ions for the adsorption of phosphate onto HA-MNP. Initial phosphate concentration $=5 \mathrm{mg} / \mathrm{L}$, concentration of each of the anions $=1 \mathrm{mM}$, $\mathrm{pH}=6.6, \mathrm{HA}-\mathrm{MNP}$ dose $=1.0 \mathrm{~g} / \mathrm{L}$, temperature $=298 \mathrm{~K}$, contact time $=3$ hours

\subsection{Conclusions}

In the present work, an economical, environmentally friendly magnetic adsorbent has been applied to effectively separate phosphate present in the water system. Results showed that the phosphate removal by HA-MNP is most successful from acidic to neutral 
$\mathrm{pH}$ range. The increase of temperature also exerts a positive influence on phosphate adsorption efficiency. Investigations of adsorption kinetics and adsorption isotherm suggest that the adsorption mainly occurs through chemisorption and thus indicative of strong bonding between phosphate and the adsorbent nanoparticles. Thermodynamic study identified the removal process as endothermic and spontaneous. The negligible effect of most of the coexisting ions indicates the good selectivity of the synthesized nanoadsorbent. Finally, this HA-MNP with its competitive adsorption capacity and easy separation advantage can be a promising agent for the removal of phosphate from aqueous solution. 


\section{CHAPTER THREE}

Kinetic and Mechanistic Evaluation of Inorganic Arsenic Species Adsorption onto Humic Acid Grafted Magnetite Nanoparticles 


\subsection{Abstract}

Humic acid coated magnetic iron oxide nanoparticles (HA-MNP) were synthesized, characterized, and studied for the removal of toxic inorganic arsenic species from aqueous media. The adsorption of As(III) and As(V) followed pseudo-second order kinetics and the observed data were accurately modeled employing Freundlich adsorption isotherm. Application of the Weber and Morris intraparticle diffusion model to the observed kinetic data suggest that the adsorption occurs in three distinct stages, fast, intermediate, and slow steps. We propose the initial stage is governed by surface association, followed by intraparticle diffusion of arsenic through the HA matrix and finally, chemical reaction or bonding between the arsenic species and HA functionality. The HA-MNP nano-adsorbent absorbs $>95 \%$ of the inorganic arsenic species with an absorption capacity of 12.2-12.6 $\mathrm{mg} / \mathrm{g}$ from aqueous media and is effective under a variety of conditions. Post arsenic adsorption characterization of the nanoparticles suggests that As(III) binds with the carboxylate group of HA through a proposed ester type linkage while electrophilic reactions can occur between the nucleophilic functional groups present in HA and the electrophilic arsenic atom in $\mathrm{As}(\mathrm{V})$. The results obtained demonstrated that HA-MNP are robust and have promise for effective As (III) and As(V) remediation.

\subsection{Keywords}

Arsenic, magnetic nanoparticles, adsorption kinetics, adsorption isotherms,

\subsection{Introduction}

Arsenic occurrence in aquatic environments is the result of natural and man-made sources. While arsenic is discharged by industrial processes and used in agricultural 
applications, water contamination by arsenic is most often the contribution of dissolution or leaching of solid phase arsenic contained within the rocks, soil and minerals into groundwater (Amini et al., 2008; Mondal et al., 2014; Zheng et al., 2015). This class one carcinogen has already exerted severe negative consequences on the health of more than a hundred million people as poisoned by arsenic contaminated groundwater used for drinking, irrigation and other household purpose (Brammer and Ravenscroft, 2009; Rahman et al., 2014; Yan et al., 2012). Bangladesh, India, China, Vietnam, Argentina, Pakistan, USA, Chile and Mexico are among the countries most affected by arsenic contaminated tubewells and aquifers with arsenic concentrations well above the maximum contamination limit of $10 \mu \mathrm{g} / \mathrm{L}$ set by WHO (Rahman et al., 2014). Geology, topography, temporal variability influence the water $\mathrm{pH}$ and redox potentials and thus affects arsenic solubility (Buschmann et al., 2007; Fendorf et al., 2010). Arsenite, As(III) and arsenate, $\mathrm{As}(\mathrm{V})$ are the most common toxic forms of arsenic present in drinking water sources. The major species in the reducing environment of groundwater is the more mobile and more toxic arsenite (Yu et al., 2013). Development and implementation of effective methods for the removal of arsenic species from drinking water sources are critical to ensure quality water for millions of people worldwide.

Humic substances (HS) in aquatic systems are derived from the breakdown of soil humus and aquatic plants through different biological and chemical processes (Thurman and Malcolm, 1981). Different molecular moieties and wide variety of organic functional groups of HS are responsible for its structural diversity and physico-chemical properties such as solubility and surface charge distribution (Cook and Langford, 1998). The more hydrophobic, large molecular weight fraction of HS, commonly referred to a/s humic acid 
(HA) generally exhibits higher sorption and complexation characteristics over other HS fractions (De Paolis and Kukkonen, 1997; Meier et al., 1999). Humic acid coated/modified adsorbents for the environment friendly remediation of different contaminants from water have been studied (J. Liu et al., 2008; Wu et al., 2011; Yang and Xing, 2009). Here we report the use of humic acid grafted to iron oxide nanoparticles for the adsorption of highly toxic inorganic arsenic species from water.

Adsorption is one of the most effective methods for toxic species remediation from aqueous media as it can limit the mobility and bioavailability of potent toxins at relatively low cost and simple operation (Chang et al., 2010). Use of nanoadsorbent is particularly attractive because engineered nanomaterials can be tailored for greater surface area and stronger binding capacities (Kurniawan et al., 2012).

Iron based nano-adsorbents have received tremendous attention due to the availability and low cost of the raw materials. The strong magnetic property of tailor-made iron particles is conducive for easy recovery and/or separation. Magnetite $\left(\mathrm{Fe}_{3} \mathrm{O}_{4}\right)$ nanoparticles are among the most promising adsorbents with the advantages of superparamagnetic properties, easy preparation and bio-compatibility. However, agglomeration and the loss of magnetic strength over time resulting from auto-oxidations limits the commercial applications of bare iron oxide nanoparticles (J. Liu et al., 2008). These constraints have been addressed using organic substrates to coat the surface of magnetite $\left(\mathrm{Fe}_{3} \mathrm{O}_{4}\right)$ nanoparticles. The coating protects against auto-oxidation of the iron oxide core. Tremendous potential is observed for the environmental applications of magnetite nanoparticles coated with humic acid (HA), where the surface charge associated 
with the nanoparticles is converted from positive to negative upon the appropriate coating of humic acid on magnetite (Illés and Tombácz, 2006; Tombácz et al., 2013). The strong affinity of polyanionic humic acid to magnetite is found to be useful in coating the surface effectively which in effect significantly reduces or eliminates the nanotoxicity of bare magnetite nanoparticles (MNP) and enhances their chemical and colloidal stability (Illés and Tombácz, 2003; Peng et al., 2012). The saturation magnetization of bare MNP and HA-MNP are reported to be 79.6 and $68.1 \mathrm{emu} / \mathrm{g}$ respectively, thus demonstrates the retention of strong magnetic property by the nanoparticles even after the coating of humic acid on the surface (J. Liu et al., 2008). Liu et al. was the first to demonstrate the potential application of humic acid coated magnetite nanoparticles (HA-MNP) for the adsorption and removal of toxic metal cations (J. Liu et al., 2008). Although the application of negatively charged HA-MNP materials for adsorption of toxic cations is effective due to electrostatic attractions between adsorbent surface and toxic cations involved, we recently reported the successful removal of anionic chromium and phosphate from water using HAMNP (Jiang et al., 2014; Rashid et al., 2017). The adsorption mechanisms for anionic species is not based on electrostatic interactions but rather likely through the formation of chemical bonds between the adsorbate and the different functional groups present in humic acid. The carboxylic, phenolic, amino, and sulfhydryl moieties of HA can act as a potential binding sites for the toxic arsenic species. In the solution $\mathrm{pH}$ range of 3 to 9 , the charge neutral $\mathrm{H}_{3} \mathrm{AsO}_{3}$ is the dominant species of $\mathrm{As}(\mathrm{III})$ whereas for $\mathrm{As}(\mathrm{V})$, the negatively charged $\mathrm{H}_{2} \mathrm{AsO}_{4}{ }^{-}$and $\mathrm{HAsO}_{4}{ }^{2-}$ are the most prevalent forms (Liu et al., 2015). Here we examined the removal of both As(III) and As(V) using HA-MNP. The detailed characterization of HA-MNP and As-HA-MNP provide fundamental information about the 
bonding and adsorption mechanisms of As (III) and As(V) to the humic acid materials which can be extended to understand the fate, transport, and bioavailability of As (III) and $\mathrm{As}(\mathrm{V})$ in the natural aqueous systems. The results demonstrate for the first time that HANMPs are an effective nano-adsorbent for As(III) and As(V). The As adsorption is readily modeled and predictable which are critical to meet specific treatment objectives in real-life applications. The knowledge obtained from the study can help guide the improvement of water treatment methodologies using green materials.

\subsection{Experimental section}

\subsubsection{Materials}

Ammonium hydroxide (29.2\%), ferric chloride hexahydrate (98.8\%), sodium arsenite and sodium arsenate dibasic heptahydrate $(\geq 98 \%)$ were purchased from Fisher Scientific. Ferrous chloride tetrahydrate $(\geq 99 \%)$ and humic acid sodium salt were purchased from Sigma Aldrich.

\subsubsection{Synthesis and application of HA-MNP}

The nanoparticles were synthesized using co-precipitation reported elsewhere (J. Liu et al., 2008). Summary of the synthesis procedure are given in chapter 2 . The arsenic solution with the added nanoparticles were mixed in the $50 \mathrm{~mL}$ plastic bottle and agitated in the orbit shaker at $250 \mathrm{rpm}$ (Lab line instrument Inc., model 3520). For the adsorption experiments, the initial solution $\mathrm{pH}$ of arsenic was adjusted by using $0.1 \mathrm{M} \mathrm{HCl}$ and $0.1 \mathrm{M}$ $\mathrm{NaOH}$ and monitored by $\mathrm{pH}$ meter (Mettler Toledo, model: SevenEasy). The particles were separated from solution and residual arsenic concentration and speciation were measured employing a Perkin Elmar ICP-MS coupled with HPLC. Although handheld magnet 
provides effective separation of the treated nanoparticles, to comply with the requirement of the analytical facility and to conveniently handle large number of samples of small volume, $0.45 \mu \mathrm{m}$ syringe filters were used to filter the arsenic solution before analyzing in LC-ICP-MS.

\subsection{Results and discussion}

\subsubsection{Characterization}

HA-MNP were subjected to detail characterization before and after the adsorption of $\operatorname{As}(\mathrm{III})$ and $\mathrm{As}(\mathrm{V})$ species. Details of the sample preparation and characterization techniques are provided in Appendix B. The newly synthesized HA-MNPs exhibited the established key features (Jiang et al., 2014; J. Liu et al., 2008; Rashid et al., 2017). The FTIR spectra of HA-MNP (Figure B1) exhibits characteristic band at $1598 \mathrm{~cm}^{-1}$ indicative of the $\mathrm{C}=\mathrm{O}$ stretching of carboxylate functionality present in $\mathrm{HA}$, the red shift from typical carboxylate band $\left(1700 \mathrm{~cm}^{-1}\right)$ is characteristic of a weaker $\mathrm{C}=\mathrm{O}$ bond as the carbonyl oxygen complexes with the magnetite core (Rashid et al., 2017). The strong broad IR band at $3300-2700 \mathrm{~cm}^{-1}$ observed in the neat HA-MNP can be attributed to the presence of phenolic $\mathrm{O}-\mathrm{H}$ and/or carboxylic acid groups of HA in HA-MNP. A significant reduction in the $\mathrm{O}-\mathrm{H}$ signal is observed after the adsorption of $\mathrm{As}(\mathrm{III})$ and $\mathrm{As}(\mathrm{V})$, suggesting the formation of chemical bond between the O-H groups in the HA coating and the As species. The TEM image of the HA-MNP (Figure 3.1a) illustrates a thin film coating of humic acid on the magnetite surface. The TEM measurements yield the average diameter of $10.6 \mathrm{~nm}$ for the synthesized HA-MNP with standard deviation of 3.5 (Figure B2). STEM-HAADF image of arsenic loaded HA-MNP is shown in Figure 3.1b. High resolution TEM image of 
the arsenic laden nanoparticles (Figure 3.1c) reveals the characteristic lattice fringe distance of the original HA-MNP as $3.0 \AA$ and $4.9 \AA$ corresponding to the (220) and (111) crystallographic planes of magnetite.

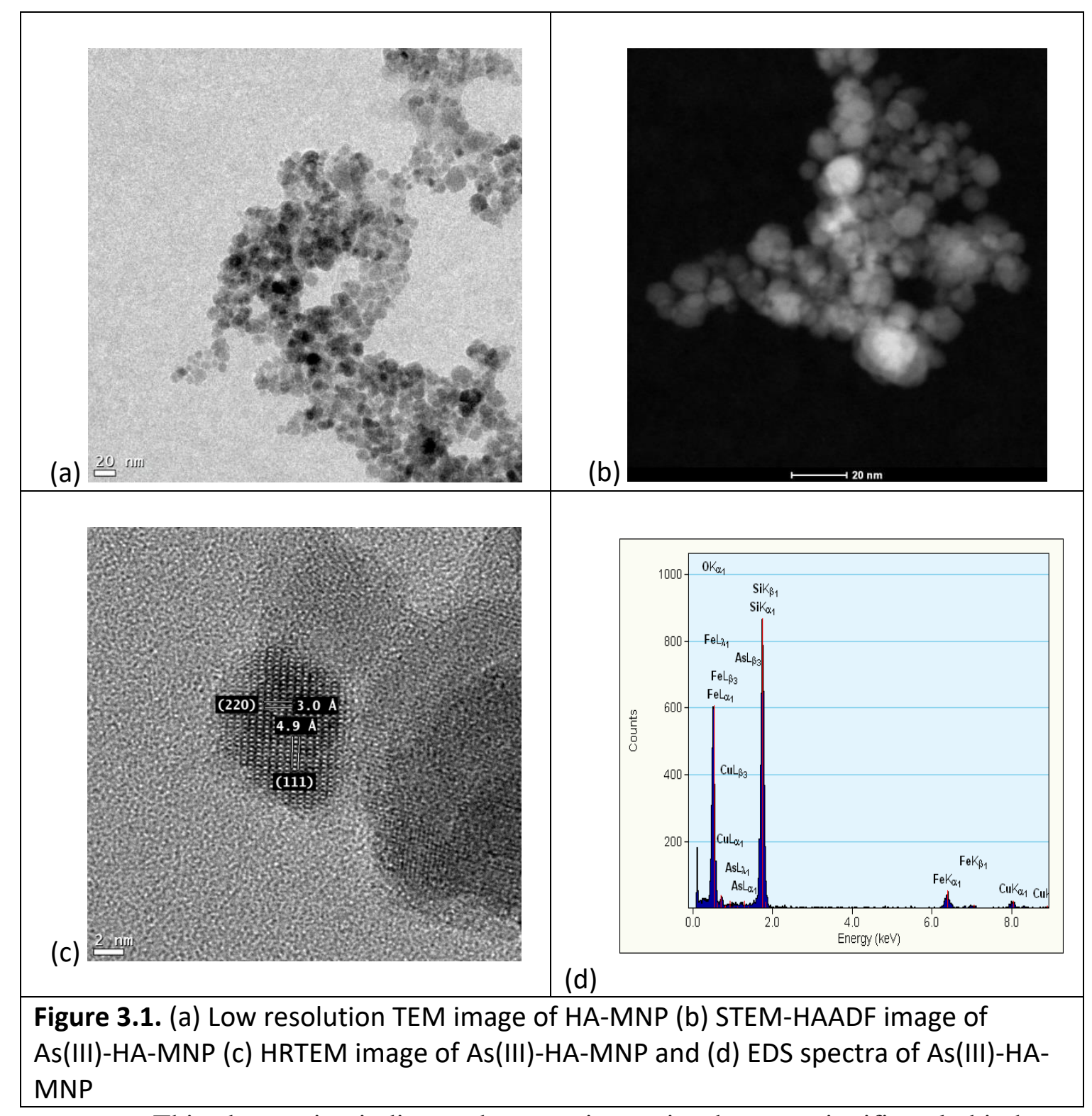

This observation indicates that arsenic species does not significantly bind to or change the crystalline lattice of the iron oxide core material. Since the HA-MNP core is unchanged upon adsorption of arsenic, the humic acid shell appears to shield the magnetite 
core from the arsenic species, thus suggesting that adsorption occurs within the humic acid matrix. EDS spectra of the As-loaded HA-MNP confirms the presence of arsenic in the nanoparticle surface (Figure 3.1d). The copper $(\mathrm{Cu})$ and silicon (Si) peaks in the EDS spectra are from the grids which are made of copper with a thin film coating of silicon on top. The Raman spectra of HA-MNP (Figure 3.2) shows the characteristic magnetite bands at 535 and $668 \mathrm{~cm}^{-1}$ while the characteristic bands associated with maghemite at 350,500 and $720 \mathrm{~cm}^{-1}$ are not observed (Daou et al., 2006). With respect to the comparison of the Raman peaks at 220,280 , and $700 \mathrm{~cm}^{-1}$, there is clearly variation in the relative proportion of these peaks. Such changes may be due to changes in the HA backbone or functionality upon binding of the arsenic species. Raman spectrum of the As(III)-HA-MNP (Figure 3.2) includes a band at $321 \mathrm{~cm}^{-1}$ which is assigned to the vibrational stretching of As(III)-O bond and a band at $357 \mathrm{~cm}^{-1}$ corresponds to the bending of $\mathrm{O}-\mathrm{As}(\mathrm{V})-\mathrm{O}$ bond (Goldberg and Johnston, 2001). While As(III) can be oxidized to $\mathrm{As}(\mathrm{V})$ by photochemical processes, great care was taken to eliminate light exposure of materials used in the experiments involving As(III). However, in an oxygen saturated environment in the presence of HAMNP, conversion of As(III) to As(V) is observed (Figure B3) even in the absence of light. The HA-MNP promoted transformation of As(III) to As(V) under dark conditions could be initiated by trace metals in the HA materials and/or the presence of molecular oxygen. 


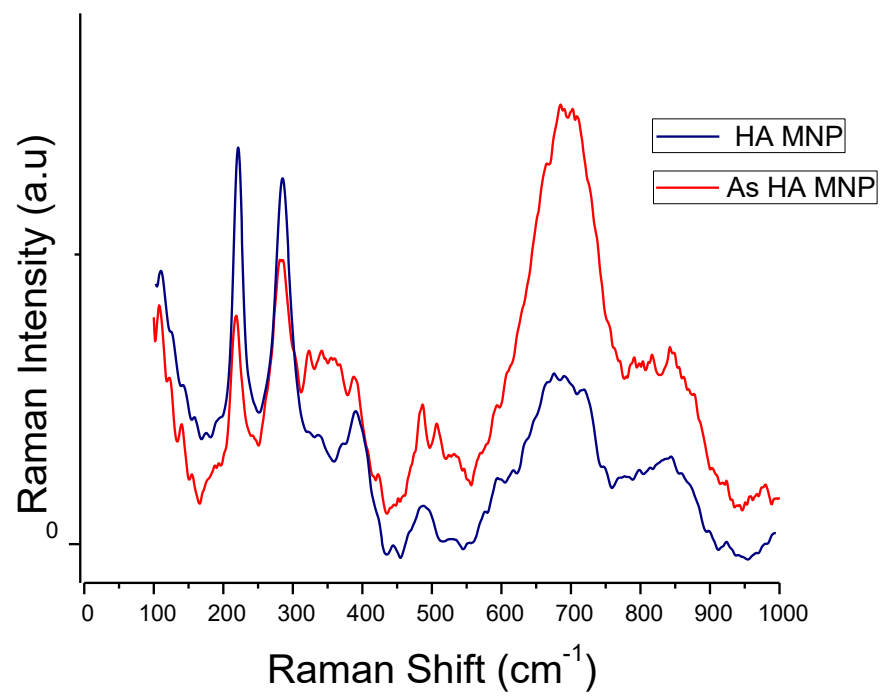

Figure 3.2. Raman spectra of HA-MNP and As(III)-HA-MNP

The wide scan XPS spectra of HA-MNP (Figure B4a) shows the binding energy of approximately 285,529 and $710 \mathrm{eV}$ that corresponds to the photoelectron lines of $\mathrm{C} 1 \mathrm{~s}, \mathrm{O} 1 \mathrm{~s}$ and Fe2p respectively (Chandra et al., 2010). Deconvolution of the peaks with corrected binding energy of adventitious carbon $(284.8 \mathrm{eV})$ indicates the presence of $\mathrm{C}-\mathrm{C}$ and $\mathrm{C}-\mathrm{H}$ at $284.8 \mathrm{eV}$ and the carboxylate group $\left(\mathrm{COO}^{-}\right)$at $288.5 \mathrm{eV}$ from $\mathrm{HA}$, all pertaining to $\mathrm{C} 1 \mathrm{~s}$ (Figure B4b) (Wilson and Langell, 2014; Yang et al., 2009). For O1s (Figure B4c), the two peaks at 528.8 and $531.4 \mathrm{eV}$ can be ascribed to the anionic oxygen in magnetite and the oxygen containing functional groups of HA respectively (Lin et al., 1997; Wilson and Langell, 2014). In case of Fe2p spectra (Figure B4d), the Fe2p $3 / 2$ peak at 708.9 and 710.6 $\mathrm{eV}$ are due to the presence of $\mathrm{Fe}^{2+}$ and $\mathrm{Fe}^{3+}$ respectively while the peak at 724.1 is for Fe2p1/2 (Grosvenor et al., 2004). The peak at 740.3 eV corresponds to the OKL23 $\mathrm{L}_{23}$ Auger lines of oxygen. The absence of the characteristic satellite peak of maghemite $\left(\gamma-\mathrm{Fe}_{2} \mathrm{O}_{3}\right)$ at $719.0 \mathrm{eV}$ further indicates that the coating of humic acid successfully inhibits the oxidation 
of magnetite core (Zhang et al., 2004). Iron K-edge XANES spectra and $\mathrm{k}^{3}$ weighted EXAFS spectra of bare magnetite and HA-MNP are similar and consistent with the magnetite spectra reported in the literature [Figure B5(a \& b)] (Sun et al., 2014). The arsenic K-edge XANES spectra of As(III) and As(V) loaded HA-MNP are shown in Figure B6. Although arsenic samples for XAS experiment were prepared in the nitrogen glovebox, partial conversion of $\mathrm{As}(\mathrm{III})$ to $\mathrm{As}(\mathrm{V})$ in the HA-MNP treated samples are observed (Figure B6a) whereas the XANES spectra of the adsorbed $\mathrm{As}(\mathrm{V})$ species remains largely unaffected (Figure B6b). The exposure of HA-MNP bound As(III) to molecular oxygen, the presence of trace metals in HA and/or the oxidizing environment of the beamline are assumed to play roles in the oxidation of HA-MNP adsorbed As(III) to As(V). At higher $\mathrm{pH}, \mathrm{As}(\mathrm{III})$ is more readily converted to $\mathrm{As}(\mathrm{V})$ which may be related to $\mathrm{pKa}$, change in speciation and susceptibility to oxidation. Linear combination fitting of Athena (Ravel and Newville, 2005) was used to determine the percent conversion of As(III) to As(V) in As (III) loaded HA-MNP sample at neutral pH (Figure B7). As clearly observed from the figure, initially there was no $\mathrm{As}(\mathrm{V})$ species present in the sample meaning that the absence of molecular oxygen in the nitrogen glovebox inhibits the oxidation of As(III). However, with the exposure of the sample to the beamline, $25 \%$ of $\mathrm{As}(\mathrm{III})$ is converted to $\mathrm{As}(\mathrm{V})$ in 4.5 hours suggesting that the beam induced oxidation played a critical role in the conversion process.

\subsubsection{Kinetics of arsenic adsorption}

The adsorption equilibrium and the corresponding uptake capacity for As(III) and $\mathrm{As}(\mathrm{V})$ of HA-MNP were determined to assess for their possible implementation. The 
adsorption experiments were run for three hours with samples collected at pre-determined time intervals. The collected samples were filtered to separate the As-loaded HA-MNP from the solution and the filtrates analyzed by HPLC-ICP-MS to monitor the residual concentration of the As species in the solution. The results demonstrate As(V) is adsorbed by HA-MNP faster and to a greater extent than As(III). At a HA-MNP loading dose of 0.2 $\mathrm{g} / \mathrm{L}$ and $200 \mathrm{ppb}$ of the arsenic species, the level of As(III) can be reduced below the drinking water maximum contaminant level (MCL) of 10 ppb within 180 mins, while only 60 mins is required to reduce the concentration of As(V) below the MCL (Figure 3.3).

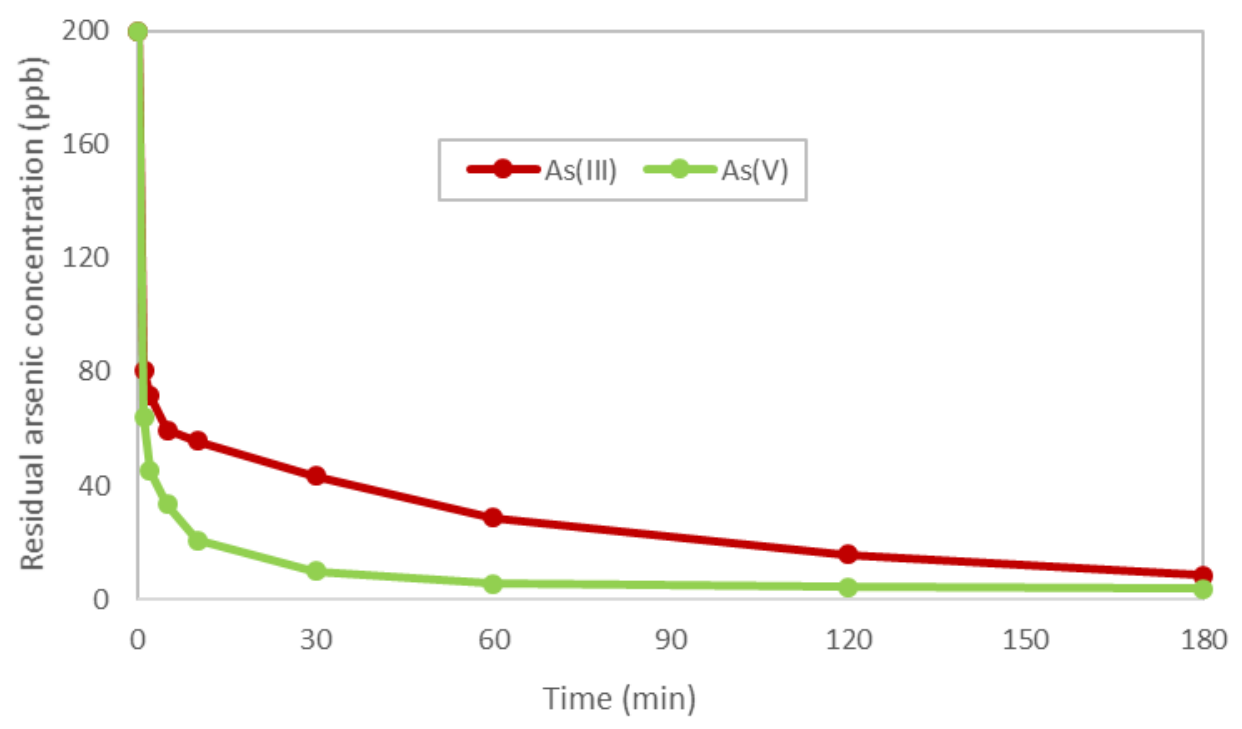

Figure 3.3. Comparison of adsorption kinetics of $\mathrm{As}(\mathrm{III})$ and $\mathrm{As}(\mathrm{V})$ on HA-MNP. $[\mathrm{As}(\mathrm{III})]_{0}=200 \mathrm{ppb},[\mathrm{As}(\mathrm{V})]_{0}=200 \mathrm{ppb}, \mathrm{pH}=6.6, \mathrm{HA}-\mathrm{MNP}$ dose $=0.2 \mathrm{~g} / \mathrm{L}$, temperature $=25^{\circ} \mathrm{C}$

Within one min of exposure to the HA-MNP, the initial concentrations of As(III) and $\mathrm{As}(\mathrm{V})$ are reduced by $>50 \%$. For an arsenic mixture of $200 \mathrm{ppb}$ As(III) and $200 \mathrm{ppb}$ $\mathrm{As}(\mathrm{V})$ (total initial arsenic concentration of $400 \mathrm{ppb}$ ), the complete removal of arsenic species was achieved at a dose of $0.2 \mathrm{~g} / \mathrm{L}$ HA-MNP illustrated by Figure B8. Results from 
the competition study suggest that As(III) and As(V) might have some preferential sorption sites in HA surface of HA-MNP and so, the presence of one arsenic species did not appear to interfere significantly in the removal process of another. The difference in formal charge and the presence (or absence) of lone pair of electrons in the arsenic atom of the studied arsenic species has made them susceptible to attack by the two different classes of functional groups of HA with completely opposite characteristics.

Adsorption efficiency and the adsorption mechanisms were evaluated by fitting the experimental data into the Lagergren's pseudo-first order and Ho and McKay's pseudosecond order kinetic models (Ho and McKay, 1999; Tseng et al., 2010). The pseudo-first order model determines the sorption constant based on solid surface capacity while the pseudo-second order model works on solid phase sorption (Ho and McKay, 1999). The full mathematical expressions of the two models are given in Appendix B. The kinetic parameters obtained from the application of the models to the experimental data for As(III) and $\mathrm{As}(\mathrm{V})$ adsorption on HA-MNP are summarized in Table 3.1. For the pseudo-second order model, there is an excellent match observed between the experimental and calculated $\mathrm{Q}_{\mathrm{e}}$ values. The high correlation coefficient $\left(\mathrm{R}^{2}\right)$ also indicates the best fitting of the adsorption process with the pseudo-second order model. This finding suggests that for the arsenic adsorption process, rate is proportional to the square of the number of available adsorption sites in the nanoparticles (Chen et al., 2011; Ho and McKay, 1999). The kinetic data of arsenic adsorption was further investigated by using the Weber and Morris intraparticle diffusion model (Appendix B) which when applied to the observed results shows that three distinct steps are associated with the adsorption process (Figure 3.4). 
Table 3.1. Kinetic parameters for the adsorption of arsenic onto HA-MNP

\begin{tabular}{|c|c|c|c|c|c|c|c|}
\hline \multirow[b]{2}{*}{$\begin{array}{l}\mathrm{C}_{0} \\
(0.2 \mathrm{mg} / \mathrm{L})\end{array}$} & \multirow[b]{2}{*}{$\begin{array}{l}\text { Qe, } \\
\text { expt. } \\
(\mathrm{mg} / \mathrm{g})\end{array}$} & \multicolumn{3}{|c|}{ Pseudo-first order kinetics } & \multicolumn{3}{|c|}{ Pseudo-second order kinetics } \\
\hline & & $\begin{array}{l}\text { Qe, } \\
\text { calc. } \\
(\mathrm{mg} / \mathrm{g})\end{array}$ & $\begin{array}{l}\mathrm{k}_{1} \\
\left(\min ^{-1}\right)\end{array}$ & $\mathrm{R}^{2}$ & $\begin{array}{l}\text { Qe, } \\
\text { calc. } \\
(\mathrm{mg} / \mathrm{g})\end{array}$ & $\begin{array}{l}\mathrm{k}_{2} \\
\left(\mathrm{~g} \mathrm{mg}^{-1} \mathrm{~min}^{-}\right. \\
1)\end{array}$ & $\mathrm{R}^{2}$ \\
\hline $\operatorname{As}($ III) & 0.96 & 0.30 & $0.02 \pm 0.001$ & 0.98 & 0.96 & $0.35 \pm 0.02$ & 0.99 \\
\hline $\mathbf{A s}(\mathbf{V})$ & 0.98 & 0.17 & $0.04 \pm 0.003$ & 0.93 & 0.99 & $1.31 \pm 0.09$ & 0.99 \\
\hline
\end{tabular}

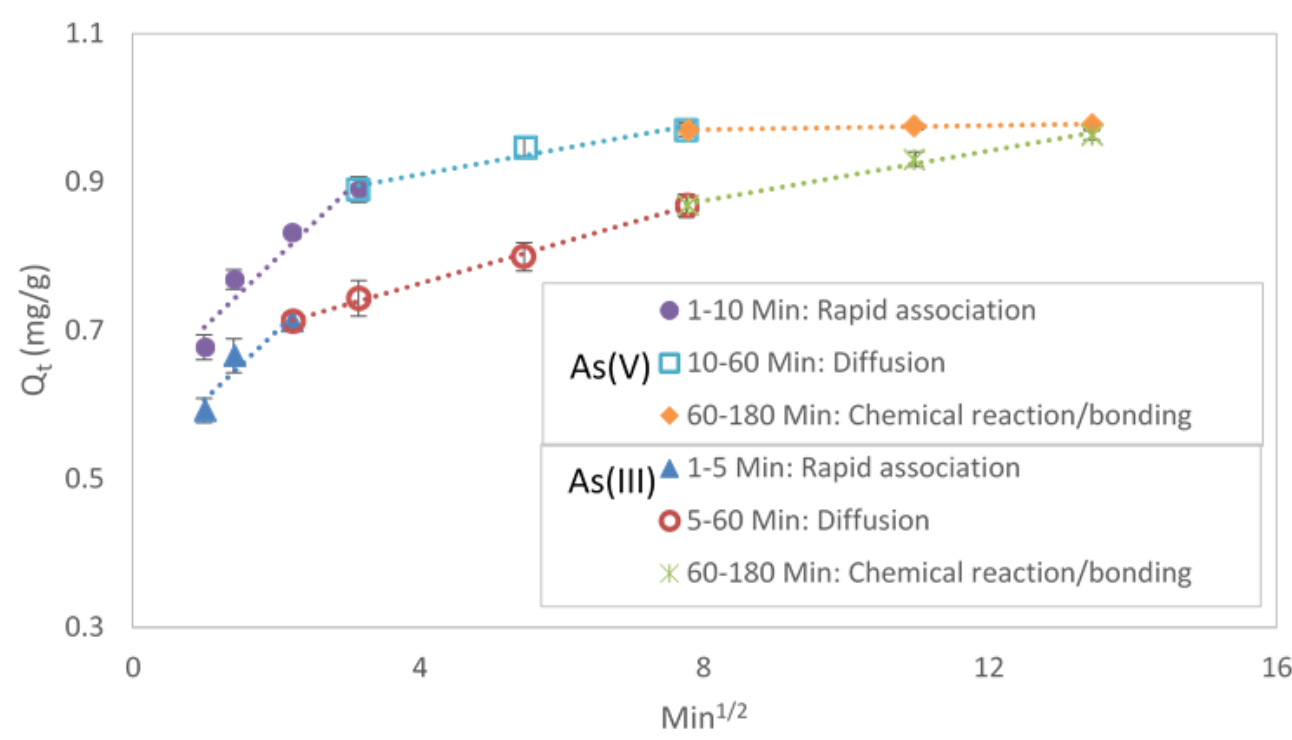

Figure 3.4. Weber-Morris intraparticle diffusion plot of $\mathrm{As}(\mathrm{III})$ and $\mathrm{As}(\mathrm{V})$ adsorption kinetic data. $[\mathrm{As}(\mathrm{III})]_{0}=200 \mathrm{ppb},[\mathrm{As}(\mathrm{V})]_{0}=200 \mathrm{ppb}, \mathrm{pH}=6.6, \mathrm{HA}-\mathrm{MNP}$ dose $=0.2 \mathrm{~g} / \mathrm{L}$, temperature $=25^{\circ} \mathrm{C}$

We propose the first stage as the initial, rapid association of arsenic on the HAMNP surface, second stage is the diffusion of arsenic species into the HA matrix of the nanoparticles and the final stage is the adsorbent-adsorbate chemical reaction/bonding that eventually lead to equilibrium. Overall, the adsorption of arsenic species on HA-MNP can 
be viewed as a complex, multi-step adsorbent-adsorbate interaction where sharing or exchange of electrons and bonding between the synthesized nanoparticles and the target arsenic species played critical roles in the observed behavior.

\subsubsection{Adsorption isotherms}

The adsorption isotherms of individual arsenic species were measured as a function of initial arsenic concentration to investigate the interactions between solid surface and adsorbent relative to the aqueous solvation of arsenic. The initial arsenic concentration was varied from 0.1 to $10 \mathrm{mg} / \mathrm{L}$ at constant loading of HA-MNP $(0.2 \mathrm{~g} / \mathrm{L})$. Data from the isotherm study were fitted in the Langmuir and Freundlich models (Appendix B) to probe the adsorption mechanisms at the solid-liquid interface. The major differences between the two models are the assumptions about the surface characteristics and the mechanism of solute binding onto the adsorbent surface. The Langmuir model assumes homogeneous adsorbent surface with a finite number of identical adsorption sites which can be occupied by only one target molecule leading to the formation of one uniform monolayer (Allen et al., 2004; Mishra and Ramaprabhu, 2010). In contrast, differential adsorption is assumed in Freundlich model where multilayer adsorption can occur on heterogeneous adsorbent surface having different degrees of affinity for the adsorbate with stronger binding sites occupied first (Foo, K.Y.; Hameed, 2010). Based on the correlation coefficient for the Langmuir and Freundlich plots of the measured experimental data, the adsorption process is found more consistent with the Freundlich model indicative of the multilayer formation and/or heterogeneous adsorption surface sites of HA-MNP. The parameters from the Langmuir and Freundlich isotherms equation are presented in Table 3.2. 
Table 3.2. Adsorption isotherm parameters for the binding of As(III) and As(V) onto HAMNP

\section{Langmuir isotherm}

\begin{tabular}{lllllll}
\hline Species & $\mathrm{Q}_{\max }(\mathrm{mg} / \mathrm{g})$ & $\mathrm{b}(\mathrm{L} / \mathrm{mg})$ & $\mathrm{R}^{2}$ & $\mathrm{~K}_{\mathrm{f}}$ & $1 / \mathrm{n}$ & $\mathrm{R}^{2}$ \\
\hline $\mathbf{A s}(\mathbf{I I I})$ & 12.2 & 3.46 & 0.96 & 2.96 & 0.57 & 0.99 \\
\hline $\mathbf{A s}(\mathbf{V})$ & 12.6 & 4.88 & 0.94 & 2.30 & 0.28 & 0.99 \\
\hline
\end{tabular}

From Freundlich model, the value of $1 / \mathrm{n}$ less than 1 is indicative of chemisorption of As(III) and As(V) on HA-MNP (Foo, K.Y.; Hameed, 2010). Although the relative adsorption capacity $\left(\mathrm{K}_{\mathrm{f}}\right)$ is found to be slightly higher for $\mathrm{As}(\mathrm{III})$ than $\mathrm{As}(\mathrm{V})$ (2.96 vs 2.30), the much lower $1 / \mathrm{n}$ value of $\mathrm{As}(\mathrm{V})(0.28)$ supports its stronger adsorption intensity compared to As(III) (0.57). This is also evident from the kinetic data where faster and more extensive adsorption was observed for $\mathrm{As}(\mathrm{V})$ relative to $\mathrm{As}(\mathrm{III})$. The maximum adsorption capacities of HA-MNP measured under our experimental condition are 12.2 and $12.6 \mathrm{mg} / \mathrm{g}$ for $\mathrm{As}(\mathrm{III})$ and $\mathrm{As}(\mathrm{V})$ respectively. Similar types of coated and uncoated iron oxide adsorbents reported in the literature shows the maximum removal capacity for both As(III) and $\mathrm{As}(\mathrm{V})$ in the range of 5.27 to $16.63 \mathrm{mg} / \mathrm{g}$ (Chandra et al., 2010; Lan, 2015; Liu et al., 2015). The competitive arsenic adsorption capacity of HA-MNP validates its strong potential to be used in real life arsenic treatment plants.

\subsection{4 $\mathrm{pH}$ effect}

The $\mathrm{pH}$ dependent adsorption and binding mechanisms of oxyanions are complicated by their speciation and the surface charge of the absorbent (He et al., 2009; 
Liang et al., 2012). To probe the influence of solution $\mathrm{pH}$, the initial $\mathrm{pH}$ of aqueous solutions of $\mathrm{As}(\mathrm{III})$ and $\mathrm{As}(\mathrm{V})$ was adjusted using $0.1 \mathrm{M} \mathrm{NaOH}$ and $0.1 \mathrm{M} \mathrm{HCl}$. The adsorption of $\mathrm{As}(\mathrm{III})$ and $\mathrm{As}(\mathrm{V})$ on HA-MNP was unchanged from $\mathrm{pH} 3$ to 8 (Figure B9). But under highly alkaline conditions the adsorption of arsenic decreased. For As(III), at pH $8 \& 10$, adsorption (removal) was $96 \%$ and $78 \%$ respectively; for $\mathrm{As}(\mathrm{V})$ at the same $\mathrm{pH}$, it was $98 \%$ and $70 \%$ respectively. While adsorption was reduced overall, the HAMNP still exhibit significant adsorption of both As(III) and As(V) under highly alkaline conditions. The modest decrease in adsorption can be explained by formal and surface charges as a function of solution $\mathrm{pH}$ considering the $\mathrm{pH}_{\mathrm{pzc}}$ of $\mathrm{HA}-\mathrm{MNP}$ and the $\mathrm{pKa}$ values of the arsenic species. As(V) exists in monoanionic $\left(\mathrm{H}_{2} \mathrm{AsO}_{4}{ }^{-}\right)$and di-anionic $\left(\mathrm{HAsO}_{4}{ }^{2-}\right)$ forms whereas As(III) mostly exists as a stable neutral hydroxo complex, $\mathrm{As}(\mathrm{OH})_{3}$ over the range of solution $\mathrm{pH}$ studied. The HA-MNP is negatively charged at solution $\mathrm{pH}$ greater than its $\mathrm{pH}_{\mathrm{pzc}}$ of 3.3 (Jiang et al., 2014). Attractive electrostatic interactions are minimal or non-existent in binding the neutral As(III) on HA-MNP; for As(V) however, electrostatic repulsion between negatively charged sorbent and sorbate could inhibit adsorption at $\mathrm{pH}>3.3$. Despite the electrostatic repulsion, chemical reactions between the functional groups of humic acids and $\mathrm{As}(\mathrm{V})$ appear to be dominant in the adsorption process. The possible binding mechanisms for $\mathrm{As}(\mathrm{III})$ and $\mathrm{As}(\mathrm{V})$ can include ligand exchange and/or formation of adducts through esterification (Buschmann et al., 2006). Decrease in the characteristic O-H group signal in IR spectra of the HA-MNP upon addition of $\mathrm{As}(\mathrm{III})$ and $\mathrm{As}(\mathrm{V})$ indicate the $\mathrm{OH}$ groups are critical and transformed upon exposure to arsenic consistent with the formation of ester-type bonds. Raman peaks in the As (III) laden materials also exhibit bands characteristic of ester or ether formation 
reactions between the $\mathrm{OH}$ group associated with the HA and the arsenic species. With this in mind, we proposed the following reaction mechanisms: for As(III), ester type linkages could form (equation 3.1) due to reaction between the carboxylate functional group in HA with the nucleophilic $\mathrm{OH}$ of $\mathrm{As}(\mathrm{III})$. Conversely, nucleophilic functional groups, such as phenolic $-\mathrm{OH}, \mathrm{RSH}, \mathrm{RCOO}-, \mathrm{R}^{-\mathrm{NH}_{2}}$ can undergo addition type reactions with the electrophilic arsenic atom in As(V) (equation 3.2) (Buschmann et al., 2006).
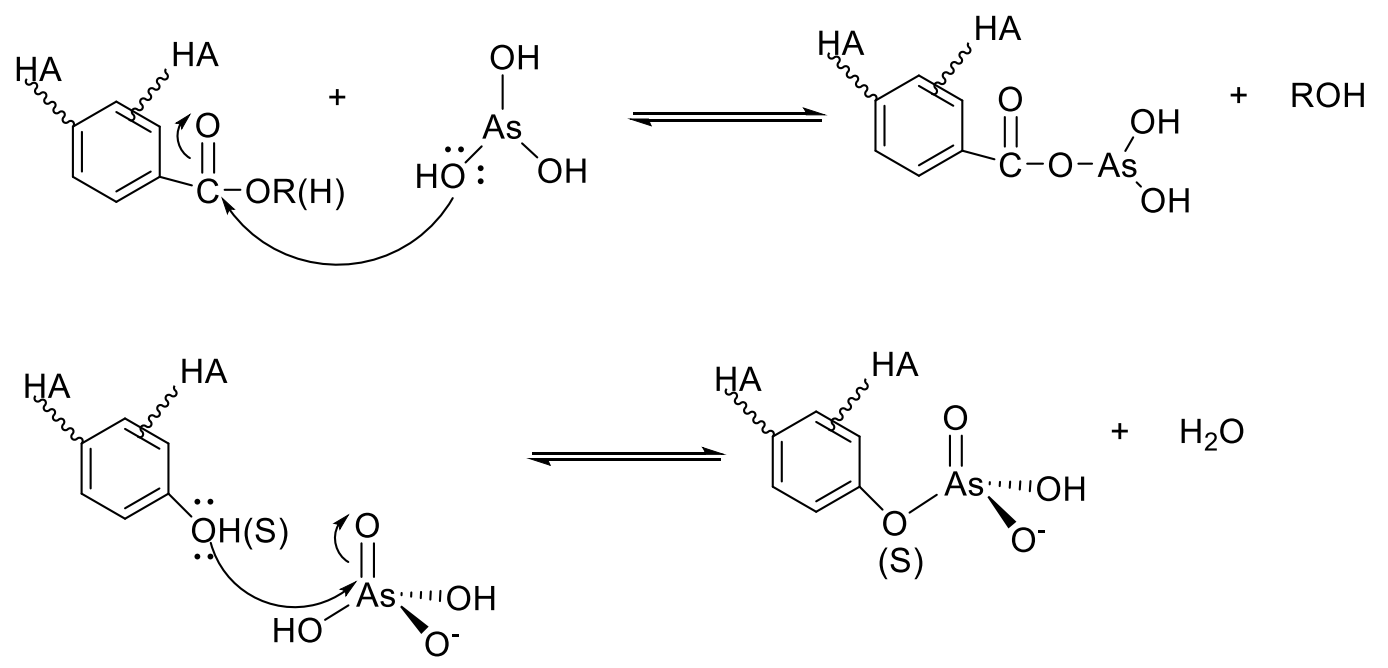

HA-MNP adsorption of As(V) is stronger and more extensive than As(III). The four oxygen atoms attached to the central $\mathrm{As}(\mathrm{V})$ can serve as chelating atoms or as nucleophiles in addition type reactions. The electronegativity of the oxygen atoms and pi bond also make the $\mathrm{As}(\mathrm{V})$ atom electrophilic and susceptible to accepting an electron pair or addition-elimination mechanisms such as addition of phenolate entity resulting in the formation of ester type functionalities (Buschmann et al., 2006). The lone electron pair and $\mathrm{sp}^{3}$ hybridization of As(III) make it unreactive as an electrophile. The lower reactivity of As(III) can reduce binding to HA-MNP as observed in the study (Ren et al., 2017). Under strongly alkaline conditions $(\mathrm{pH}>9)$ with solution $\mathrm{pH}$ above the $\mathrm{pKa}$ of the As(III) and 
$\mathrm{As}(\mathrm{V})$ species, the repulsion between the negatively charged As species and HA-MNP slows down the adsorption and/or ligand exchange processes. Also, the higher concentrations of hydroxide present under alkaline conditions may hydrolyze the ester linkages between the arsenic species and the hydroxyl groups associated with HA materials resulting in lower observed adsorption of the arsenic species on HA-MNP.

\subsubsection{Influence of co-existing ions}

The influence of different anions that commonly exist in natural waters contaminated with arsenic on HA-MNP adsorption were studied. The anions, $\mathrm{SO}_{4}{ }^{2-}, \mathrm{CO}_{3}{ }^{2}$, $\mathrm{PO}_{4}^{3-}, \mathrm{Cl}^{-}$and $\mathrm{NO}_{3}{ }^{-}$were added individually at $1 \mathrm{mM}$ to the specific adsorbent-adsorbate mixtures. Sulfate, chloride, and nitrate showed no inhibition on the adsorption of As(III) and $\mathrm{As}(\mathrm{V})$ shown in Figure B10. Phosphate exhibited modest competition for the adsorption sites leading to slight decreases in the adsorption of both $\mathrm{As}(\mathrm{III})$ and $\mathrm{As}(\mathrm{V})$ on HA-MNP. Arsenic and phosphorous are from group 15 of the periodic table and share some structural and chemical similarities (Paul et al., 2015). Arsenic and phosphorous thus can exhibit analogous adsorption and chelating properties in competing for adsorption onto HA-MNP sites. However, in natural water systems, the mass ratio of phosphate to arsenic is generally quite low and not a concern in most cases ( $\mathrm{Li}$ et al., 2014). Carbonate showed modest inhibition of the adsorption of $\mathrm{As}(\mathrm{V})$ species. The addition of carbonate to As(III) and $\mathrm{As}(\mathrm{V})$ solutions results in an alkaline solution, $\mathrm{pH} \approx 9$. Under these conditions, $\mathrm{As}(\mathrm{III})$ exist predominantly as a neutral species while $\mathrm{As}(\mathrm{V})$ exists in the di-anionic form and the strong repulsion with HA-MNP can reduce the uptake of $\mathrm{As}(\mathrm{V})$. In a separate study, we have also investigated the effect of iron presence in the adsorption process since arsenic and iron commonly co-exists under similar geochemical environment in the aqueous 
system. Analysis of the residual arsenic concentration showed that (Table B1) more than 97\% of the arsenic species were adsorbed on HA-MNP surface which means iron does not exhibit any interference or compete with the arsenic species for the binding sites of the nanoparticles. In summary, most common ions had minimal influence on the adsorption of $\mathrm{As}(\mathrm{III})$ and $\mathrm{As}(\mathrm{V})$ under the neutral $\mathrm{pH}$ conditions encountered in natural water systems.

\subsubsection{Release of humic acid and As desorption study}

The presence of humic materials can interfere with water treatment processes and lead to disinfection byproduct (DBP) formation. Leaching of humic acid from HA-MNP or presence of free HA in solution can compete for the adsorption of the arsenic species, which is undesirable since As bound to free HA will not be removed during the magnetic collection of As laden HA-MNP (Wang and Mulligan, 2006). Loss of HA from the surface of the nanoparticle can also increase the exposure of the magnetite core to the ambient environment and subsequent oxidation. To determine the amount of humic material leached from HA-MNP upon adsorption of arsenic, batch experiments were carried out. $0.05 \mathrm{~g}$ of HA-MNP was separately loaded in $50 \mathrm{~mL}$ of water (control), As(III) and As(V) solutions with $\mathrm{pH}$ adjusted to $6.6 \pm 0.1$. The reaction was carried out at room temperature for a total of three hours. After separation of the HA-MNP, the concentration of DOM in the resulting solution measured by TOC analysis was used to determine the free humic acid in different samples. The DOM concentrations regardless of the presence of As(III) or $\mathrm{As}(\mathrm{V})$ is between 0.25 and $0.57 \mathrm{mg} / \mathrm{L}$ (Table B2), which is within the typical concentration of NOM found in the aquatic environments (Jin et al., 2012). The result demonstrates the stability and robustness of the synthesized nanoparticles. Desorption study was carried out by treating the arsenic adsorbed nanoparticles with $\mathrm{H}_{2} \mathrm{O}_{2}$ and $\mathrm{HNO}_{3}$ at $110{ }^{\circ} \mathrm{C}$ for 90 
minutes. The mass balance calculation of total arsenic showed that more than 99\% (data not shown) of the adsorbed species can be successfully recovered from the HA-MNP surface.

\subsection{Conclusions}

The environmentally friendly, magnetic adsorbent HA-MNP has been found consistently effective for the removal of $\mathrm{As}(\mathrm{III})$ and $\mathrm{As}(\mathrm{V})$ under different environmental conditions. Study indicates the adsorption of $\mathrm{As}(\mathrm{III})$ and $\mathrm{As}(\mathrm{V})$ occurs in three different stages within the functionality of the HA coating via surface association, intraparticle diffusion and complexation reactions or ligand exchange. Presence of characteristic bands of $\mathrm{As}(\mathrm{III})-\mathrm{O}$ and $\mathrm{O}-\mathrm{As}(\mathrm{V})-\mathrm{O}$ in the Raman spectra of arsenic loaded HA-MNP, fitting of the kinetic data into the pseudo-second order model and Freundlich isotherm, pattern/efficiency of binding of $\mathrm{As}(\mathrm{III})$ and $\mathrm{As}(\mathrm{V})$ on $\mathrm{HA}-\mathrm{MNP}$ at different $\mathrm{pH}$ - all suggest that chemisorption played the major role in the arsenic species removal process using HAMNP. TEM, FTIR, XAS and TOC analysis of the synthesized HA-MNP after arsenic adsorption shows that the magnetite core remains unaffected throughout the process, thus confirming the robust nature of HA coating that perfectly shields the magnetite core of the nanoparticles. The successful arsenic remediation process with detailed characterizations and mechanistic insights presented in the paper can be an important layout for the design and development of a sustainable water treatment technology. 


\section{CHAPTER FOUR}

Study of the Sequestration of Toxic Selenium Species from Water by using NOM

Grafted Magnetic Iron Oxide Nanoparticles 


\subsection{Abstract}

Human health and ecological balance are at risk from the presence of selenium in aqueous systems. The present work demonstrates the successful removal of two highly toxic selenium species, $\mathrm{Se}(\mathrm{IV})$ and $\mathrm{Se}(\mathrm{VI})$ from water by using the laboratory synthesized magnetite nanoparticles coated with a thin film of humic acid. The remediation process followed the pseudo-second order kinetics with rate constants 3.87 and $1.86 \mathrm{~g} \mathrm{mg}^{-1} \mathrm{~min}^{-1}$ for $500 \mathrm{ppb}$ of $\mathrm{Se}(\mathrm{IV})$ and $\mathrm{Se}(\mathrm{VI})$ respectively. The Langmuir isotherm model fitted the adsorption data well suggesting the formation of a monolayer by the selenium species on the nanoparticle surface. The preferred binding sites of $\mathrm{Se}(\mathrm{IV})$ and $\mathrm{Se}(\mathrm{VI})$ and their binding mechanism with the humic acid coated iron oxides are found to be different as the presence of one species did not interfere in the removal of another. The observed adsorption behavior is indicative of mostly inner sphere complex formation by Se(IV) and outer sphere complex by (VI). The effect of $\mathrm{pH}$ was insignificant on the adsorption process under acidic and neutral conditions, however adsorption is significantly less under alkaline conditions. The investigation of the influence of coexisting ions reveals the intense competition from sulfate and phosphate for the adsorption sites. The magnetic nanoparticles exhibit good adsorption efficiency and their strong environmental compatibility make these unique materials promising for the simultaneous removal of $\mathrm{Se}(\mathrm{IV})$ and $\mathrm{Se}(\mathrm{VI})$ from water.

\subsection{Keywords}

Selenite, selenate, magnetic nanoparticles, adsorption, water treatment 


\subsection{Introduction}

Natural and anthropogenic discharge of selenium (Se) into aqueous systems is an environment and health concern. Globally, more than 80,000 tons of selenium are released every year, $\sim 95 \%$ of which is the result of anthropogenic activities (Fordyce, 2013). While selenium is an essential nutrient at trace levels ( $\leq 40 \mu \mathrm{g} / \mathrm{day})$ in the human body, it is toxic at modest level ( $\geq 400 \mu \mathrm{g} /$ day) (Gonzalez et al., 2012; Tan et al., 2016). Such a narrow margin between essential and toxic concentration levels can also contribute to negative effects on fish, birds and other wildlife of the ecosystem (Pettine et al., 2015). Accumulation of elevated levels of Se in the human body are reported to cause hair loss, fingernail brittleness, hepatotoxicity and kidney damage while alkali diseases, blind staggers, deformities etc. are the common consequences in fish and animals exposed to selenium through consumption of selenium containing plants and foods (Fordyce, 2013; Goldhaber, 2003; Hamilton, 2004; Navarro-Alarcon and Cabrera-Vique, 2008; Tinggi, 2003). The United States Environmental Protection Agency (US EPA) and WHO have set 50 and 40 ppb maximum contamination level (MCL) of selenium in drinking water (Fu et al., 2014) since water is one of the direct routes for human exposure to high selenium concentrations.

The mobility, bioavailability and toxicity of selenium depends greatly on its speciation which is governed by the different forms of use and discharge, geochemical reactions in the soil and water system, $\mathrm{pH}$, redox environment and thermodynamic conditions. Among different oxidation species of Se ranging from -2 to +6 , the most prevailing forms in the surface water, ground water and wetlands are the two highly toxic, 
inorganic oxyanions of selenium, selenite $\left[\mathrm{SeO}_{3}{ }^{2-}\right.$ or $\left.\mathrm{Se}(\mathrm{IV})\right]$ and selenate $\left[\mathrm{SeO}_{4}{ }^{2-}\right.$ or $\mathrm{Se}(\mathrm{VI})$ ] (Szlachta and Chubar, 2013). While Se(IV) is more lethal than Se(VI), the threat poses by the latter is associated with its high solubility and bioavailability (Fu et al., 2014). Several studies have been reported for $\mathrm{Se}(\mathrm{IV})$ and $\mathrm{Se}(\mathrm{VI})$ removal from water using different remediation techniques of which adsorption is found as the most preferred method. The process can effectively influence the mobility of the potent water toxins like selenium in a simple, economic operation procedure without any toxic sludge generation. Use of nanoadsorbent has particularly received significant attention for selenium treatment owing to high surface to volume ratio, greater surface energy and strong regeneration potential (Yamani et al., 2014). Magnetic iron oxide nanoparticles have the added advantage of easy and quick recovery from the reaction vessel by using a simple magnetic field. Magnetite $\left(\mathrm{Fe}_{3} \mathrm{O}_{4}\right)$ is one such magnetic material that has been investigated for different environmental applications (Liu et al., 2015; Martínez et al., 2006) However, the bare magnetite nanoparticles tend to agglomerate and auto-oxidize over time which significantly reduces its surface area and magnetic properties respectively (J. Liu et al., 2008). Surface coating of magnetite nanoparticles using organic substrate such as humic acid can effectively shield the magnetite core and thus addresses the auto-oxidation and agglomeration concern.

Humic acid (HA) is a polyfunctional natural organic matter that is abundant in the environment. It is a subclass of humic substance that exhibits strong affinity to different metal cations, oxyanions, metal oxides, organic and inorganic pollutants present in the aqueous system (Aiken et al., 2011; De Paolis and Kukkonen, 1997). The strong interaction 
of humic acid with magnetite $\left(\mathrm{Fe}_{3} \mathrm{O}_{4}\right)$ is reported in the literature although the application of the nanoparticles for environmental remediation work is still in the early stage.

The present study entails the remediation of $\mathrm{Se}(\mathrm{IV})$ and $\mathrm{Se}(\mathrm{VI})$ from water using the laboratory synthesized humic acid coated magnetite nanoparticles (HA-MNP) under different conditions pertinent to natural aqueous environments. The mechanistic insights of the adsorption process are assessed by using established kinetic and isotherm models and by charactering the nanoparticles before and after Se treatment.

\subsection{Experimental section}

\subsubsection{Materials}

Sodium selenite $\left(\mathrm{Na}_{2} \mathrm{SeO}_{3},>98 \%\right)$ and sodium selenate $\left(\mathrm{Na}_{2} \mathrm{SeO}_{4},>98 \%\right)$ were received from Sigma to prepare the standards and sample solution of $\mathrm{Se}(\mathrm{IV})$ and $\mathrm{Se}(\mathrm{VI})$ respectively. The nanoparticle synthesis reagent ferric chloride hexahydrate $\left(\mathrm{FeCl}_{3} \cdot 6 \mathrm{H}_{2} \mathrm{O}\right.$, 98.8\%) and ammonium hydroxides $\left(\mathrm{NH}_{4} \mathrm{OH}, 29.15 \%\right)$ were obtained from Fisher while ferrous chloride tetrahydrate $\left(\mathrm{FeCl}_{2} .4 \mathrm{H}_{2} \mathrm{O}\right)$ and humic acid sodium salt were purchased from Sigma Aldrich. Sodium carbonate $\left(\mathrm{Na}_{2} \mathrm{CO}_{3}\right.$, Sigma, $\left.99 \%\right)$, sodium sulfate $\left(\mathrm{Na}_{2} \mathrm{SO}_{4}\right.$, Fisher, $98 \%)$, sodium chloride ( $\mathrm{NaCl}$, Fisher, $99 \%)$ potassium phosphate $\left(\mathrm{KH}_{2} \mathrm{PO} 4\right.$, Sigma, 99\%) and sodium nitrate $\left(\mathrm{NaNO}_{3}\right.$, Sigma, $\left.98 \%\right)$ were used as received for competitive adsorption experiments. Ammonium carbonate, $\left(\mathrm{NH}_{4}\right)_{2} \mathrm{CO}_{3}(99 \%)$ and ammonium bicarbonate, $\mathrm{NH}_{4} \mathrm{HCO}_{3}$ (Fisher, 99\%) were purchased from Fisher to use as buffer in HPLC for selenium speciation. Ultrapure deionized water was used in all cases for solutions and sample preparation. 


\subsubsection{Synthesis and characterization of HA-MNP}

The co-precipitation method was used for the synthesis of humic acid grafted magnetite nanoparticles (HA-MNP). The detail procedure is discussed in chapter 2 and 3. In depth characterizations of the synthesized HA-MNP have already been reported from our research group and by other researchers (please see chapter $2 \& 3$ ).

\subsubsection{Experimental setup}

Selenium salts were dissolved in a pre-determined volume of Millipore water for the preparation of standard and stock solutions of $\mathrm{Se}(\mathrm{IV})$ and $\mathrm{Se}(\mathrm{VI})$. Batch adsorption experiments were carried out by mixing the target Se species and HA-MNP under different environmentally relevant conditions. From the initial experiments, it was observed that the adsorption efficiency of $\mathrm{Se}(\mathrm{IV})$ is much higher than $\mathrm{Se}(\mathrm{VI})$. So, except for the adsorption isotherm and competition study (between Se species), all other experiments were carried out with particular amount of adsorbent (HA-MNP) loading for the same initial concentration of $\mathrm{Se}(\mathrm{IV})$ and $\mathrm{Se}(\mathrm{VI})$. In general, $500 \mathrm{ppb}$ of $\mathrm{Se}(\mathrm{IV})$ and/or $\mathrm{Se}(\mathrm{VI})$ solution were added to the $50 \mathrm{~mL}$ reaction vessels where the concentration of the added HA-MNP was kept 0.50 and $1.0 \mathrm{~g} / \mathrm{L}$ respectively. The mixture was then placed in the orbit shaker at a rotation speed of $250 \mathrm{rpm}$. The samples collected at different time intervals within the planned time span were then filtered and analyzed in the HPLC-ICP-MS to determine the residual concentration of Se species. For Se species competition study, $500 \mathrm{ppb} \mathrm{Se}(\mathrm{IV})$ and $500 \mathrm{ppb} \mathrm{Se}(\mathrm{VI})$ were added in the same reaction vessel with adsorbent concentration of 1.0 g/L. To calculate adsorption capacity and to get insights about the adsorbent-adsorbate interaction, adsorption isotherm experiments were carried out. A wide range of $\mathrm{Se}$ 
concentration starting from $500 \mathrm{ppb}$ to $40 \mathrm{ppm}$ were used with a fixed dose of HA-MNP $(1.0 \mathrm{~g} / \mathrm{L})$ and the reaction was run for three hours. Since $\mathrm{pH}$ plays a very important role in determining the Se speciation as well as the adsorption efficiency, influence of $\mathrm{pH}$ on the overall removal process of $\mathrm{Se}(\mathrm{IV})$ and $\mathrm{Se}(\mathrm{VI})$ were explored by changing the initial solution $\mathrm{pH}$ from 3 to 10 . The effect of ionic strength for Se adsorption was examined by adding different strength $\mathrm{NaCl}(0.01,0.1$ and $1 \mathrm{M})$ in the reaction vessel with the aforementioned concentration of Se species and HA-MNP. The presence of different coexisting ions in the water system were also studied to get a comprehensive picture of Se trapping and separation efficiency by the nanoparticles. To analyze Se in HPLC-ICP-MS, a mixture of $80 \mathrm{mM} \mathrm{NH}_{4}\left(\mathrm{CO}_{3}\right)_{2}$ and $80 \mathrm{mM} \mathrm{NH}_{4} \mathrm{HCO}_{3}$ was used as mobile phase at a flow rate of $0.8 \mathrm{ml} / \mathrm{min}$ (Cai et al., 1995). Unless specifically stated, all the experiments are carried out for total of three hours at room temperature $\left(20^{\circ} \mathrm{C} \pm 1\right)$ and at $\mathrm{pH} 7.5 \pm 0.1$.

\subsection{Results and discussion}

\subsubsection{Kinetic and mechanistic study}

The adsorption kinetics at the solid-solution interface is a complicated process which is governed by a number of factors such as adsorbent surface characteristics, film resistance, degree of diffusion of solutes into pores etc. (L. Zhang et al., 2009). Data from the individual and competition adsorption kinetics of Se (IV) and Se(VI) are presented in Figure 4.1 and 4.2. From the adsorption profile (Fig. 4.1), it is clear that more than $80 \%$ of the initial concentrations of each of the Se species are removed by the nanoparticles in just two minutes. The kinetics of complete removal however, suggest that the more toxic Se(IV) adsorbed faster on the HA-MNP surface than Se(VI), even with the 50\% less adsorbent 
loading $(0.5 \mathrm{~g} / \mathrm{L}$ vs $1.0 \mathrm{~g} / \mathrm{L})$. At the studied $\mathrm{pH}$ level $(7.5 \pm 0.1), \mathrm{Se}(\mathrm{IV})$ and $\mathrm{Se}(\mathrm{VI})$ exist predominantly in the form of $\mathrm{HSeO}_{3}{ }^{-}$and $\mathrm{SeO}_{4}{ }^{2-}$ (Santos et al., 2015). The negative surface charge of HA-MNP exerts stronger repulsive force to the di-anionic $\mathrm{Se}(\mathrm{VI})$ species which might lead to its lower adsorption onto the surface than Se(IV). Results from the competition study (Fig. 4.2) shows that more than $94 \%$ of $\mathrm{Se}(\mathrm{IV})$ and $\mathrm{Se}(\mathrm{VI})$ was removed by the nanoparticles which means that the presence of one species has no adverse effect on the removal of another.

Lagergren's pseudo-first order and Ho \& McKay's pseudo second order rate equations are the two well established kinetic models that are employed in the study to better understand the reaction rate and mechanisms of selenium species adsorption onto the HA-MNP surface. Detail expression of the two models are included in chapter 2.

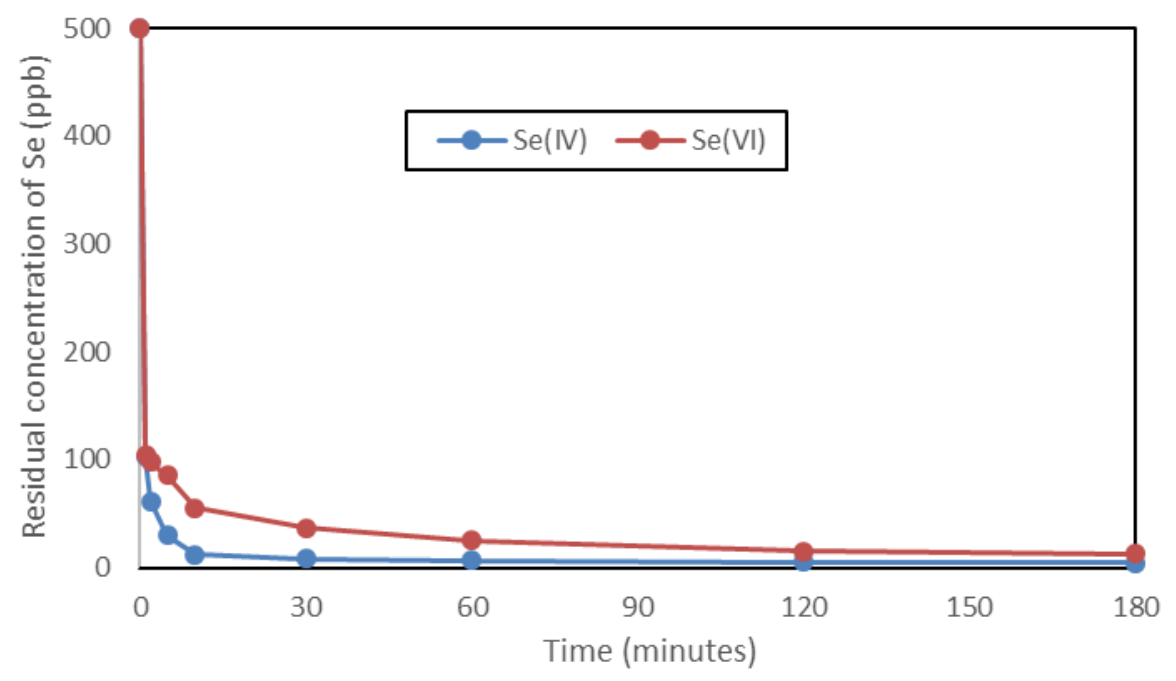

Figure 4.1. Adsorption kinetics of $\mathrm{Se}(\mathrm{IV})$ and $\mathrm{Se}(\mathrm{VI})$. $[\mathrm{Se}(\mathrm{IV})]_{0}=500 \mathrm{ppb},[\mathrm{Se}(\mathrm{VI})]_{0}=$ $500 \mathrm{ppb},[\mathrm{HA}-\mathrm{MNP}]=0.5 \mathrm{~g} / \mathrm{L}$ for $\mathrm{Se}(\mathrm{IV})$ and $1.0 \mathrm{~g} / \mathrm{L}$ for $\mathrm{Se}(\mathrm{VI})$ 


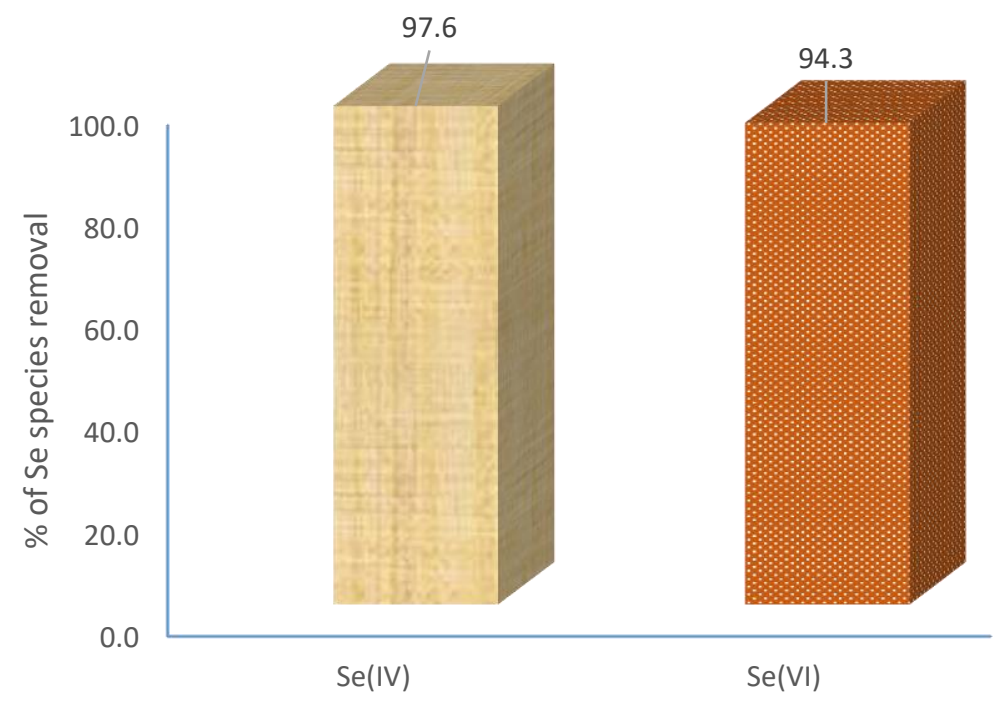

Figure 4.2. Competitive adsorption of $\mathrm{Se}(\mathrm{IV})$ and $\mathrm{Se}(\mathrm{VI})$ by HA-MNP from the same solution. $[\mathrm{Se}(\mathrm{IV})]_{0}=500 \mathrm{ppb},[\mathrm{Se}(\mathrm{VI})]_{0}=500 \mathrm{ppb},[\mathrm{HA}-\mathrm{MNP}]=1.0 \mathrm{~g} / \mathrm{L}$

The pseudo-first order model considers that the single adsorption site is involved for the reaction with the adsorbing molecule while two site occupancy by each solute molecule takes place in the pseudo-second order kinetic model (Rudzinski and Plazinski, 2006). In both instances, the adsorption rate largely depends on the amount of solid adsorbent, sample volume and initial solute concentration. The derived parameters from the fitting of the kinetic data into the two equations suggest that (Table 4.1) both the Se species adsorption process can be best described by the pseudo-second order kinetic model. This finding indicates that the binding is mainly chemisorption and the degree of adsorption depends on the solute and sorbent concentration (Sun et al., 2015). 
Table 4.1. Parameters for the kinetic modeling of selenium species adsorption by HAMNP

\begin{tabular}{|c|c|c|c|c|c|c|c|}
\hline \multirow{3}{*}{$\begin{array}{l}\mathrm{C}_{0} \\
(0.5 \mathrm{mg} / \mathrm{L})\end{array}$} & \multirow{3}{*}{$\begin{array}{l}\mathrm{Q}_{\mathrm{e}}, \exp \text {. } \\
(\mathrm{mg} / \mathrm{g})\end{array}$} & \multicolumn{3}{|c|}{ Pseudo-first order model } & \multicolumn{3}{|c|}{ Pseudo-second order model } \\
\hline & & $\mathrm{Q}_{\mathrm{e}}$ & $\mathrm{k}_{1}$ & & $\mathrm{Q}_{\mathrm{e}}$ & $\mathrm{k}_{2}$ & \\
\hline & & $(\mathrm{mg} / \mathrm{g})$ & $\left(\min ^{-1}\right)$ & $\mathrm{R}^{2}$ & $(\mathrm{mg} / \mathrm{g})$ & $\left(\mathrm{g} \mathrm{mg}^{-1} \min ^{-1}\right)$ & $\mathrm{R}^{2}$ \\
\hline $\operatorname{Se}(\mathbf{I V})$ & 0.99 & 0.06 & 0.04 & 0.77 & 0.99 & 3.87 & 0.99 \\
\hline $\operatorname{Se}(\mathbf{V I})$ & 0.49 & 0.08 & 0.03 & 0.98 & 0.49 & 1.86 & 0.99 \\
\hline
\end{tabular}

The relatively slower adsorption of $\mathrm{Se}(\mathrm{VI})$ is also supported by the pseudo-second order rate constant and thus, indicates that the strong repulsive force made it difficult for $\mathrm{Se}(\mathrm{VI})$ anions to reach the finite number of sorption sites available after the initial adsorption (Gupta et al., 2010).

The data from adsorption kinetics were further analyzed using the Weber-Morris Intraparticle diffusion model. The mathematical representation and explanation of the model is given in Chapter $2 \& 3$. The significance of the model is that it can tell whether intraparticle diffusion is the only rate limiting step or more than one step is associated in the target species adsorption process. The plotting of the data in the intraparticle diffusion model is shown in Figure 4.3. 


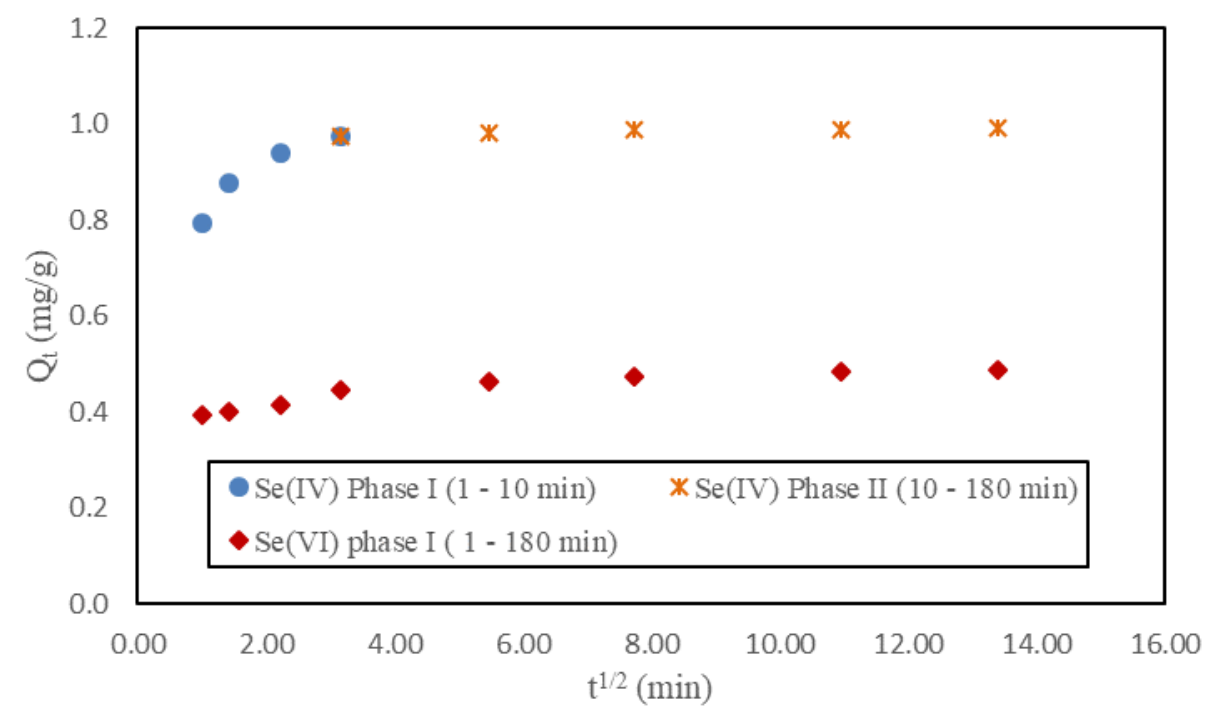

Figure 4.3. Weber-Morris intraparticle diffusion model for the adsorption of $\mathrm{Se}(\mathrm{IV})$ and $\mathrm{Se}(\mathrm{VI})$ by HA-MNP.

As it can be seen from the figure (Fig. 4.3), for both $\mathrm{Se}(\mathrm{IV})$ and $\mathrm{Se}(\mathrm{VI})$, the plotted data do not pass through the origin and hence, intraparticle diffusion is not the rate limiting step. There are two distinct adsorption phases observed for se(IV) adsorption, external surface diffusion followed by intraparticle diffusion. In case of Se(VI), external surface diffusion is found to be the main driving force in the removal process. The study of ionic effect showed that (Fig. 4.4) with the increase of $\mathrm{NaCl}$ concentration, $\mathrm{Se}(\mathrm{IV})$ adsorption remained largely unaffected while Se(VI) adsorption steadily decreases. 


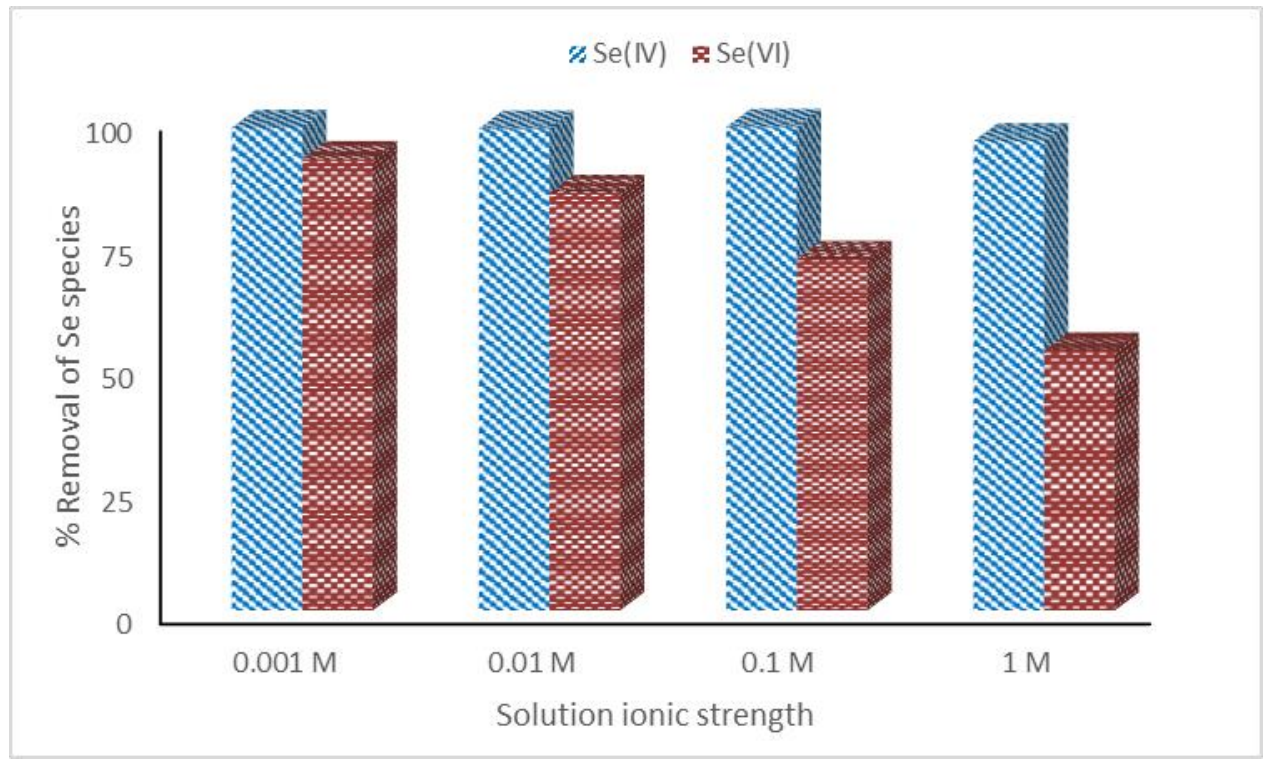

Figure 4.4. Effect of ionic strength on Se adsorption by HA-MNP. [Se(IV) $]_{0}=500 \mathrm{ppb}$, $[\mathrm{Se}(\mathrm{VI})]_{0}=500 \mathrm{ppb},[\mathrm{HA}-\mathrm{MNP}]=0.5 \mathrm{~g} / \mathrm{L}$ for $\mathrm{Se}(\mathrm{IV})$ and $1.0 \mathrm{~g} / \mathrm{L}$ for $\mathrm{Se}(\mathrm{VI})$

The findings suggest the formation of strong inner sphere complexes by $\mathrm{Se}(\mathrm{IV})$ since the inner sphere complexes are not usually affected by ionic strength variation while weak outer sphere complexes are formed by Se(VI) (N. Zhang et al., 2008). The chemical bonding between the oxygen atom of Se(IV) and the functional groups of HA-MNP results in specific adsorption and the formation of inner sphere complexes. For $\mathrm{Se}(\mathrm{VI})$, however, non-specific adsorption dominates in the adsorption process as the oxyanions do not undergo much of covalent bonding with the functional groups of the surface sites (Jordan et al., 2013).

\subsubsection{Isotherm modeling}

The study of adsorption isotherm provides the Se-HA-MNP relationship at equilibrium and the maximum uptake limit of $\mathrm{Se}(\mathrm{IV})$ and $\mathrm{Se}(\mathrm{VI})$ by the nanoparticles. A wide range of initial concentration of $\mathrm{Se}(\mathrm{IV})$ and $\mathrm{Se}(\mathrm{VI})$ are examined at room temperature 
for a constant loading of the adsorbent. Increased amount of solute yields higher equilibrium concentration and greater adsorbent-adsorbate interactions which leads to an increment in adsorption of both the selenium species (Lu et al., 2017). The adsorption data are characterized by Langmuir and Freundlich isotherm models. The mathematical expressions of the two models are discussed in chapter 2. The Langmuir adsorption model considers that the available sites on the adsorbent surface have identical adsorption energy where solute binding takes place only through thermal and material contact. The adsorption rate at equilibrium is proportional to the solute-surface collisions frequency and the number of solute molecules available for the unoccupied adsorption sites (Rudzinski and Plazinski, 2006). The Freundlich adsorption isotherm, on the other hand, is an empirical model that supports the formation of multilayer on adsorbent surface through reversible adsorption process (Foo, K.Y.; Hameed, 2010). Fitting of the adsorption data into the two models reveals that the binding of both $\mathrm{Se}(\mathrm{IV})$ and se(VI) follows Langmuir isotherm (Table 4.2). This finding lead to the suggestion that the adsorption process of $\mathrm{Se}(\mathrm{IV})$ and $\mathrm{Se}(\mathrm{VI})$ occurs through the formation of monolayer on the surface site. The adsorbed molecules have no interaction among themselves and all the surface sites of HA-MNP can have equal probability for adsorption. The maximum adsorption capacity of $\mathrm{Se}(\mathrm{IV})$ and $\mathrm{Se}(\mathrm{VI})$ are 5.46 and $4.63 \mathrm{mg} / \mathrm{g}$ respectively. The higher bond energy of Se(IV) is observed from the Langmuir isotherm constant (b) which further suggest the greater metal-ligand bond stability of the more toxic Se(IV) with HA-MNP than Se(VI) (Szlachta and Chubar, 2013). 
Table 4.2. Parameters for the isotherm modeling of selenium species adsorption by HAMNP

\begin{tabular}{|c|c|c|c|c|c|c|}
\hline \multicolumn{4}{|c|}{ Langmuir model } & \multicolumn{3}{|c|}{ Freundlich model } \\
\hline Species & $\mathrm{Q}_{\max }(\mathrm{mg} / \mathrm{g})$ & $\mathrm{b}(\mathrm{L} / \mathrm{mg})$ & $\mathrm{R}^{2}$ & $\mathrm{~K}_{\mathrm{f}}(\mathrm{mg} / \mathrm{g})$ & $1 / \mathrm{n}$ & $\mathrm{R}^{2}$ \\
\hline $\operatorname{Se}(I V)$ & 5.46 & 22.91 & 0.99 & 1.71 & 0.24 & 0.88 \\
\hline $\operatorname{Se}(V I)$ & 4.63 & 2.08 & 0.99 & 0.41 & 2.41 & 0.98 \\
\hline
\end{tabular}

\subsection{3 $\mathrm{pH}$ and interference study}

The occurrence of different speciation in aqueous system can alter the physicochemical characteristics of the target oxyanion (Conde and Sanz Alaejos, 1997). The influence of $\mathrm{pH}$ is critical to examine in the selenium adsorption process as the oxyanion speciation and the adsorbent surface charge largely depends on water $\mathrm{pH}$. The results of the Se species adsorption on HA-MNP for the investigated $\mathrm{pH}$ range (3 to 10) are shown in Figure 4.5. The overall adsorption capacity remains largely unaffected in the acidic and neutral $\mathrm{pH}$ range ( $\mathrm{pH} 3$ to 7). However, a decreasing trend in adsorption capacity is observed as the solution becomes alkaline ( 8 and more). The $\mathrm{pH}$ point of zero charge $\left(\mathrm{pH}_{\mathrm{pzc}}\right)$ of HA-MNP is 3.3 (Jiang et al., 2014). As the solution $\mathrm{pH}$ becomes higher than the $\mathrm{pH}_{\mathrm{pzc}}$, the deprotonated sites on the adsorbent surface increases gradually which then exhibits greater repulsion to the selenium anions and outweighs the adsorption affinity (Szlachta and Chubar, 2013). The effect of co-existing ions is presented in Fig. 4.6. As observed from the results, chloride, nitrate and carbonate showed little to no effect in the Se adsorption process. Sulfate demonstrated strong competition with $\mathrm{Se}(\mathrm{VI})$ for the 
adsorbent sites which is found to be the case for most of the adsorbents reported in the literature (Yamani et al., 2014).

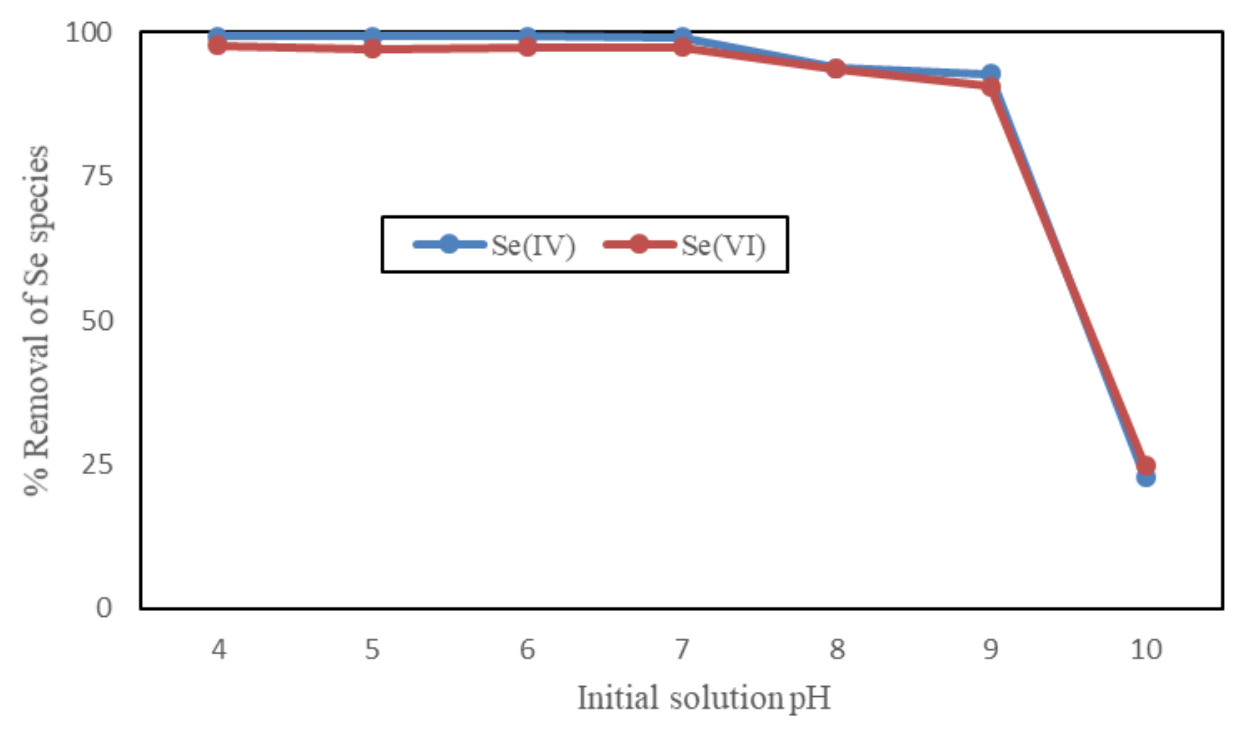

Figure 4.5. Effect of solution $\mathrm{pH}$ on Se adsorption by HA-MNP. $[\mathrm{Se}(\mathrm{IV})]_{0}=500 \mathrm{ppb}$, $[\mathrm{Se}(\mathrm{VI})]_{0}=500 \mathrm{ppb},[\mathrm{HA}-\mathrm{MNP}]=0.5 \mathrm{~g} / \mathrm{L}$ for $\mathrm{Se}(\mathrm{IV})$ and $1.0 \mathrm{~g} / \mathrm{L}$ for $\mathrm{Se}(\mathrm{VI})$

In the presence of phosphate in water, adsorption of both $\mathrm{Se}(\mathrm{IV})$ and $\mathrm{Se}(\mathrm{VI})$ was very minimal. From our previous study (chapter 2), we found that the adsorption of phosphate is very strong on the HA-MNP surface. Also, in terms of geometric structure and chemical properties, $\mathrm{Se}(\mathrm{IV})$ and $\mathrm{Se}(\mathrm{VI})$ closely resembles to phosphate and sulfate respectively (Chan et al., 2009). So, some pre-treatment is necessary for prior removal of phosphate and sulfate if they exist in the Se contaminated aqueous system in excessive amount. 


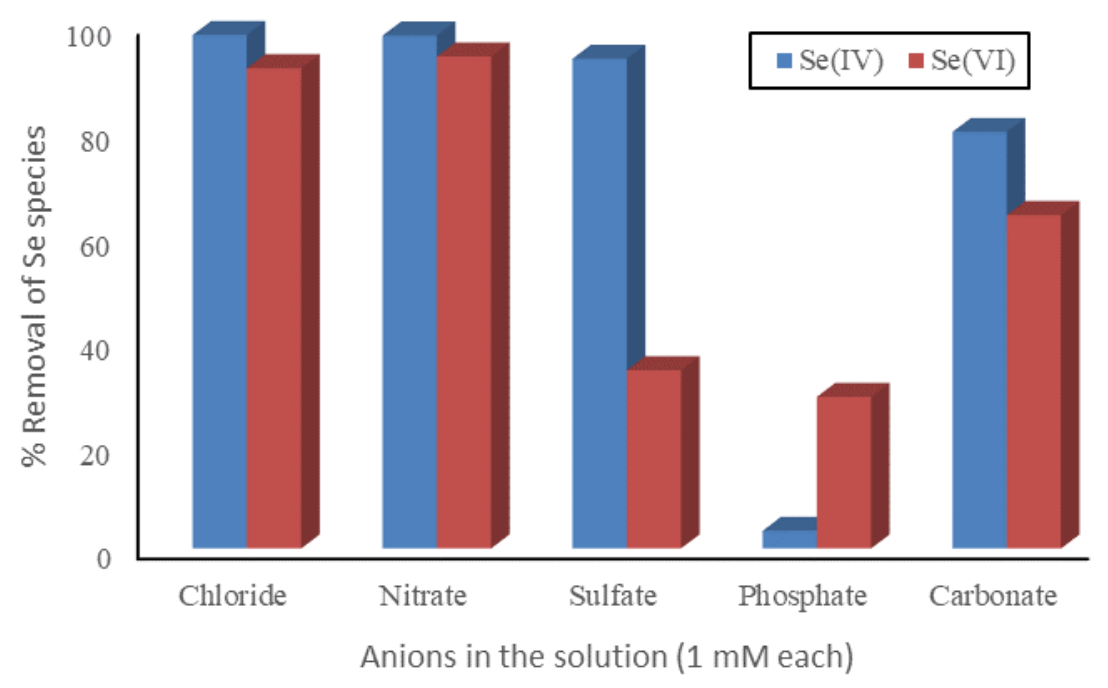

Figure 4.6. Effect of co-existing ions on Se adsorption by HA-MNP. [Se(IV) $]_{0}=500 \mathrm{ppb}$, $[\mathrm{Se}(\mathrm{VI})]_{0}=500 \mathrm{ppb},[\mathrm{HA}-\mathrm{MNP}]=0.5 \mathrm{~g} / \mathrm{L}$ for $\mathrm{Se}(\mathrm{IV})$ and $1.0 \mathrm{~g} / \mathrm{L}$ for $\mathrm{Se}(\mathrm{VI})$

\subsection{Conclusions}

The remediation of two toxic Se species using a single adsorbent is presented in the paper. The selected material (HA-MNP) is environmentally compatible and very easy to prepare. The magnetic nature of the adsorbent is conducive for easy separation after the treatment. The synthesized nanoparticles were able to remove more than $80 \%$ of Se(IV) and $\mathrm{Se}(\mathrm{VI})$ in just two minutes through the process of chemisorption. The material exhibited consistent removal performance in the acidic and neutral $\mathrm{pH}$ range. $\mathrm{Se}(\mathrm{IV})$ and $\mathrm{Se}(\mathrm{VI})$ most likely binds with the HA-MNP surface by forming inner and outer sphere surface complexes, respectively. The study shows the strong potential of the nanomaterials for the large-scale application in the selenium contaminated wastewater treatment. 


\section{CHAPTER FIVE}

Efficient Removal of As(III) from Water by using the Photocatalytic and Adsorptive Properties of Humic Acid Coated Magnetic Nanoparticles 


\subsection{Abstract}

The photoinduced oxidation of highly toxic As(III) is examined by using humic acid coated magnetite nanoparticles (HA-MNP) as a sensitizer. Results from the variation of different experimental parameters revealed that the photoirradiation of HA-MNP in an oxygen saturated environment provides the most effective As(III) conversion and adsorption rate. In presence of light and $\mathrm{O}_{2}$, in just 60 minutes more than $99 \%$ of As species has been successfully removed from the aqueous solution. The effect of $\mathrm{pH}$ was insignificant at mild acidic to neutral solution; however, the adsorbent surface shows relatively less affinity for arsenic as the $\mathrm{pH}$ goes higher. Among different ROS produced by HA-MNP, the generation of hydroxyl radical $\left(\mathrm{OH}^{*}\right)$ is monitored and quantified using coumarin as a trapping agent that in turn, produce $7-\mathrm{HC}$ which is a strong fluorescent compound. The rate of formation of 7-HC coumarin by HA-MNP is $2.9 * 10^{-3} \mu \mathrm{M} / \mathrm{min}$ for an initial coumarin concentration of $125 \mu \mathrm{M}$ and HA-MNP concentration of $1.0 \mathrm{~g} / \mathrm{L}$. The easy preparation, simple operation and magnetic separation could make the nanoparticle a strong candidate for the remediation of poisonous arsenic from the water system.

\section{$5.2 \quad$ Keywords}

Reactive oxygen species, photoconversion, adsorption, arsenite, hydroxyl radical, magnetic separation

\section{$5.3 \quad$ Introduction}

Water contamination by arsenic (As) is a big natural catastrophe that has already affected the health, economy and lives of millions of peoples around the world. The 
occurrence of arsenic in groundwater mainly takes place through natural processes which makes it difficult to regulate or prevent the flow (Mohan and Pittman, 2007). Inorganic forms of arsenic, arsenite or $\mathrm{As}(\mathrm{III})$ and arsenate or $\mathrm{As}(\mathrm{V})$ are mostly prevalent in the groundwater and drinking water of the arsenic affected areas (Xu et al., 2006). Although both the forms of As are highly poisonous, As(III) has reportedly more mobility, higher toxicity and lower adsorbent affinity than As(V) (Zhang and Itoh, 2006). Oxidation of $\mathrm{As}(\mathrm{III})$ to $\mathrm{As}(\mathrm{V})$ is therefore desirable for the efficient remediation of arsenic species from the water system.

Humic acid (HA) is a natural organic matter (NOM) that is highly pervasive in the environment. It is a complex heterogeneous mixture of polyanionic compounds that shows high binding tendency to metals, metal oxides and organic pollutants and thus plays a critical role in the environment. The robust coating of humic acid on the magnetite $\left(\mathrm{Fe}_{3} \mathrm{O}_{4}\right)$ nanoparticle surface has demonstrated the strong complexation capability of humic acid (J. Liu et al., 2008). The thin layer of HA film eventually addresses the auto-oxidation and agglomeration issue of bare magnetite without affecting the magnetic properties of the iron oxide core.

Although the adsorptive property of HA-MNP is investigated to some extent for the remediation of different water contaminants (Jiang et al., 2014; J. Liu et al., 2008), its photochemical properties are largely unexplored. Upon irradiation of light, the chromophoric part of HA or dissolved organic matter (DOM) such as aromatic ketones and aldehydes, quinones and phenolic compounds (Fig. 5.1) can act as a photosensitizer that 
generates excited triplet state of HA and different reactive oxygen species (ROS) (Del Vecchio and Blough, 2004; Ma et al., 2010).

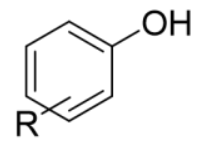

Phenols

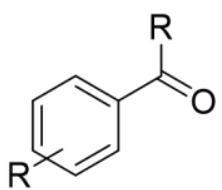

Aromatic carbonyls

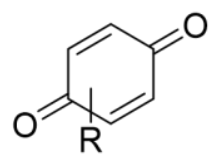

Aromatic quinones

Figure 5.1. Chromophoric part of humic acid (HA)

The overall process is very complex owing to the mostly undefined chemical composition of HA. A simplified pathway of ROS production by HA is shown in Fig. 5.2 (Dalrymple et al., 2010). Upon absorption of light, the electronic absorption spectrum of ground state HA shifts to a longer wavelength with the chromophores move to singlet excited state $\left({ }^{1} \mathrm{HA}^{*}\right)$ which usually takes place in the order of femtoseconds (Rosario-Ortiz and Canonica, 2016). The ${ }^{1} \mathrm{HA}^{*}$ can go back to its original state through vibrational relaxation or go to excited triplet state via intersystem crossing (ISC). The ${ }^{3} \mathrm{HA}^{*}$ can react with molecular oxygen to produce different ROS. The ${ }^{3} \mathrm{HA}^{*}$ and ROS plays a critical role in the environment from the perspective of water contaminant oxidation or degradation, metal redox geochemistry determination, ocean carbon cycling alteration etc. (Chen et al., 2009; Guerard et al., 2009; Rose and Waite, 2006; Wang et al., 2009). Hydroxyl radical $\left(\mathrm{OH}^{*}\right)$ is an important ROS, the generation pathway from HA irradiation is still not fully understood. In aqueous system, hydroxyl radical can be generated from the photolysis of nitrite and nitrate (Eq. 1 - 3), by Fenton reaction (Eq. 4) or by the photolysis of $\mathrm{H}_{2} \mathrm{O}_{2}$ (Eq. 5) (Blough, 1998; Cooper et al., 1988; TAKEDA et al., 2004). 


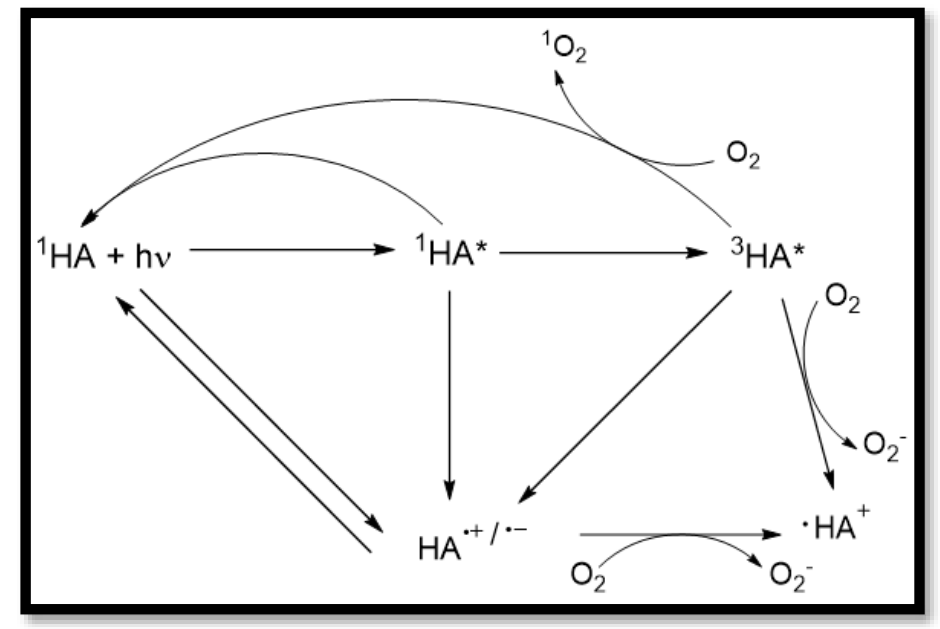

Figure 5.2. Photogeneration of different ROS via charge transfer from HA interaction with $\mathrm{O}_{2}$

However, recent reports indicated that the quinone part of HA can lead to the production of hydroxyl radical upon irradiation through the mechanism of hydrogen abstraction (Blough, 1998; TAKEDA et al., 2004).

$$
\begin{aligned}
& \mathrm{NO}_{2}^{-}+\mathrm{hv} \longrightarrow \mathrm{NOH}^{-} \mathrm{O}^{-} \\
& \mathrm{NO}_{3}^{-}+\mathrm{hv} \dot{\mathrm{NO}}_{2}+\mathrm{OH}^{-} \\
& \mathrm{O}^{-}+\mathrm{H}_{2} \mathrm{O} \longrightarrow \mathrm{OH}^{-}+\mathrm{OH}^{-} \\
& \mathrm{Fe}(\mathrm{II})+\mathrm{H}_{2} \mathrm{O}_{2} \longrightarrow \mathrm{Fe}(\mathrm{III})+\mathrm{OH}^{-}+\mathrm{OH}^{-} \\
& \mathrm{H}_{2} \mathrm{O}_{2}+\mathrm{hv} \longrightarrow 2 \mathrm{OH}^{\cdot}
\end{aligned}
$$

Study shows that the coating of humic acid on the surface of magnetite nanoparticles (HA-MNP) does not significantly change the photochemical behavior of HA (Carlos et al., 2012). The adsorptive property of HA-MNP for the successful remediation of toxic arsenic species, As(III) and As(V) has already been demonstrated (Chapter 3). The characterization of the nanoparticles before and after the treatment of As species has also 
been elaborately discussed (Chapter $2 \& 3$ ). Since the removal efficiency of more toxic As(III) has been found to be relatively slower by HA-MNP than As(V) (Chapter 3), the present study aims to exploit the photochemical characteristics of HA-MNP to convert $\mathrm{As}(\mathrm{III})$ to $\mathrm{As}(\mathrm{V})$ which might help to enhance the adsorption rate significantly. The production of hydroxyl radical $\left(\mathrm{OH}^{*}\right)$ during the irradiation of the nanoparticles will also be investigated by using coumarin as a probe.

\subsection{Experimental section}

\subsubsection{Materials}

Sodium arsenite and sodium arsenate dibasic heptahydrate $(\geq 98 \%)$ were purchased from Fisher Scientific for the preparation of standards and sample solutions. Ammonium hydroxide (29.2\%) and ferric chloride hexahydrate (98.8\%) were obtained from the same company and were used in the synthesis of nanoparticles. Ferrous chloride tetrahydrate ( $\geq$ 99\%) and humic acid sodium salt are the two other raw materials used in nanoparticles' synthesis and were obtained from Sigma Aldrich. The hydroxyl radical trapping agent, coumarin $((\geq 99 \%)$ and the standard, 7-hydroxy coumarin (99\%) were also sourced from Sigma. In all cases, Millipore water was used for samples and standards preparations.

\subsubsection{Methods}

Coumarin was used to trap hydroxyl radical that eventually produce highly fluorescent molecule, 7-hydroxycoumarin (7-HC) (Eq. 5.6). 


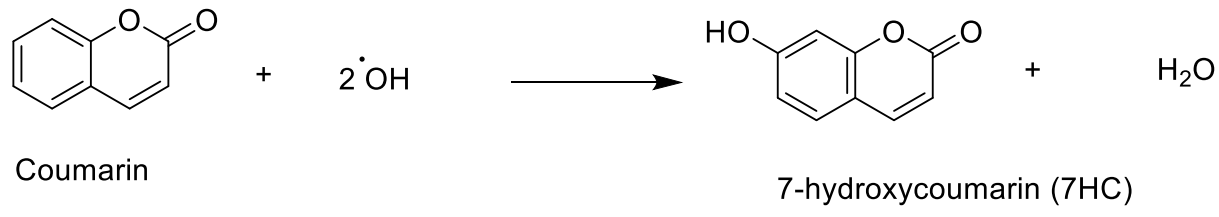

$0.05 \mathrm{~g}$ HA-MNP is added to the $50 \mathrm{~mL}$ of $125 \mu \mathrm{M}$ coumarin solution. The solution was purged with oxygen/argon from 15 minutes prior to the entire irradiation period. The illumination of the suspension was carried out in a photochemical reactor (Southern New England UV company, RPR-100). The reactor contains 14 phosphor-coated low pressure mercury lamps of $350 \mathrm{~nm}$ and a cooling fan. Samples were collected at specific time intervals, filtered using $0.45 \mu \mathrm{m}$ syringe filter and finally analyzed in the Fluorometer. Different concentrations of 7-HC were run as standards in the Fluorometer to prepare a calibration curve with excitation and emission wavelength set at 332 and $455 \mathrm{~nm}$. Another experiment was also carried out using the same concentration coumarin solution and dark to figure out whether there is any hydroxyl radical produced in the solution in absence of light. For As(III) photoconversion and adsorption experiments, $50 \mathrm{~mL}$ of $200 \mathrm{ppb} \mathrm{As}(\mathrm{III})$ and $0.01 \mathrm{~g}$ HA-MNP $(0.2 \mathrm{~g} / \mathrm{L})$ were added to reaction vessel, purged with oxygen and then placed in the photochemical reactor with the same experimental set up as mentioned before. Similar experiments were carried out in dark and/or in argon purging. The samples collected at pre-determined time intervals were analyzed in HPLC-ICPMS to find the residual concentration of As species in solution. 


\subsection{Results and discussion}

\subsubsection{Formation of hydroxyl radical}

The fluorescence intensity of 7-HC generated from the reaction between coumarin and $\mathrm{OH}^{*}$ (from HA-MNP) in presence of light is presented in Figure 5.3. The concentration of 7-HC is calculated from the standard calibration curve of 7-HC and is shown in Fig. 5.4. An increasing trend of the production of hydroxyl radical is observed with respect to time.

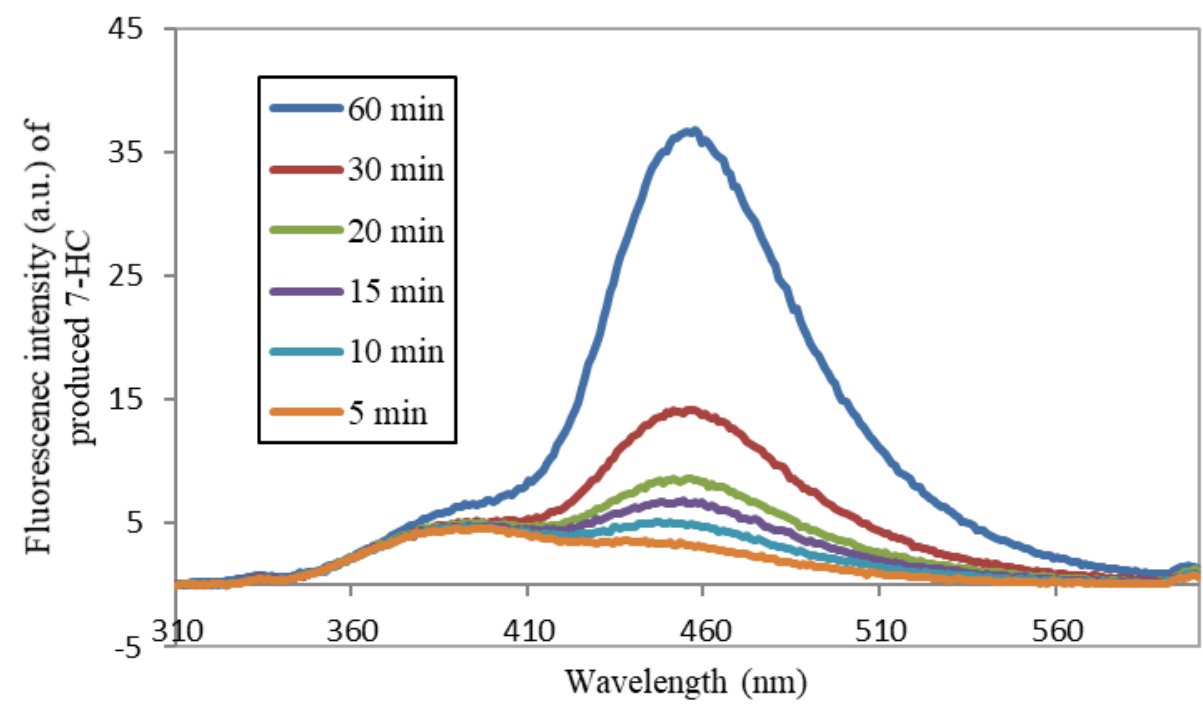

Figure 5.3. Fluorescence intensity of 7-HC generated from the reaction between coumarin and hydroxyl radical. [coumarin $]_{0}=125 \mu \mathrm{M}$, $[$ HA-MNP] $=1.0 \mathrm{~g} / \mathrm{L}$, Total lamps $=14$, Light wavelength $=350 \mathrm{~nm}$

The concentration of 7-HC is also monitored by carrying out the same reaction in the dark (Fig. 5.5). From the figure, it is clear that no significant production of $\mathrm{OH}^{*}$ takes place when the light source is taken away and thus suggest the role of photochemical process in the generation of the ROS from HA-MNP. 


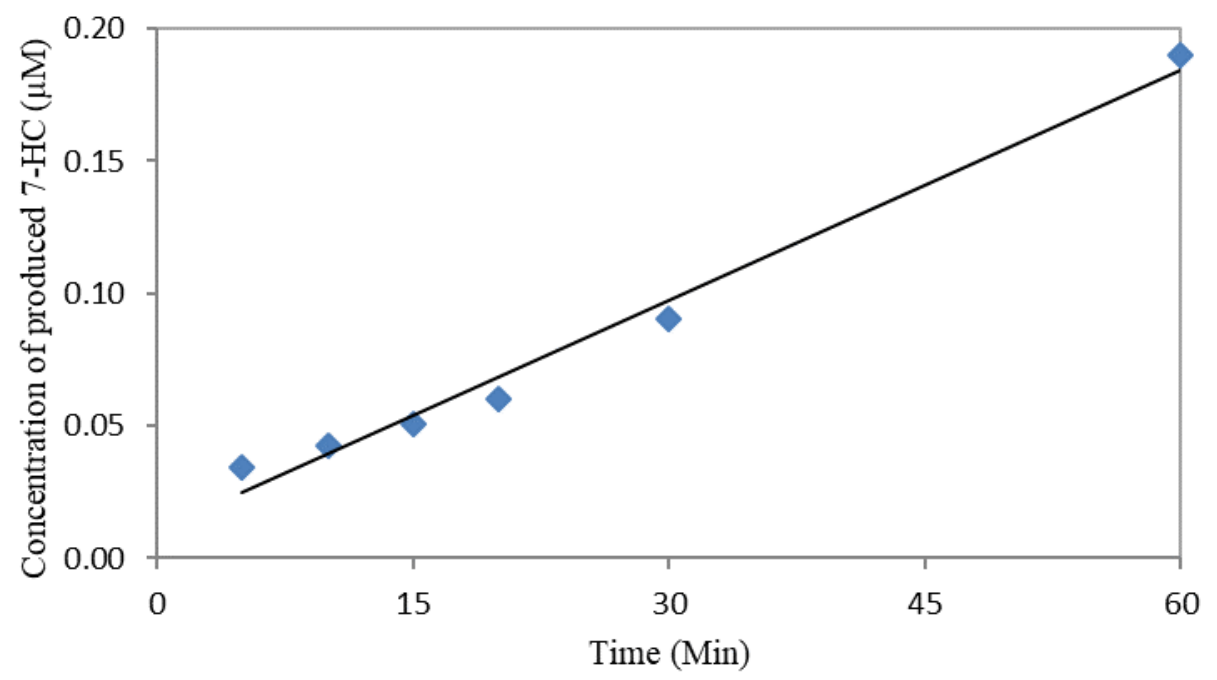

Figure 5.4. Concentration of 7-HC generated from the reaction between coumarin and hydroxyl radical. $[\text { coumarin }]_{0}=125 \mu \mathrm{M},[\mathrm{HA}-\mathrm{MNP}]=1.0 \mathrm{~g} / \mathrm{L}$, Total lamps $=14$, Light wavelength $=350 \mathrm{~nm}$

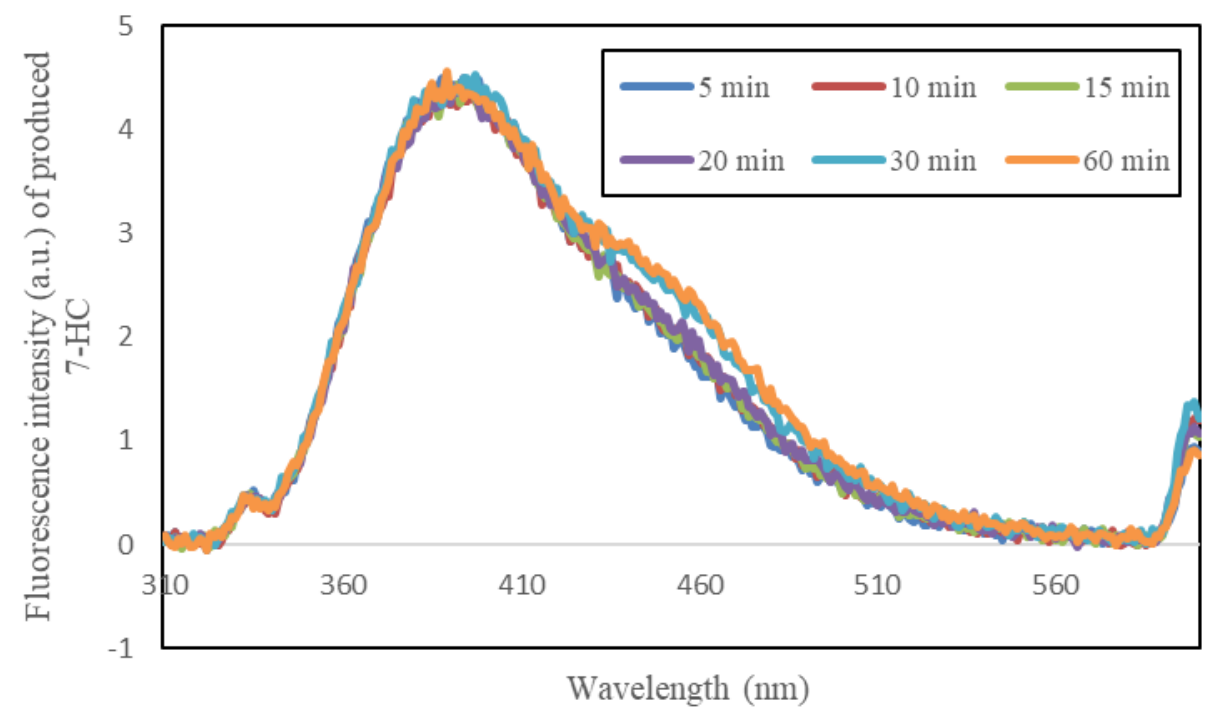

Figure 5.5. Concentration of 7-HC generated from the reaction between coumarin and hydroxyl radical in absence of light. [coumarin $]_{0}=125 \mu \mathrm{M},[\mathrm{HA}-\mathrm{MNP}]=1.0 \mathrm{~g} / \mathrm{L}$

The quantification of corrected 7-HC production by HA-MNP after the subtraction of its production in the dark is given in table 5.1. 
Table 5.1. Corrected concentration of 7-HC with respect to time

\begin{tabular}{|l|r|r|r|r|r|r|}
\hline Time (Min) & 5 & 10 & 15 & 20 & 30 & 60 \\
\hline Intensity of 7-HC in light (a.u.) & 3.27 & 4.90 & 6.63 & 8.56 & 14.42 & 36.04 \\
\hline Intensity of 7-HC in dark (a.u.) & 1.97 & 2.00 & 2.00 & 2.14 & 2.35 & 2.39 \\
\hline Intensity corrected (a.u.) & 1.30 & 2.90 & 4.63 & 6.42 & 12.07 & 33.65 \\
\hline Corrected conc. of 7-HC ( $\mu \mathrm{M})$ & 0.03 & 0.03 & 0.04 & 0.05 & 0.08 & 0.18 \\
\hline
\end{tabular}

A plot of corrected 7-HC formation by HA-MNP vs time is shown in Fig. 5.6. The rate of formation of $7-\mathrm{HC}$ is obtained from the slope of the graph which is $2.9 * 10^{-3}$ $\mu \mathrm{M} / \mathrm{min}$.

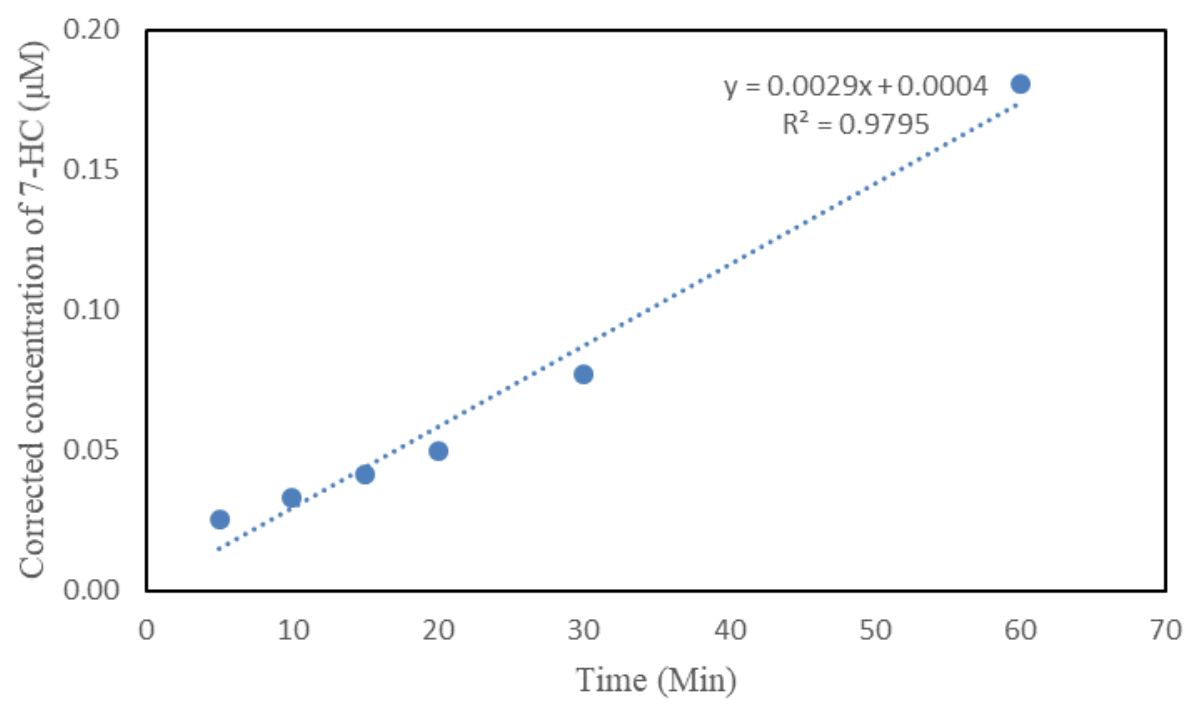

Figure 5.6. Formation kinetics of $7-\mathrm{HC}$ after the correction of concentration in dark condition

\subsubsection{As(III) oxidation and adsorption kinetics}

The HA-MNP mediated photo-oxidation of As(III) to As(V) and the simultaneous oxidation of both the species are shown in Fig. 5.7. In just one minute, more than $40 \%$ of As(III) is converted to $\mathrm{As}(\mathrm{V})$, while within one hour, more than $99 \%$ of the initial concentration of As (200 ppb) was adsorbed by the HA-MNP (0.2 g/L). 


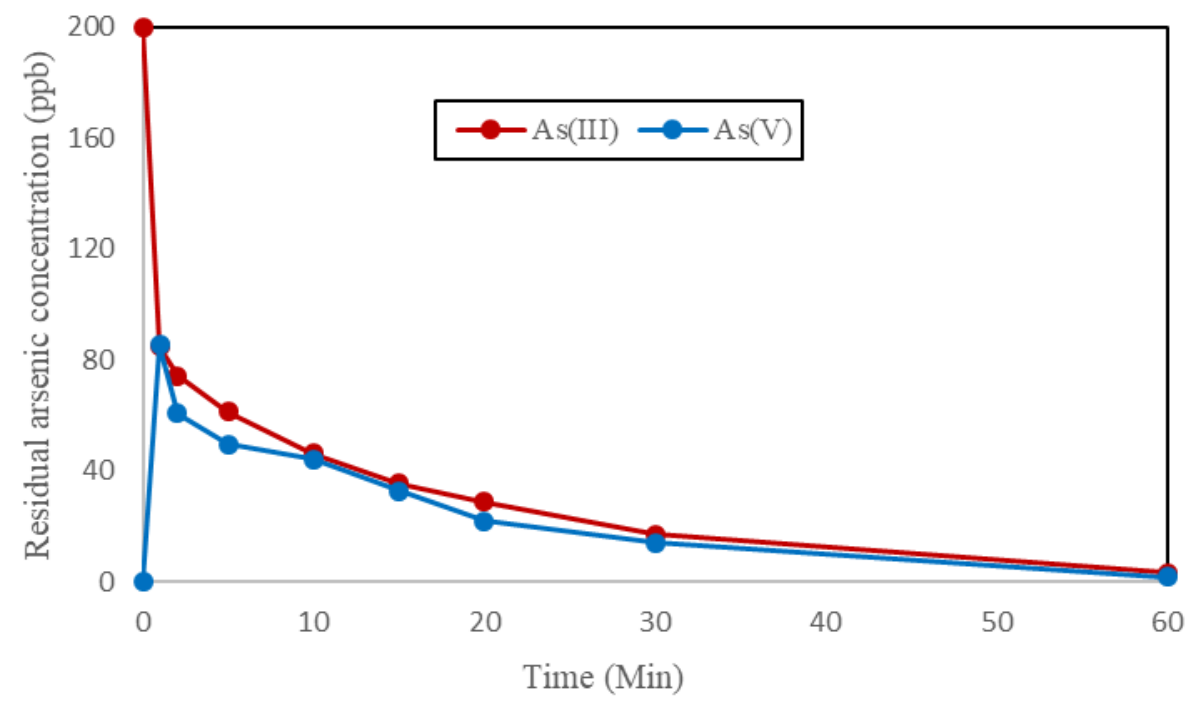

Figure 5.7. Photo-oxidation and adsorption of $\mathrm{As}(\mathrm{III})$ by $\mathrm{HA-MNP}$ in presence of $\mathrm{O}_{2}$. $[\mathrm{As}(\mathrm{III})]_{0}=200 \mathrm{ppb},[\mathrm{HA}-\mathrm{MNP}]=0.2 \mathrm{~g} / \mathrm{L}$, total lamps $=14$, light wavelength $=350 \mathrm{~nm}$

In our previous study, we have seen that with the use of adsorptive property alone of HA-MNP, it took three hours to remove As(III) from the aqueous solution for the same initial concentration of As(III) and HA-MNP loading. The exposure of As(III) solution to the oxygen saturated and HA-MNP induced photocatalytic environment not only helps to convert As(III) to As(V) but also increase the surface energy to adsorb the As species in a much efficient manner.

To examine the role of molecular oxygen and light, several other experiments were carried out. When the same experiment was carried out in an oxygen saturated environment but in absence of light, very little conversion of As(III) to As(V) is observed (Fig. 5.8). The removal efficiency of HA-MNP also drops significantly. After 60 minutes, the residual concentration of As(III) in the solution was $\sim 34 \mathrm{ppb}$ which is quite high than the maximum acceptable concentration of arsenic in drinking water i. e., $10 \mathrm{ppb}$. The finding suggests 
that irradiation of HA-MNP solution is indispensable for the generation of ROS as well as for increasing the rate of adsorption.

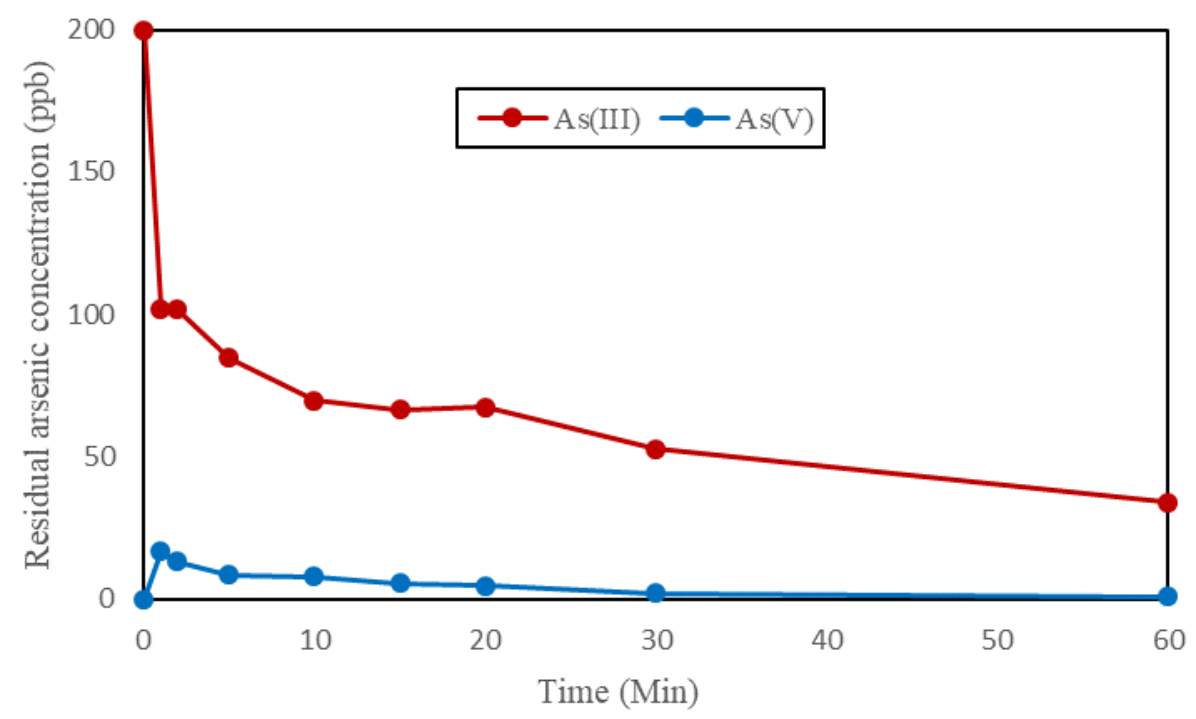

Figure 5.8. Oxidation and adsorption of As(III) by HA-MNP in presence of $\mathrm{O}_{2}$ and without light. $[\mathrm{As}(\mathrm{III})]_{0}=200 \mathrm{ppb},[\mathrm{HA}-\mathrm{MNP}]=0.2 \mathrm{~g} / \mathrm{L}$

The third experiment was carried out by replacing oxygen with argon to see if it has any effect in the overall photo-conversion and removal process. In an argon saturated environment, again very little conversion of $\mathrm{As}(\mathrm{III})$ to $\mathrm{As}(\mathrm{V})$ is observed (Fig. 5.9). Also, the removal of As(III) could not go below the prescribed limit after one hour. This result indicates that the presence of oxygen in the reaction vessel is very vital both for the increment of the photo-conversion and adsorption rate. Oxygen helps to generate different ROS including $\mathrm{OH}^{\bullet}$ either by energy transfer or by sequential univalent reduction process (Apel and Hirt, 2004). 


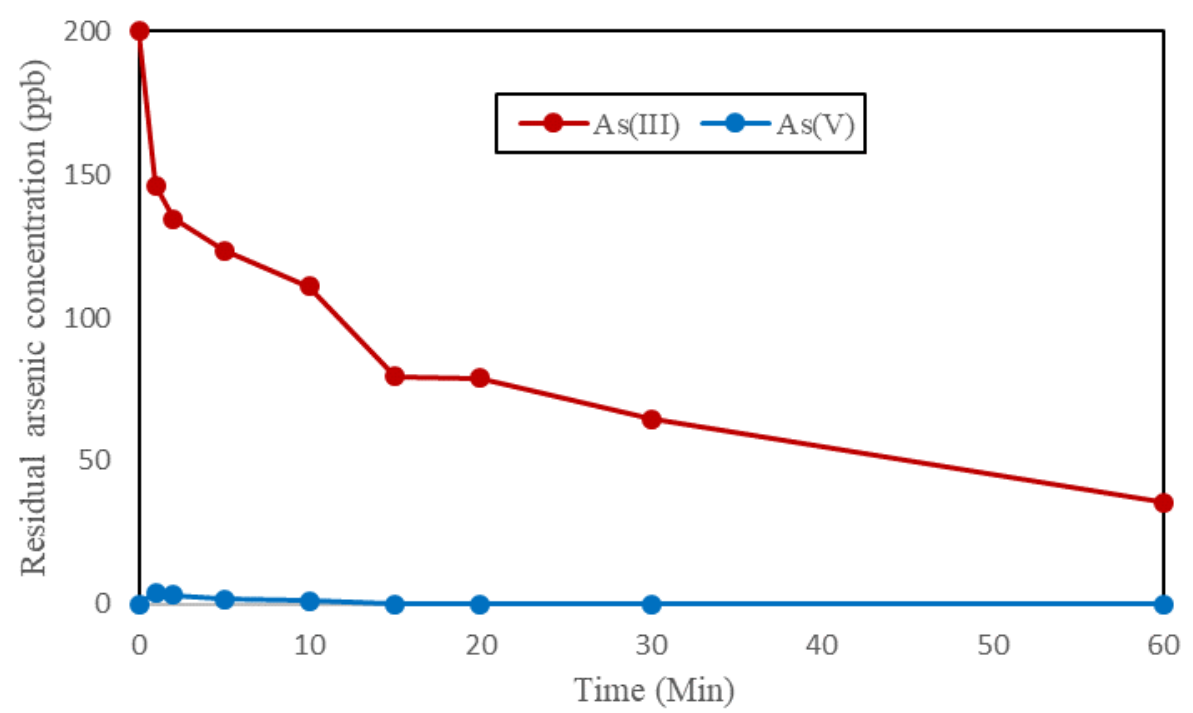

Figure 5.9. Photo-oxidation and adsorption of As(III) by HA-MNP in presence of argon. $[\mathrm{As}(\mathrm{III})]_{0}=200 \mathrm{ppb},[\mathrm{HA}-\mathrm{MNP}]=0.2 \mathrm{~g} / \mathrm{L}$, total lamps $=14$, light wavelength $=350 \mathrm{~nm}$

The final experiment was carried out in presence of argon and in dark condition.

The results are shown in Fig. 5.10.

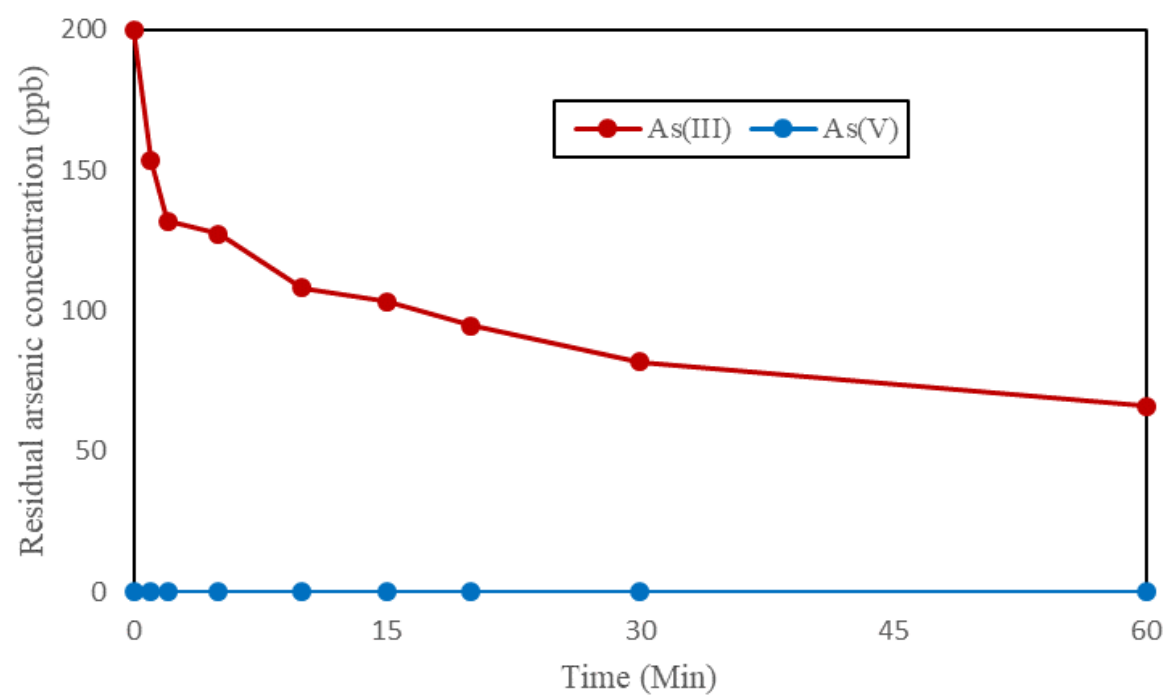

Figure 5.10. Oxidation and adsorption of As(III) by HA-MNP in presence of argon and without light. $[\mathrm{As}(\mathrm{III})]_{0}=200 \mathrm{ppb},[\mathrm{HA}-\mathrm{MNP}]=0.2 \mathrm{~g} / \mathrm{L}$ 
As it can be seen, there was no conversion of $\mathrm{As}(\mathrm{III})$ to $\mathrm{As}(\mathrm{V})$ and the rate of adsorption is the slowest of all the experiments carried out in the study. All the observations suggest that the optimum condition for the efficient conversion and adsorption of As(III) from the aqueous system is to carry out the experiment in presence of light and $\mathrm{O}_{2}$.

\subsubsection{Effect of $\mathrm{pH}$}

Since water $\mathrm{pH}$ can influence the adsorbent surface charge and the speciation of arsenic species in water, the effect of $\mathrm{pH}$ is studied for the oxidation and adsorption of As(III) by HA-MNP under irradiation and in $\mathrm{O}_{2}$ saturated environment. The range of $\mathrm{pH}$ selected was from 3 to 10 and the reaction was carried out for one hour. The results are

plotted in Fig. 5.11. More than $80 \%$ of arsenic was removed from the solution with $\mathrm{pH}$ ranging from 3 to 7 . However, at $\mathrm{pH} 8$ and above, the adsorption became slower as evident from the figure. This is consistent with our $\mathrm{pH}$ effect findings (please see chapter 3 ) without the irradiation. As the $\mathrm{pH}$ goes up, the surface charge of HA-MNP becomes more negative. Also, As(III) that exist as a neutral species in most of the studied $\mathrm{pH}$ in the acidic and neutral range becomes anionic in alkaline $\mathrm{pH}$. These two effects significantly contributed to the lower adsorption efficiency at higher $\mathrm{pH}$. 


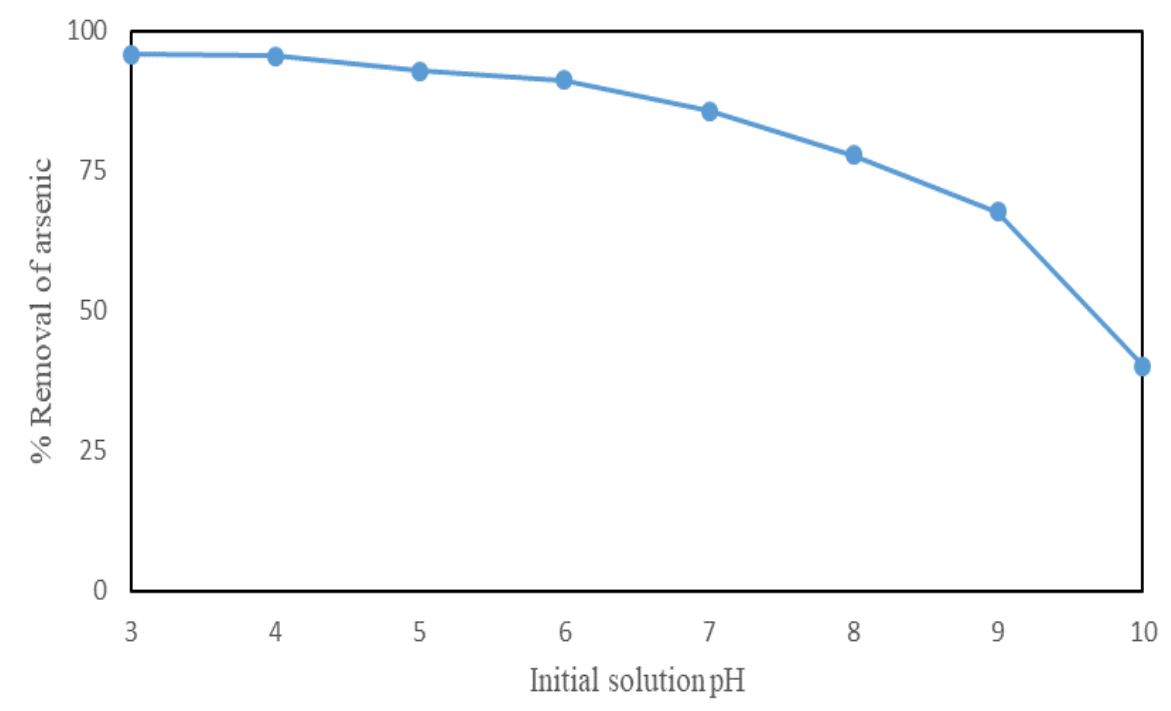

Figure 5.11. Effect of $\mathrm{pH}$ for the oxidation and adsorption of As(III) in presence of light and $\mathrm{O}_{2}$. $[\mathrm{As}(\mathrm{III})]_{0}=200 \mathrm{ppb},[\mathrm{HA}-\mathrm{MNP}]=0.2 \mathrm{~g} / \mathrm{L}$, total lamps $=14$, light wavelength $=$ $350 \mathrm{~nm}$

\subsection{Conclusion}

The photochemical property of the laboratory synthesized HA-MNP has been studied for the oxidation of As(III) under different conditions. The combination of $350 \mathrm{~nm}$ light and $\mathrm{O}_{2}$ have been found most effective for the efficient removal of As(III). The effect of $\mathrm{pH}$ on the removal process showed little to no effect except at very high $\mathrm{pH}$. Generation of $\mathrm{OH}^{*}$ upon irradiation of HA-MNP has been detected and quantified. Further investigation is required to pinpoint the production of singlet oxygen, superoxide anion radical, triplet excited state of HA etc. and the roles of each of the ROS in the phototransformation of As(III). The outcome of the study can be an important layout to ensure arsenic free, safe water for millions of peoples around the world. 
CHAPTER SIX

General Conclusions 
The adsorptive and photochemical characteristics of humic acid coated magnetite nanoparticles (HA-MNP) were examined for the remediation of toxic species of arsenic (As), selenium ( $\mathrm{Se}$ ) and phosphorous $(\mathrm{P})$ from water. The adsorbent nanoparticles were synthesized in the laboratory using a simple co-precipitation method. Transmission electron microscopy (TEM), Fourier transform infrared spectroscopy (FTIR), X-ray photoelectron spectroscopy (XPS), X-ray absorption spectroscopy (XAS) etc. were used to characterize the nanoparticles before and after the treatment of target water toxins. The strong magnetic property of the coated nanomaterials helps to separate the adsorbed pollutants after the treatment. A series of adsorption experiments were carried out to see the removal efficiency of HA-MNP under different environmentally relevant conditions. Adsorption kinetics, adsorption isotherms, effect of $\mathrm{pH}$, temperature and co-existing ions were investigated to get the mechanistic insights of the binding of each of the inorganic anions on the nanoadsorbent surface. Photoproduction of reactive oxygen species (ROS) by HA-MNP has also been evaluated for the simultaneous oxidation and adsorption of As(III).

The excessive discharge of phosphate in water from different industrial and agricultural sources can cause eutrophication which deteriorates the water quality. Removal of phosphate from aqueous solution by using HA-MNP as adsorbent has been found effective. The nanoparticles were able to remove $>90 \%$ of phosphate from the solution in three hours for an initial concentration of $2 \mathrm{ppm}$. Analysis of kinetic data suggest that the adsorption process follows pseudo-second order model while chemisorption is assumed to be the main driving force of phosphate binding on the adsorbent surface. From the intraparticle diffusion model, three distinct adsorption phases are observed that 
contributed to the removal process. The maximum adsorption capacity was found to be $28.9 \mathrm{mg} / \mathrm{g}$ with the adsorption behavior more consistent with the Freundlich isotherm model suggesting the formation of multilayer on the heterogeneous adsorbent surface. Study of temperature effect reveals that the process is endothermic and thermodynamically favorable. The material exhibited good removal efficiency across a wide $\mathrm{pH}$ range from mildly acidic to neutral and showed good selectivity in presence of different competing ions.

Arsenic (As) is a poisonous metalloid that has contaminated groundwater and drinking water of more than 70 countries all around the world. The HA-MNP adsorbent was applied for the separation of two highly toxic and widely prevalent As species, As(III) and $\mathrm{As}(\mathrm{V})$ from the water body. Results showed that the materials successfully removed both the forms of As to bring the As level down to the limit of $10 \mathrm{ppb}$, prescribed by WHO and US EPA. The adsorption mechanism fitted well Ho and McKay's pseudo-second order kinetic model and Freundlich adsorption isotherms. Detail analysis of adsorption data suggest that the binding of As on the adsorbent surface is governed by initial external surface association followed by intraparticle diffusion and equilibrium adsorption. The maximum adsorption capacities were found to be 12.2 and $12.6 \mathrm{mg} / \mathrm{g}$ for $\mathrm{As}(\mathrm{III})$ and $\mathrm{As}(\mathrm{V})$ respectively. The method has been proved effective at different $\mathrm{pH}$ level with very minimal leaching of HA from the surface. The removal process was led by strong chemical bonding of $\mathrm{As}(\mathrm{III})$ and $\mathrm{As}(\mathrm{V})$ anions with HA-MNP through ester-type linkage or by addition reaction and thus indicates the high potential of the technique to use for large scale, commercial application. 
Selenium (Se) is an essential nutrient for human body that can be toxic at slightly higher concentration. Sequestration of two highly toxic forms of selenium, Se(IV) and $\mathrm{Se}(\mathrm{VI})$ from water by the use of HA-MNP is investigated. The HA-MNP successfully removed both the Se species while relatively faster adsorption is observed for the more toxic $\mathrm{Se}(\mathrm{IV})$ than $\mathrm{Se}(\mathrm{VI})$. The adsorption kinetics followed the pseudo-second order model and the adsorbent-adsorbate relationship at equilibrium could be better explained by the Langmuir isotherm. Increasing $\mathrm{pH}$ ( 8 and above) led to a decrease in adsorption because of strong repulsion between deprotonated adsorbent surface and Se anions. Results from the effect of ionic strength study suggest the formation of inner sphere and outer sphere surface complexes by $\mathrm{Se}(\mathrm{IV})$ and $\mathrm{Se}(\mathrm{VI})$ respectively. Sulfate and phosphate appeared as the biggest competitors of Se species for the adsorbent site.

Reactive oxygen species (ROS) generation (singlet oxygen, superoxide anion radical etc.) upon irradiation of HA-MNP has already been reported. The application of the ROS produced from the illumination of HA-MNP has been examined for the photoconversion of As(III). The HA-MNP induced photo-oxidation and adsorption could effectively remove As(III) from the reaction vessel. The removal efficiency was maximum in presence of $350 \mathrm{~nm}$ light under oxygen saturated condition while minimum adsorption was observed in absence of light under argon saturated environment. Hydroxyl radical $(\mathrm{OH} \bullet)$ is an important ROS the formation kinetics of which is studied here.

In summary, HA-MNP with its robust surface coating, easy preparation procedure, strong magnetic property, competitive adsorption capacity and photochemical features can be an outstanding agent for a sustainable water treatment strategy. 


\section{REFERENCES}

A. K. Katja Amstaetter, Thomas Borch, Philip Larese-Casanova, A.K., 2010. Redox Transformation of Arsenic by Fe ( II ) -Activated Goethite ( $r$-FeOOH ). Environ. Sci. Technol. 44, 102-108. https://doi.org/10.1021/es901274s

Aiken, G.R., Hsu-Kim, H., Ryan, J.N., 2011. Influence of dissolved organic matter on the environmental fate of metals, nanoparticles, and colloids. Environ. Sci. Technol. 45, 31963201. https://doi.org/10.1021/es103992s

Allen, S.J., Mckay, G., Porter, J.F., 2004. Adsorption isotherm models for basic dye adsorption by peat in single and binary component systems. J. Colloid Interface Sci. 280, 322-333. https://doi.org/10.1016/j.jcis.2004.08.078

Almeelbi, T., Bezbaruah, A., 2012. Aqueous phosphate removal using nanoscale zerovalent iron. J. Nanoparticle Res. 14. https://doi.org/10.1007/s11051-012-0900-y

Amini, M., Abbaspour, K.C., Berg, M., Winkel, L., Hug, S.J., Hoehn, E., Yang, H., Johnson, C.A., 2008. Statistical modeling of global geogenic arsenic contamination in groundwater. Environ. Sci. Technol. 42. https://doi.org/10.1021/es702859e

Apel, K., Hirt, H., 2004. REACTIVE OXYGEN SPECIES: Metabolism, Oxidative Stress, and Signal Transduction. Annu. Rev. Plant Biol. 55, 373-399. https://doi.org/10.1146/annurev.arplant.55.031903.141701

Bhattacharyya, K.G., Sharma, A., 2004. Azadirachta indica leaf powder as an effective biosorbent for dyes: A case study with aqueous Congo Red solutions. J. Environ. Manage. 71, 217-229. https://doi.org/10.1016/j.jenvman.2004.03.002

Bidari, A., Zeini Jahromi, E., Assadi, Y., Milani Hosseini, M.R., 2007. Monitoring of selenium in water samples using dispersive liquid-liquid microextraction followed by iridium-modified tube graphite furnace atomic absorption spectrometry. Microchem. J. 87, 6-12. https://doi.org/10.1016/j.microc.2007.04.003

Blaney, L.M., Cinar, S., SenGupta, A.K., 2007. Hybrid anion exchanger for trace phosphate removal from water and wastewater. Water Res. 41, 1603-1613. https://doi.org/10.1016/j.watres.2007.01.008

Blough, N. V, 1998. Photochemical Formation of Hydroxyl Radical by Constituents of Natural Waters. Environ. Sci. Technol. 32, 2947-2953. https://doi.org/10.1021/es9710417 
Boujelben, N., Bouzid, J., Elouear, Z., Feki, M., Jamoussi, F., Montiel, A., 2008. Phosphorus removal from aqueous solution using iron coated natural and engineered sorbents. J. Hazard. Mater. 151, 103-110. https://doi.org/10.1016/j.jhazmat.2007.05.057

Brammer, H., Ravenscroft, P., 2009. Arsenic in groundwater: A threat to sustainable agriculture in South and South-east Asia. Environ. Int. 35, 647-654. https://doi.org/10.1016/j.envint.2008.10.004

Bulut, E., Ozacar, M., Sengil, I.A., 2008. Equilibrium and kinetic data and process design for adsorption of Congo Red onto bentonite. J. Hazard. Mater. 154, 613-622. https://doi.org/10.1016/j.jhazmat.2007.10.071

Buschmann, J., Berg, M., Stengel, C., Sampson, M.L., 2007. Arsenic and manganese contamination of drinking water resources in Cambodia: Coincidence of risk areas with low relief topography. Environ. Sci. Technol. 41, 2146-2152.

Buschmann, J., Kappeler, A., Lindauer, U., Kistler, D., Berg, M., Sigg, L., 2006. Arsenite and arsenate binding to dissolved humic acids: Influence of $\mathrm{pH}$, type of humic acid, and aluminum. Environ. Sci. Technol. 40, 6015-6020. https://doi.org/10.1021/es061057+

Cai, Y., Cabanas, M., Fernandez-Turiel, J.L., Abalos, M., Bayona, J.M., 1995. On-line preconcentration of selenium(IV) and selenium (VI) in aqueous matrices followed by liquid chromatography-inductively coupled plasma mass spectrometry determination. Anal. Chim. Acta 314, 183-192.

Carlos, L., Cipollone, M., Soria, D.B., Moreno, M.S., Ogilby, P.R., García, F.S., Mártire, D.O., 2012. The effect of humic acid binding to magnetite nanoparticles on the photogeneration of reactive oxygen species. Sep. Purif. Technol. 91, 23-29. https://doi.org/10.1016/j.seppur.2011.08.028

Chan, Y.T., Kuan, W.H., Chen, T.Y., Wang, M.K., 2009. Adsorption mechanism of selenate and selenite on the binary oxide systems. Water Res. 43, 4412-4420. https://doi.org/10.1016/j.watres.2009.06.056

Chandra, V., Park, J., Chun, Y., Lee, J.W., Hwang, I., Kim, K.S., 2010. Water-dispersible magnetite-reduced graphene oxide composites for arsenic removal. ACS Nano 4, 20052009.

Chang, F., Qu, J., Liu, R., 2010. Practical performance and its e ffi ciency of arsenic removal from groundwater using Fe-Mn binary oxide. J. Environ. Sci. 22, 1-6. 
Chen, J., Gu, B., LeBoeuf, E.J., Pan, H., Dai, S., 2002. Spectroscopic characterization of the structural and functional properties of natural organic matter fractions. Chemosphere 48, 59-68. https://doi.org/10.1016/S0045-6535(02)00041-3

Chen, R., Zhi, C., Yang, H., Bando, Y., Zhang, Z., Sugiur, N., Golberg, D., 2011. Arsenic (V) adsorption on $\mathrm{Fe} 3 \mathrm{O} 4$ nanoparticle-coated boron nitride nanotubes. J. Colloid Interface Sci. 359, 261-268. https://doi.org/10.1016/j.jcis.2011.02.071

Chen, Y., Hu, C., Hu, X., Qu, J., 2009. Indirect photodegradation of amine drugs in aqueous solution under simulated sunlight. Environ. Sci. Technol. 43, 2760-2765. https://doi.org/10.1021/es803325j

Cheng, W., Xu, J., Wang, Y., Wu, F., Xu, X., Li, J., 2015. Dispersion - precipitation synthesis of nanosized magnetic iron oxide for efficient removal of arsenite in water. J. Colloid Interface Sci. 445, 93-101. https://doi.org/10.1016/j.jcis.2014.12.082

Chin, Y.P., Aiken, G., O’Loughlin, E., 1994. Molecular weight, polydispersity, and spectroscopic properties of aquatic humic substances. Environ. Sci. Technol. 28, 1853-8. https://doi.org/10.1021/es00060a015

Chouyyok, W., Wiacek, R.J., Pattamakomsan, K., Sangvanich, T., Grudzien, R.M., Fryxell, G.E., Yantasee, W., 2010. Phosphate removal by anion binding on functionalized nanoporous sorbents. Environ. Sci. Technol. 44, 3073-3078. https://doi.org/10.1021/es $100787 \mathrm{~m}$

Conde, J.E., Sanz Alaejos, M., 1997. Selenium Concentrations in Natural and Environmental Waters. Chem. Rev. 97, 1979-2004. https://doi.org/10.1021/cr960100g

Cook, R.L., Langford, C.H., 1998. Structural Characterization of a Fulvic Acid and a Humic Acid Using Solid-State Ramp-CP-MAS 13 C Nuclear Magnetic Resonance. Environ. Sci. Technol. 32, 719-725. https://doi.org/10.1021/es970488c

Cooper, W.J., Zika, R.G., Petasne, R.G., Fischer, A.M., 1988. Sunlight-Induced Photochemistry of Humic Substances in Natural Waters: Major Reactive Species. Advances in Chemistry 22, 333-362. https://doi.org/10.1021/ba-1988-0219.ch022

Crini, G., Peindy, H.N., Gimbert, F., Robert, C., 2007. Removal of C.I. Basic Green 4 (Malachite Green) from aqueous solutions by adsorption using cyclodextrin-based adsorbent: Kinetic and equilibrium studies. Sep. Purif. Technol. 53, 97-110. https://doi.org/10.1016/j.seppur.2006.06.018 
Dalrymple, R.M., Carfagno, A.K., Sharpless, C.M., 2010. Correlations between Dissolved Organic Matter Optical Properties and Quantum Yields of Singlet Oxygen and Hydrogen Peroxide. Environ. Sci. Technol. 44, 5824-5829. https://doi.org/10.1021/es101005u

Daou, T.J., Pourroy, G., Bégin-Colin, S., Grenèche, J.M., Ulhaq-Bouillet, C., Legaré, P., Bernhardt, P., Leuvrey, C., Rogez, G., 2006. Hydrothermal synthesis of monodisperse magnetite nanoparticles. Chem. Mater. 18, 4399-4404. https://doi.org/10.1021/cm060805r

De-Bashan, L.E., Bashan, Y., 2004. Recent advances in removing phosphorus from wastewater and its future use as fertilizer (1997-2003). Water Res. 38, 4222-4246. https://doi.org/10.1016/j.watres.2004.07.014

De Paolis, F., Kukkonen, J., 1997. Binding of organic pollutants to humis and fulvic acids: influence of $\mathrm{pH}$ and the structura of humis material. Chemosphere 34, 1693-1704. https://doi.org/10.1016/S0045-6535(97)00026-X

Del Vecchio, R., Blough, N. V, 2004. On the Origin of the Optical Properties of Humic Substances On the Origin of the Optical Properties of Humic Substances. Environ. Sci. Technol. 38, 3885-3891. https://doi.org/10.1021/es049912h

Dou, X., Li, R., Zhao, B., Liang, W., 2010. Arsenate removal from water by zero-valent iron/activated carbon galvanic couples. J. Hazard. Mater. 182, 108-114. https://doi.org/10.1016/j.jhazmat.2010.06.004

Fendorf, S., Michael, H.A., van Geen, A., 2010. Spatial and Temporal Variations of Groundwater Arsenic in South and Southeast Asia. Science (80-. ). 328, 1123-1127. https://doi.org/10.1126/science.1172974

Foo, K.Y.; Hameed, B.H., 2010. Insights into the modeling of adsorption isotherm systems. Chem. Eng. J. 156, 2-10.

Fordyce, F.M., 2013. Selenium deficiency and toxicity in the environment. Essentials Med. Geol. Revis. Ed. 375-416. https://doi.org/10.1007/978-94-007-4375-5_16

Fu, Y., Wang, J., Liu, Q., Zeng, H., 2014. Water-dispersible magnetic nanoparticlegraphene oxide composites for selenium removal. Carbon N. Y. 77, 710-721. https://doi.org/10.1016/j.carbon.2014.05.076

Gang, D.D., Deng, B., Lin, L., 2010. As(III) removal using an iron-impregnated chitosan sorbent. J. Hazard. Mater. 182, 156-161. 
Geoffroy, N., Demopoulos, G.P., 2011. The elimination of selenium(IV) from aqueous solution by precipitation with sodium sulfide. J. Hazard. Mater. 185, 148-154. https://doi.org/10.1016/j.jhazmat.2010.09.009

Goldberg, S., Johnston, C.T., 2001. Mechanisms of Arsenic Adsorption on Amorphous Oxides Evaluated Using Macroscopic Measurements, Vibrational Spectroscopy, and Surface Complexation Modeling. J. Colloid Interface Sci. 234, 204-216. https://doi.org/10.1006/jcis.2000.7295

Goldhaber, S.B., 2003. Trace element risk assessment: Essentiality vs. toxicity. Regul. Toxicol. Pharmacol. 38, 232-242. https://doi.org/10.1016/S0273-2300(02)00020-X

Gonzalez, C.M., Hernandez, J., Peralta-Videa, J.R., Botez, C.E., Parsons, J.G., GardeaTorresdey, J.L., 2012. Sorption kinetic study of selenite and selenate onto a high and low pressure aged iron oxide nanomaterial. J. Hazard. Mater. 211-212, 138-145. https://doi.org/10.1016/j.jhazmat.2011.08.023

Grosvenor, A.P., Kobe, B.A., Biesinger, M.C., McIntyre, N.S., 2004. Investigation of multiplet splitting of $\mathrm{Fe} 2 \mathrm{p}$ XPS spectra and bonding in iron compounds. Surf. Interface Anal. 36, 1564-1574. https://doi.org/10.1002/sia.1984

Gu, B., Schmitt, J., Chen, Z., Liang, L., McCarthy, J.F., 1994. Adsorption and desorption of natural organic matter on iron oxide: mechanisms and models. Environ. Sci. Technol. 28, 38-46, https://doi.org/10.1021/es00050a007

Gücek, A., Şener, S., Bilgen, S., Mazmanci, M.A., 2005. Adsorption and kinetic studies of cationic and anionic dyes on pyrophyllite from aqueous solutions. J. Colloid Interface Sci. 286, 53-60. https://doi.org/10.1016/j.jcis.2005.01.012

Guerard, J., Chin, Y.-P., Mash, H., M Hadad, C., 2009. Photochemical Fate of Sulfadimethoxine in Aquaculture Waters. Environ. Sci. Technol. 43, 8587-8592. https://doi.org/10.1021/es9020537

Gupta, V.K., Carrott, P.J.M., Ribeiro Carrott, M.M.L., Suhas, 2009. Low-Cost adsorbents: Growing approach to wastewater treatmenta review. Crit. Rev. Environ. Sci. Technol. 39, 783-842. https://doi.org/10.1080/10643380801977610

Gupta, V.K., Rastogi, A., Nayak, A., 2010. Biosorption of nickel onto treated alga (Oedogonium hatei): Application of isotherm and kinetic models. J. Colloid Interface Sci. 342, 533-539. https://doi.org/10.1016/j.jcis.2009.10.074 
Hamayun, M., Mahmood, T., Naeem, A., Muska, M., Din, S.U., Waseem, M., 2014. Equilibrium and kinetics studies of arsenate adsorption by FePO4. Chemosphere 99, 207215. https://doi.org/10.1016/j.chemosphere.2013.10.075

Hamilton, S.J., 2004. Review of selenium toxicity in the aquatic food chain. Sci. Total Environ. 326, 1-31. https://doi.org/10.1016/j.scitotenv.2004.01.019

Hankins, N.P., Lu, N., Hilal, N., 2006. Enhanced removal of heavy metal ions bound to humic acid by polyelectrolyte flocculation. Sep. Purif. Technol. 51, 48-56. https://doi.org/10.1016/j.seppur.2005.12.022

Harper, T., Kingham, N., 1992. Removal of arsenic from wastewater using chemical precipitation methods. Water Environ. Res. 64, 200-203.

Harrison, R.J., Dunin-Borkowski, R.E., Putnis, A., 2002. Direct imaging of nanoscale magnetic interactions in minerals. Proc. Natl. Acad. Sci. U. S. A. 99, 16556-16561. https://doi.org/10.1073/pnas.262514499

He, G., Zhang, M., Pan, G., 2009. Influence of $\mathrm{pH}$ on initial concentration effect of arsenate adsorption on TiO2 surfaces: Thermodynamic, DFT, and EXAFS interpretations. J. Phys. Chem. C 113, 21679-21686. https://doi.org/10.1021/jp906019e

Ho, Y.S., McKay, G., 1999. Pseudo-second order model for sorption processes. Process Biochem. 34, 451-465. https://doi.org/10.1016/S0032-9592(98)00112-5

Ho, Y.S., McKay, G., 1998. A Comparison of Chemisorption Kinetic Models Applied to Pollutant Removal on Various Sorbents. Process Saf. Environ. Prot. 76, 332-340. https://doi.org/10.1205/095758298529696

Hua, M., Zhang, S., Pan, B., Zhang, W., Lv, L., Zhang, Q., 2012. Heavy metal removal from water/wastewater by nanosized metal oxides: A review. J. Hazard. Mater. 211-212, 317-331. https://doi.org/10.1016/j.jhazmat.2011.10.016

Huang, C.-C., Liao, Z.-X., Lu, H.-M., Pan, W.-Y., Wan, W.-L., Chen, C.-C., Sung, H.-W., 2016. Cellular Organelle-Dependent Cytotoxicity of Iron Oxide Nanoparticles and Its Implications for Cancer Diagnosis and Treatment: A Mechanistic Investigation. Chem. Mater. 28(24), 9017-9025.

Huang, W., Wang, S., Zhu, Z., Li, L., Yao, X., Rudolph, V., Haghseresht, F., 2008. Phosphate removal from wastewater using red mud. J. Hazard. Mater. 158, 35-42. https://doi.org/10.1016/j.jhazmat.2008.01.061 
Illés, E., Tombácz, E., 2006. The effect of humic acid adsorption on pH-dependent surface charging and aggregation of magnetite nanoparticles. J. Colloid Interface Sci. 295, 115123. https://doi.org/10.1016/j.jcis.2005.08.003

Illés, E., Tombácz, E., 2003. The role of variable surface charge and surface complexation in the adsorption of humic acid on magnetite. Colloids Surfaces A Physicochem. Eng. Asp. 230, 99-109. https://doi.org/10.1016/j.colsurfa.2003.09.017

Jacukowicz-sobala, I., Ocin, D., 2013. Synthesis and Evaluation of a Novel Hybrid Polymer Containing Manganese and Iron Oxides as a Sorbent for As ( III ) and As ( V ) Removal. Ind. Eng. Chem. Res. 52, 6453-6461.

Jiang, W., Cai, Q., Xu, W., Yang, M., Cai, Y., Dionysiou, D.D., O’Shea, K.E., 2014. Cr(VI) adsorption and reduction by humic acid coated on magnetite. Environ. Sci. Technol. 48, 8078-8085. https://doi.org/10.1021/es405804m

Jin, Y., Liu, F., Tong, M., Hou, Y., 2012. Removal of arsenate by cetyltrimethylammonium bromide modified magnetic nanoparticles. J. Hazard. Mater. 227-228, 46-468. https://doi.org/10.1016/j.jhazmat.2012.05.004

Jordan, N., Ritter, A., Foerstendorf, H., Scheinost, A.C., Weiß, S., Heim, K., Grenzer, J., Mücklich, A., Reuther, H., 2013. Adsorption mechanism of selenium(VI) onto maghemite. Geochim. Cosmochim. Acta 103, 63-75. https://doi.org/10.1016/j.gca.2012.09.048

Karageorgiou, K., Paschalis, M., Anastassakis, G.N., 2007. Removal of phosphate species from solution by adsorption onto calcite used as natural adsorbent. J. Hazard. Mater. 139, 447-452. https://doi.org/10.1016/j.jhazmat.2006.02.038

Kim, J., Benjamin, M.M., 2004. Modeling a novel ion exchange process for arsenic and nitrate removal. Water Res. 38, 2053-2062. https://doi.org/10.1016/j.watres.2004.01.012

Kumar, M., Badruzzaman, M., Adham, S., Oppenheimer, J., 2007. Beneficial phosphate recovery from reverse osmosis (RO) concentrate of an integrated membrane system using polymeric ligand exchanger (PLE). Water Res. 41, 2211-2219. https://doi.org/10.1016/j.watres.2007.01.042

Kurniawan, T.A., Sillanpää, M.E.T., Sillanpää, M., 2012. Nanoadsorbents for Remediation of Aquatic Environment: Local and Practical Solutions for Global Water Pollution Problems. Crit. Rev. Environ. Sci. Technol. 42, 1233-1295. https://doi.org/10.1080/10643389.2011.556553 
Lan, J., 2015. Removal of arsenic from aqueous systems by use of magnetic Fe3O4@TiO2 nanoparticles. Res. Chem. Intermed. 41, 3531-3541. https://doi.org/10.1007/s11164-013$1469-5$

Lemly, A.D., 2004. Aquatic selenium pollution is a global environmental safety issue. Ecotoxicol. Environ. Saf. 59, 44-56. https://doi.org/10.1016/S0147-6513(03)00095-2

Li, J., Wu, Y.N., Li, Z., Zhang, B., Zhu, M., Hu, X., Zhang, Y., Li, F., 2014. Zeolitic imidazolate framework- 8 with high efficiency in trace arsenate adsorption and removal from water. J. Phys. Chem. C 118, 27382-27387. https://doi.org/10.1021/jp508381m

Liang, Q., Zhao, D., Qian, T., Freeland, K., Feng, Y., 2012. Effects of Stabilizers and Water Chemistry on Arsenate Sorption by Polysaccharide-Stabilized Magnetite Nanoparticles. Ind. Eng. Chem. Res. 51(5), 2407-2418. https://doi.org/10.1021/ie201801d

Lin, T.C., Seshadri, G., Kelber, J.A., 1997. A consistent method for quantitative XPS peak analysis of thin oxide films on clean polycrystalline iron surfaces. Appl. Surf. Sci. 119, 8392. https://doi.org/10.1016/S0169-4332(97)00167-0

Liu, C.H., Chuang, Y.H., Chen, T.Y., Tian, Y., Li, H., Wang, M.K., Zhang, W., 2015. Mechanism of Arsenic Adsorption on Magnetite Nanoparticles from Water: Thermodynamic and Spectroscopic Studies. Environ. Sci. Technol. 49. https://doi.org/10.1021/acs.est.5b00381

Liu, H., Sun, X., Yin, C., Hu, C., 2008. Removal of phosphate by mesoporous ZrO2. J. Hazard. Mater. 151, 616-622. https://doi.org/10.1016/j.jhazmat.2007.06.033

Liu, J., Wan, L., Zhang, L., Zhou, Q., 2011. Effect of pH, ionic strength, and temperature on the phosphate adsorption onto lanthanum-doped activated carbon fiber. J. Colloid Interface Sci. 364, 490-496. https://doi.org/10.1016/j.jcis.2011.08.067

Liu, J., Zhao, Z., Jiang, G., 2008. Coating Fe3O4 Magnetic Nanoparticles with Humic Acid for High Efficient Removal of Heavy Metals in Water. Environ. Sci. Technol. 42, 69496954. https://doi.org/10.1021/es800924c

Lu, Z., Yu, J., Zeng, H., Liu, Q., 2017. Polyamine-modified magnetic graphene oxide nanocomposite for enhanced selenium removal. Sep. Purif. Technol. 183, 249-257. https://doi.org/10.1016/j.seppur.2017.04.010

Lubal, P., Široký, D., Fetsch, D., Havel, J., 1998. The acidobasic and complexation properties of humic acids study of complexation of czech humic acids with metal ions. Talanta 47, 401-412. https://doi.org/10.1016/S0039-9140(98)00143-X 
M.Mekonnen, M., Hoekstra, Y.A., 2016. Four Billion People Experience Water Scarcity. Sci. Adv. 2, 1-7. https://doi.org/10.1126/sciadv.1500323

Ma, J., Del Vecchio, R., Golanoski, K.S., Boyle, E.S., Blough, N. V, 2010. Optical Properties of Humic Substances and CDOM: Effects of Borohydride Reduction. Environ. Sci. Technol. 44, 5395-5402. https://doi.org/10.1021/es100880q

Maity, D., Agrawal, D.C., 2007. Synthesis of iron oxide nanoparticles under oxidizing environment and their stabilization in aqueous and non-aqueous media. J. Magn. Magn. Mater. 308, 46-55. https://doi.org/10.1016/j.jmmm.2006.05.001

Martínez, M., Giménez, J., De Pablo, J., Rovira, M., Duro, L., 2006. Sorption of selenium(IV) and selenium(VI) onto magnetite. Appl. Surf. Sci. 252, 3767-3773. https://doi.org/10.1016/j.apsusc.2005.05.067

Mayo, J.T., Yavuz, C., Yean, S., Cong, L., Shipley, H., Yu, W., Falkner, J., Kan, A., Tomson, M., Colvin, V.L., 2007. The effect of nanocrystalline magnetite size on arsenic removal. Sci. Technol. Adv. Mater. 8, 71-75. https://doi.org/10.1016/j.stam.2006.10.005

Meier, M., Namjesnik-Dejanovic, K., Maurice, P.A., Chin, Y.P., Aiken, G.R., 1999. Fractionation of aquatic natural organic matter upon sorption to goethite and kaolinite. Chem. Geol. 157, 275-284. https://doi.org/10.1016/S0009-2541(99)00006-6

Mezenner, N.Y., Bensmaili, A., 2009. Kinetics and thermodynamic study of phosphate adsorption on iron hydroxide-eggshell waste. Chem. Eng. J. 147, 87-96. https://doi.org/10.1016/j.cej.2008.06.024

Mishra, A.K., Ramaprabhu, S., 2010. Magnetite decorated multiwalled carbon nanotube based supercapacitor for arsenic removal and desalination of seawater. J. Phys. Chem. C 114, 2583-2590. https://doi.org/10.1021/jp911631w

Mohan, D., Pittman, C.U., 2007. Arsenic removal from water/wastewater using adsorbents-A critical review. J. Hazard. Mater. 142, 1-53. https://doi.org/10.1016/j.jhazmat.2007.01.006

Mondal, P., Bhowmick, S., Jullok, N., Ye, W., Van Renterghem, W., Van Den Berghe, S., Van Der Bruggen, B., 2014. Behavior of As(V) with ZVI-H2O system and the reduction to As(0). J. Phys. Chem. C 118, 21614-21621. https://doi.org/10.1021/jp505174k 
Naujokas, M.F., Anderson, B., Ahsan, H., Vasken Aposhian, H., Graziano, J.H., Thompson, C., Suk, W.A., 2013. The broad scope of health effects from chronic arsenic exposure: Update on a worldwide public health problem. Environ. Health Perspect. 121, 295-302. https://doi.org/10.1289/ehp.1205875

Navarro-Alarcon, M., Cabrera-Vique, C., 2008. Selenium in food and the human body: A review. Sci. Total Environ. 400, 115-141. https://doi.org/10.1016/j.scitotenv.2008.06.024

Nickson, R., McArthur, J., Burgess, W., Matin Ahmed, K., Ravenscroft, P., Rahman, M., 1998. Arsenic poisoning of Bangladesh groundwater. Nature 395, 338. https://doi.org/10.1038/26387

Ning, R.Y., 2002. Arsenic removal by reverse osmosis. Desalination 143, 237-241. https://doi.org/10.1016/S0011-9164(02)00262-X

Nishimura, T., Hashimoto, H., Nakayama, M., 2007. Removal of selenium(VI) from aqueous solution with polyamine-type weakly basic ion exchange resin. Sep. Sci. Technol. 42, 3155-3167. https://doi.org/10.1080/01496390701513107

Oehmen, A., Lemos, P.C., Carvalho, G., Yuan, Z., Keller, J., Blackall, L.L., Reis, M.A.M., 2007. Advances in enhanced biological phosphorus removal: From micro to macro scale. Water Res. 41, 2271-2300. https://doi.org/10.1016/j.watres.2007.02.030

Pan, B., Han, F., Nie, G., Wu, B., He, K., Lu, L., 2014. New Strategy to Enhance Phosphate Removal from Water by Hydrous Manganese Oxide. Environ. Sci. Technol. 48(9), 51015107. https://doi.org/10.1021/es5004044

Paul, B., Parashar, V., Mishra, A., 2015. Graphene in the Fe3O4 nano-composite switching the negative influence of humic acid coating into an enhancing effect in the removal of arsenic from water. Environ. Sci. Water Res. Technol. 1, 77-83. https://doi.org/10.1039/C4EW00034J

Peng, L., Qin, P., Lei, M., Zeng, Q., Song, H., Yang, J., Shao, J., Liao, B., Gu, J., 2012. Modifying Fe $3 \mathrm{O} 4$ nanoparticles with humic acid for removal of Rhodamine B in water. J. Hazard. Mater. 209-210, 193-198. https://doi.org/10.1016/j.jhazmat.2012.01.011

Pettine, M., McDonald, T.J., Sohn, M., Anquandah, G.A.K., Zboril, R., Sharma, V.K., 2015. A critical review of selenium analysis in natural water samples. Trends Environ. Anal. Chem. 5, 1-7. https://doi.org/10.1016/j.teac.2015.01.001 
Polizzotto, M.L., Kocar, B.D., Benner, S.G., Sampson, M., Fendorf, S., 2008. Near-surface wetland sediments as a source of arsenic release to ground water in Asia. Nature 454, 505508. https://doi.org/10.1038/nature07093

Postel, S.L., daily, G.C., Ehrlich, P.R., 1996. Human appropriation of renewable freshwater. Science 271, 785-788, https://doi.org/10.1126/science.271.5250.785

Pradeep, T., Anshup, 2009. Noble metal nanoparticles for water purification: A critical review. Thin Solid Films 517, 6441-6478. https://doi.org/10.1016/j.tsf.2009.03.195

Qu, X., Alvarez, P.J.J., Li, Q., 2013. Applications of nanotechnology in water and wastewater treatment. Water Res. 47, 3931-3946. https://doi.org/10.1016/j.watres.2012.09.058

Rahman, S., Kim, K.H., Saha, S.K., Swaraz, A.M., Paul, D.K., 2014. Review of remediation techniques for arsenic (As) contamination: Anovel approach utilizing bio$\begin{array}{llll}\text { organisms. } & \text { J. } & \text { Environ. } & \text { Manage. }\end{array}$ https://doi.org/10.1016/j.jenvman.2013.12.027

Rashid, M., Price, N.T., Gracia Pinilla, Miguel, O'Shea, K.E., 2017. Effective removal of phosphate from aqueous solution using humic acid coated magnetite nanoparticles. Water Res. 123, 353-360. https://doi.org/10.1016/j.watres.2017.06.085

Ravel, B., Newville, M., 2005. ATHENA, ARTEMIS, HEPHAESTUS: Data analysis for X-ray absorption spectroscopy using IFEFFIT. J. Synchrotron Radiat. 12, 537-541. https://doi.org/10.1107/S0909049505012719

Ren, J., Fan, W., Wang, X., Ma, Q., Li, X., Xu, Z., Wei, C., 2017. In fl uences of sizefractionated humic acids on arsenite and arsenate complexation and toxicity to Daphnia magna. Water Res. 108, 68-77. https://doi.org/10.1016/j.watres.2016.10.052

Rosario-Ortiz, F.L., Canonica, S., 2016. Probe Compounds to Assess the Photochemical Activity of Dissolved Organic Matter. Environ. Sci. Technol. 50, 12532-12547. https://doi.org/10.1021/acs.est.6b02776

Rose, A.L., Waite, T.D., 2006. Role of superoxide in the photochemical reduction of iron in seawater. Geochim. Cosmochim. Acta 70, 3869-3882. https://doi.org/https://doi.org/10.1016/j.gca.2006.06.008 
Rudzinski, W., Plazinski, W., 2006. Kinetics of solute adsorption at solid/solution interfaces: A theoretical development of the empirical pseudo-first and pseudo-second order kinetic rate equations, based on applying the statistical rate theory of interfacial transport. J. Phys. Chem. B 110, 16514-16525. https://doi.org/10.1021/jp061779n

Santos, S., Ungureanu, G., Boaventura, R., Botelho, C., 2015. Selenium contaminated waters: An overview of analytical methods, treatment options and recent advances in sorption methods. Sci. Total Environ. 521-522, 246-260. https://doi.org/10.1016/j.scitotenv.2015.03.107

Schwarzenbach, R.P., Escher, B.I., Fenner, K., Hofstetter, T.B., Johnson, C.A., von Gunten, U., Wehrli, B., 2006. The Challenge of Micropollutants in Aquatic Systems. Science (80-. ). 313, 1072 LP-1077.

Seida, Y., Nakano, Y., 2002. Removal of phosphate by layered double hydroxides containing iron. Water Res. 36, 1306-1312. https://doi.org/10.1016/S00431354(01)00340-2

Sharma, A.K., Tjell, J.C., Sloth, J.J., Holm, P.E., 2014. Review of arsenic contamination, exposure through water and food and low cost mitigation options for rural areas. Appl. Geochemistry 41, 11-33. https://doi.org/10.1016/j.apgeochem.2013.11.012

Smedley, P.L., Kinniburgh, D.G., 2002. A review of the source, behaviour and distribution of arsenic in natural waters. Appl. Geochemistry 17, 517-568.

Stoddard, J.L., Van Sickle, J., Herlihy, A.T., Brahney, J., Paulsen, S., Peck, D. V., Mitchell, R., Pollard, A.I., 2016. Continental-Scale Increase in Lake and Stream Phosphorus: Are Oligotrophic Systems Disappearing in the United States? Environ. Sci. Technol. 50, 34093415. https://doi.org/10.1021/acs.est.5b05950

Sun, W., Pan, W., Wang, F., Xu, N., 2015. Removal of Se ( IV ) and Se ( VI ) by MFe2O4 nanoparticles from aqueous solution. Chem. Eng. J. 273, 353-362. https://doi.org/10.1016/j.cej.2015.03.061

Sun, Y., Guan, X., Wang, J., Meng, X., Xu, C., Zhou, G., 2014. E ff ect of Weak Magnetic Field on Arsenate and Arsenite Removal from Water by Zerovalent Iron: An XAFS Investigation. Environ. Sci. Technol. 48(12), 6850-6858.

Szlachta, M., Chubar, N., 2013. The application of Fe-Mn hydrous oxides based adsorbent for removing selenium species from water. Chem. Eng. J. 217, 159-168. https://doi.org/10.1016/j.cej.2012.11.100 
Tahir, S.S., Rauf, N., 2006. Removal of a cationic dye from aqueous solutions by adsorption onto bentonite clay. Chemosphere 63, 1842-1848. https://doi.org/10.1016/j.chemosphere.2005.10.033

Takeda, K., Takedoi, H., Yamaji, S., Ohta, K., Sakugawa, H., 2004. Determination of Hydroxyl Radical Photoproduction Rates in Natural Waters. Anal. Sci. 20, 153-158. https://doi.org/10.2116/analsci.20.153

Tan, L.C., Nancharaiah, Y. V., van Hullebusch, E.D., Lens, P.N.L., 2016. Selenium: environmental significance, pollution, and biological treatment technologies. Biotechnol. Adv. 34, 886-907. https://doi.org/10.1016/j.biotechadv.2016.05.005

Tang, W.W., Zeng, G.M., Gong, J.L., Liang, J., Xu, P., Zhang, C., Huang, B. Bin, 2014. Impact of humic/fulvic acid on the removal of heavy metals from aqueous solutions using nanomaterials: A review. Sci. Total Environ. 468-469, 1014-1027. https://doi.org/10.1016/j.scitotenv.2013.09.044

Thurman, E.M., Malcolm, R.L., 1981. Preparative Isolation of Aquatic Humic Substances. Environ. Sci. Technol. 15, 463-466. https://doi.org/10.1021/es00086a012

Tinggi, U., 2003. Essentiality and toxicity of selenium and its status in Australia: A review. Toxicol. Lett. 137, 103-110. https://doi.org/10.1016/S0378-4274(02)00384-3

Tombácz, E., Tóth, I.Y., Nesztor, D., Illés, E., Hajdú, A., Szekeres, M., L.Vékás, 2013. Adsorption of organic acids on magnetite nanoparticles, $\mathrm{pH}$-dependent colloidal stability and salt tolerance. Colloids Surfaces A Physicochem. Eng. Asp. 435, 91-96. https://doi.org/10.1016/j.colsurfa.2013.01.023

Tseng, R.L., Wu, F.C., Juang, R.S., 2010. Characteristics and applications of the Lagergren's first-order equation for adsorption kinetics. J. Taiwan Inst. Chem. Eng. 41, 661-669. https://doi.org/10.1016/j.jtice.2010.01.014

Wang, S., Mulligan, C.N., 2006. Effect of natural organic matter on arsenic release from soils and sediments into groundwater. Environ. Geochem. Health 28, 197-214. https://doi.org/10.1007/s10653-005-9032-y

Wang, W., Johnson, C.G., Takeda, K., Zafiriou, O.C., 2009. Measuring the Photochemical Production of Carbon Dioxide from Marine Dissolved Organic Matter by Pool Isotope Exchange. Environ. Sci. Technol. 43, 8604-8609. https://doi.org/10.1021/es901543e 
Wilson, D., Langell, M.A., 2014. XPS analysis of oleylamine/oleic acid capped Fe3O4 nanoparticles as a function of temperature. Appl. Surf. Sci. 303, 6-13. https://doi.org/10.1016/j.apsusc.2014.02.006

Wu, F.C., Tseng, R.L., Juang, R.S., 2001. Enhanced abilities of highly swollen chitosan beads for color removal and tyrosinase immobilization. J. Hazard. Mater. 81, 167-177. https://doi.org/10.1016/S0304-3894(00)00340-X

Wu, P., Zhang, Q., Dai, Y., Zhu, N., Dang, Z., Li, P., Wu, J., Wang, X., 2011. Adsorption of $\mathrm{Cu}(\mathrm{II}), \mathrm{Cd}(\mathrm{II})$ and $\mathrm{Cr}(\mathrm{III})$ ions from aqueous solutions on humic acid modified $\mathrm{Ca}$ montmorillonite. Geoderma 164, 215-219. https://doi.org/10.1016/j.geoderma.2011.06.012

Xie, F., Wu, F., Liu, G., Mu, Y., Feng, C., Wang, H., Giesy, J.P., 2014. Removal of phosphate from eutrophic lakes through adsorption by in situ formation of magnesium hydroxide from diatomite. Environ. Sci. Technol. 48, 582-590. https://doi.org/10.1021/es4037379

Xu, P., Zeng, G.M., Huang, D.L., Feng, C.L., Hu, S., Zhao, M.H., Lai, C., Wei, Z., Huang, C., Xie, G.X., Liu, Z.F., 2012. Use of iron oxide nanomaterials in wastewater treatment: A review. Sci. Total Environ. 424, 1-10. https://doi.org/10.1016/j.scitotenv.2012.02.023

Xu, T., Cai, Y., Mezyk, S.P., O'Shea, K.E., 2006. The roles of hydroxyl radical, superoxide anion radical, and hydrogen peroxide in the oxidation of arsenite by ultrasonic irradiation. ACS Symp. Ser. 915, 333-343.

Yamani, J.S., Lounsbury, A.W., Zimmerman, J.B., 2014. Adsorption of selenite and selenate by nanocrystalline aluminum oxide, neat and impregnated in chitosan beads. Water Res. 50, 373-381. https://doi.org/10.1016/j.watres.2013.10.054

Yan, L.G., Xu, Y.Y., Yu, H.Q., Xin, X.D., Wei, Q., Du, B., 2010. Adsorption of phosphate from aqueous solution by hydroxy-aluminum, hydroxy-iron and hydroxy-iron-aluminum pillared bentonites. J. Hazard. Mater. 179, 244-250. https://doi.org/10.1016/j.jhazmat.2010.02.086

Yan, W., Ramos, M.A. V, Koel, B.E., Zhang, W.X., 2012. As(III) sequestration by iron nanoparticles: Study of solid-phase redox transformations with X-ray photoelectron spectroscopy. J. Phys. Chem. C 116, 5303-5311. https://doi.org/10.1021/jp208600n 
Yang, D., Velamakanni, A., Bozoklu, G., Park, S., Stoller, M., Piner, R.D., Stankovich, S., Jung, I., Field, D.A., Ventrice, C.A., Ruoff, R.S., 2009. Chemical analysis of graphene oxide films after heat and chemical treatments by X-ray photoelectron and Micro-Raman spectroscopy. Carbon N. Y. 47, 145-152. https://doi.org/10.1016/j.carbon.2008.09.045

Yang, K., Xing, B., 2009. Sorption of phenanthrene by humic acid-coated nanosized TiO2 and ZnO. Environ. Sci. Technol. 43, 1845-1851.

https://doi.org/10.1021/es802880m

Yang, S., Zong, P., Ren, X., Wang, Q., Wang, X., 2012. Rapid and Highly E ffi cient Preconcentration of Eu ( III ) by Core - Shell Structured Fe 3 O 4 @ Humic Acid Magnetic Nanoparticles. ACS Appl. Mater. Interfaces 4, 6891-6900.

Yoon, Y., Park, W.K., Hwang, T.M., Yoon, D.H., Yang, W.S., Kang, J.W., 2016. Comparative evaluation of magnetite-graphene oxide and magnetite-reduced graphene oxide composite for As(III) and As(V) removal. J. Hazard. Mater. 304, 196-204. https://doi.org/10.1016/j.jhazmat.2015.10.053

Yu, L., Peng, X., Ni, F., Li, J., Wang, D., Luan, Z., 2013. Arsenite removal from aqueous solutions by $\square-\mathrm{Fe} 2 \mathrm{O} 3-\mathrm{TiO} 2$ magnetic nanoparticles through simultaneous photocatalytic oxidation and adsorption. J. Hazard. Mater. 246-247, 10-17. https://doi.org/10.1016/j.jhazmat.2012.12.007

Zelmanov, G., Semiat, R., 2013. Selenium removal from water and its recovery using iron $(\mathrm{Fe} 3+)$ oxide/hydroxide-based nanoparticles sol (NanoFe) as an adsorbent. Sep. Purif. Technol. 103, 167-172. https://doi.org/10.1016/j.seppur.2012.10.037

Zeng, L., Li, X., Liu, J., 2004. Adsorptive removal of phosphate from aqueous solutions using iron oxide tailings. Water Res. 38, 1318-1326. https://doi.org/10.1016/j.watres.2003.12.009

Zhang, D., Liu, Z., Han, S., Li, C., Lei, B., Stewart, M.P., Tour, J.M., Zhou, C., 2004. Magnetite (Fe 3O 4) core-shell nanowires: Synthesis and magnetoresistance. Nano Lett. 4, 2151-2155. https://doi.org/10.1021/n1048758u

Zhang, F.S., Itoh, H., 2006. Photocatalytic oxidation and removal of arsenite from water using slag-iron oxide-TiO2adsorbent. Chemosphere 65, 125-131. https://doi.org/10.1016/j.chemosphere.2006.02.027

Zhang, G., Liu, H., Liu, R., Qu, J., 2009. Removal of phosphate from water by a Fe-Mn binary oxide adsorbent. J. Colloid Interface Sci. 335, 168-174. https://doi.org/10.1016/j.jcis.2009.03.019 
Zhang, L., Liu, N., Yang, L., Lin, Q., 2009. Sorption behavior of nano-TiO2for the removal of selenium ions from aqueous solution. J. Hazard. Mater. 170, 1197-1203. https://doi.org/10.1016/j.jhazmat.2009.05.098

Zhang, N., Lin, L.S., Gang, D., 2008. Adsorptive selenite removal from water using ironcoated GAC adsorbents. Water Res. 42, 3809-3816.

https://doi.org/10.1016/j.watres.2008.07.025

Zhang, X., Zhang, P., Wu, Z., Zhang, L., Zeng, G., Zhou, C., 2013. Adsorption of methylene blue onto humic acid-coated Fe3O4nanoparticles. Colloids Surfaces A Physicochem. Eng. Asp. 435, 85-90. https://doi.org/10.1016/j.colsurfa.2012.12.056

Zhang, Y., Okeke, B.C., Frankenberger, W.T., 2008. Bacterial reduction of selenate to elemental selenium utilizing molasses as a carbon source. Bioresour. Technol. 99, 12671273. https://doi.org/10.1016/j.biortech.2007.02.048

Zheng, S., Jiang, W., Rashid, M., Cai, Y., Dionysiou, D.D., O’Shea, K.E., 2015. Selective reduction of $\mathrm{Cr}(\mathrm{VI})$ in chromium, copper and arsenic (CCA) mixed waste streams using UV/TiO2 photocatalysis. Molecules 20, 2622-2635.

Zhou, P., Yan, H., Gu, B., 2005. Competitive complexation of metal ions with humic substances. Chemosphere 58, 1327-1337.

Zimmerman, J.B., Mihelcic, J.R., Smith, J., 2008. Global stressors on water quality and quantity. Environ. Sci. Technol. 42, 4247-4254. https://doi.org/10.1021/es0871457 


\section{APPENDICES}

Appendix A Chapter 2

Table A1. Summary of the concentration of dissolved organic carbon (DOC) due to leaching of NOM from HA-MNP at different $\mathrm{pH}$

\begin{tabular}{lll}
\hline Initial conc. of HA-MNP (ppm) & Initial solution $\mathrm{pH}$ & Final conc. of DOC (ppm) \\
\hline & 4.0 & $4.2 * 10^{-2}$ \\
100 & 7.0 & $2.1 * 10^{-2}$ \\
& 10.0 & $7.2 * 10^{-2}$ \\
\hline
\end{tabular}
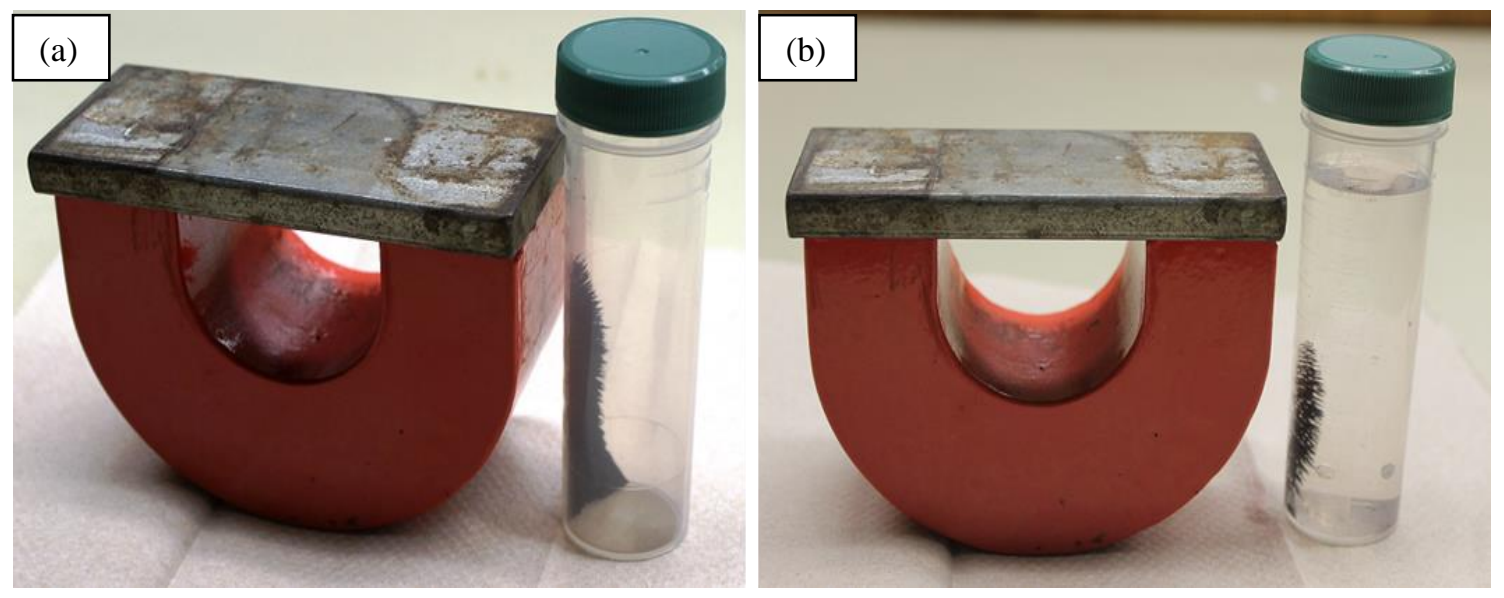

Figure A1: Synthesized humic acid coated magnetite nanoparticles (HA-MNP) in presence of a handheld magnet a) before adsorption of phosphate b) after adsorption of phosphate 


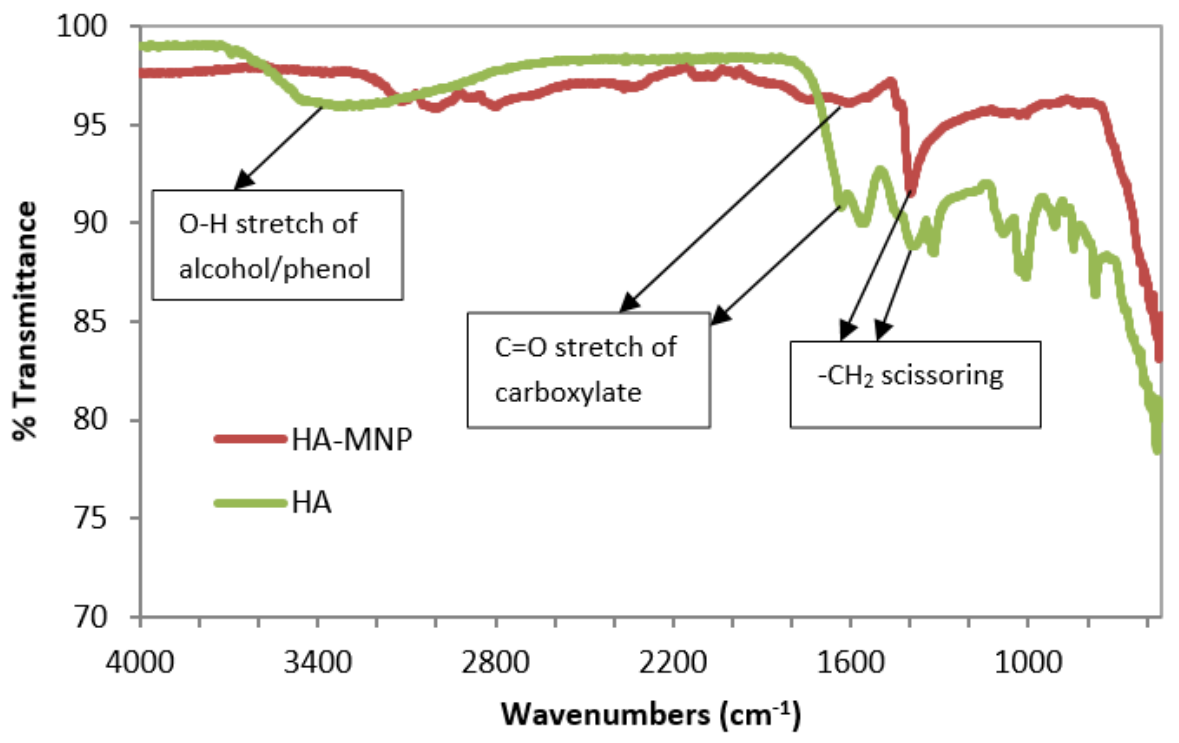

Figure A2: FTIR spectra of humic acid (HA) and humic acid coated magnetite nanoparticles (HA-MNP) 


\section{Appendix B Chapter 3}

\section{HA-MNP characterization}

The FTIR spectra of the nanoparticles before and after adsorption of arsenic species were obtained from the PerkinElmer FTIR in the spectral range of $600-4000 \mathrm{~cm}^{-1}$ with 32 scans per spectrum. Surface morphology and microstructure of the nanoparticles with and without arsenic treatment were examined by collecting the images in transmission electron microscopy and in high angular annual dark field (HAADF-STEM). The images were recorded on a FEI TITAN G2 80-300 instrument operated at $300 \mathrm{kV}$. The sample was dropped (after an ultrasonic bath in ethanol) onto a carbon-coated copper grid which was then dried at ambient conditions prior to analysis. The vibrational properties of nanostructures were identified using Thermo Scientific XDR Raman microscope using a $532 \mathrm{~nm}$ laser as exciting light source with $5 \mathrm{~mW}$ power. For FTIR, TEM and Raman analysis, all the arsenic adsorption experiments were carried out using $200 \mathrm{ppb}$ As(III) or $\mathrm{As}(\mathrm{V})$ as adsorbate and $1.0 \mathrm{~g} / \mathrm{L} \mathrm{HA}-\mathrm{MNP}$ as adsorbent with initial solution of $\mathrm{pH}$ 6.6. Xray photoelectron spectroscopy (XPS) and x-ray absorption spectroscopy (XAS) data were obtained from the Advanced Photon Source at Argonne National Laboratory. XPS measurements were made using an unmonochromatized $\mathrm{Mg} \mathrm{K \alpha}$ X-ray source and a Scienta Omicron Argus electron energy analyzer operating at $20 \mathrm{eV}$ pass energy. The base pressure in the ultra-high vacuum analysis chamber, to which samples were transferred from an induction chamber, was about $2 \times 10^{-10}$ Torr. Casa XPS software was used for analysis and curve fitting. X-ray absorption spectra were obtained at room temperature at beamline 9BM, where the energy of the x-ray beam was selected by a fixed-exit double crystal 
monochromator with Si (111) crystals. The standards for the As K-edge and Fe K-edge were prepared by adding boron nitride to the arsenic salts, untreated HA-MNP and bare MNP. The experimental samples were made from the arsenic treated HA-MNP which were collected through filtration from solution, vacuum dried, homogenized and finally pressed into $7 \mathrm{~mm}$ pellets. Both the standards and the samples were sealed using Kapton tape before placing into the beamline. All Fe K-edge XAS data was collected in transmission mode. As K-edge was collected in transmission mode for standards and fluorescence mode for the arsenic treated nanoparticles. Either a four-element silicon drift detector or a twelveelement Ge solid-state detector was used for florescence data collection. In order to mitigate air exposure before time dependent studies, the sample was transferred to a nitrogen glovebox immediately after being treated with arsenic solution and dried in an oven. The sample was pressed into a pellet and sealed in Kapton tape within the glovebox. Upon removal from the glovebox, the sample was immediately taken to the beamline to begin alignment and XAS data collection. As(III) HA-MNP data shown in Figure S5a was smoothed by three iterations of a three-point smoothing algorithm.

\section{Adsorption kinetics and isotherm study}

Adsorption kinetics of As(III) and As(V) were examined by fitting the obtained data in the pseudo-first order and pseudo-second order kinetic models. The mathematical expressions of the pseudo-first order and pseudo-second order kinetic models are shown in equation $\mathrm{B} 1$ \& $\mathrm{B} 2$ respectively-

$$
\ln (Q e-Q t)=\ln Q e-k_{1} t
$$


$\frac{t}{Q_{t}}=\frac{1}{k_{2} Q_{e}^{2}}+\frac{1}{Q_{e}} t$

Where $\mathrm{Q}_{\mathrm{e}}$ and $\mathrm{Q}_{\mathrm{t}}$ stands for the amount of arsenic adsorbed on the HA-MNP surface at equilibrium and at time $\mathrm{t}$ respectively. $\mathrm{k}_{1}$ and $\mathrm{k}_{2}$ are the corresponding rate constants for the pseudo-first order and the pseudo-second order kinetic models and $t$ is the time in minutes for all cases. To get better insights of the adsorption mechanism, Weber and Morris intraparticle diffusion model was used which can be represented as-

$Q_{t}=k_{i d} t^{1 / 2}+c$

Where $\mathrm{Q}_{\mathrm{t}}$ is the adsorbed amount of $\mathrm{As}(\mathrm{III})$ or $\mathrm{As}(\mathrm{V})$ in $\mathrm{mg} / \mathrm{g}, \mathrm{K}_{\mathrm{id}}$ is the diffusion rate constant and $\mathrm{c}$ is the intercept.

The binding of arsenic species with HA-MNP were also modeled using the Langmuir and Freundlich adsorption isotherm. The mathematical expressions of Langmuir and Freundlich isotherms are shown in equation B4 \& B5 respectively -

$$
\begin{aligned}
& \frac{C_{e}}{Q_{e}}=\frac{1}{b Q_{\max }}+\frac{C_{e}}{Q_{\max }} \\
& \log Q_{e}=\log K_{f}+\frac{1}{n} \log C_{e}
\end{aligned}
$$

Where $\mathrm{C}_{\mathrm{e}}$ is the equilibrium concentration of adsorbate arsenic in solution $(\mathrm{mg} / \mathrm{L})$ and $\mathrm{Q}_{\mathrm{e}}$ is the amount of adsorbate adsorbed on the HA-MNP surface (mg/g) at equilibrium. $\mathrm{Q}_{\max }$ is the maximum adsorption capacity of the adsorbent $(\mathrm{mg} / \mathrm{g})$ and $\mathrm{b}$ is the Langmuir constant representing the energy of adsorption. $\mathrm{K}_{\mathrm{f}}$ is a measure of relative adsorption capacity $(\mathrm{L} / \mathrm{mg}$ ) and $1 / \mathrm{n}$ represents adsorption intensity (dimensionless). For $1 / \mathrm{n}$ above or 
below 1 refers to the binding mechanism as cooperative adsorption or chemisorption while the value close to 0 implies greater surface heterogeneity.

Table B1. Effect of iron in the adsorption of arsenic species on HA-MNP

\begin{tabular}{llll}
\hline $\mathrm{Fe}^{2+}$ concentration & $\begin{array}{l}\text { Initial As } \\
\text { concentration }\end{array}$ & $\begin{array}{l}\text { Residual As concentration } \\
\text { in water after treatment }\end{array}$ & $\begin{array}{l}\% \text { removal of } \\
\text { As }\end{array}$ \\
\hline \multirow{2}{*}{$1.0 \mathrm{ppm}$} & $200 \mathrm{ppb}[\mathrm{As}(\mathrm{III})]$ & $6 \mathrm{ppb}[\mathrm{As}(\mathrm{III})]$ & $97 \%$ \\
& $200 \mathrm{ppb}[\mathrm{As}(\mathrm{V})]$ & $4 \mathrm{ppb}[\mathrm{As}(\mathrm{V})]$ & $98 \%$ \\
\hline
\end{tabular}

Table B2. Release of dissolved organic carbon from HA-MNP before and after arsenic adsorption

\begin{tabular}{|c|c|c|c|}
\hline $\begin{array}{l}\text { Initial HA-MNP } \\
\text { concentration } \\
(\mathrm{ppm})\end{array}$ & $\begin{array}{l}\text { Initial solution } \\
\mathrm{pH}\end{array}$ & Species & $\begin{array}{l}\text { Final DOC } \\
\text { concentration (ppm) }\end{array}$ \\
\hline \multirow{3}{*}{1000} & \multirow{3}{*}{$6.6 \pm 0.1$} & HA-MNP & 0.25 \\
\hline & & As(III)-HA-MNP & 0.48 \\
\hline & & As(V)-HA-MNP & 0.57 \\
\hline
\end{tabular}




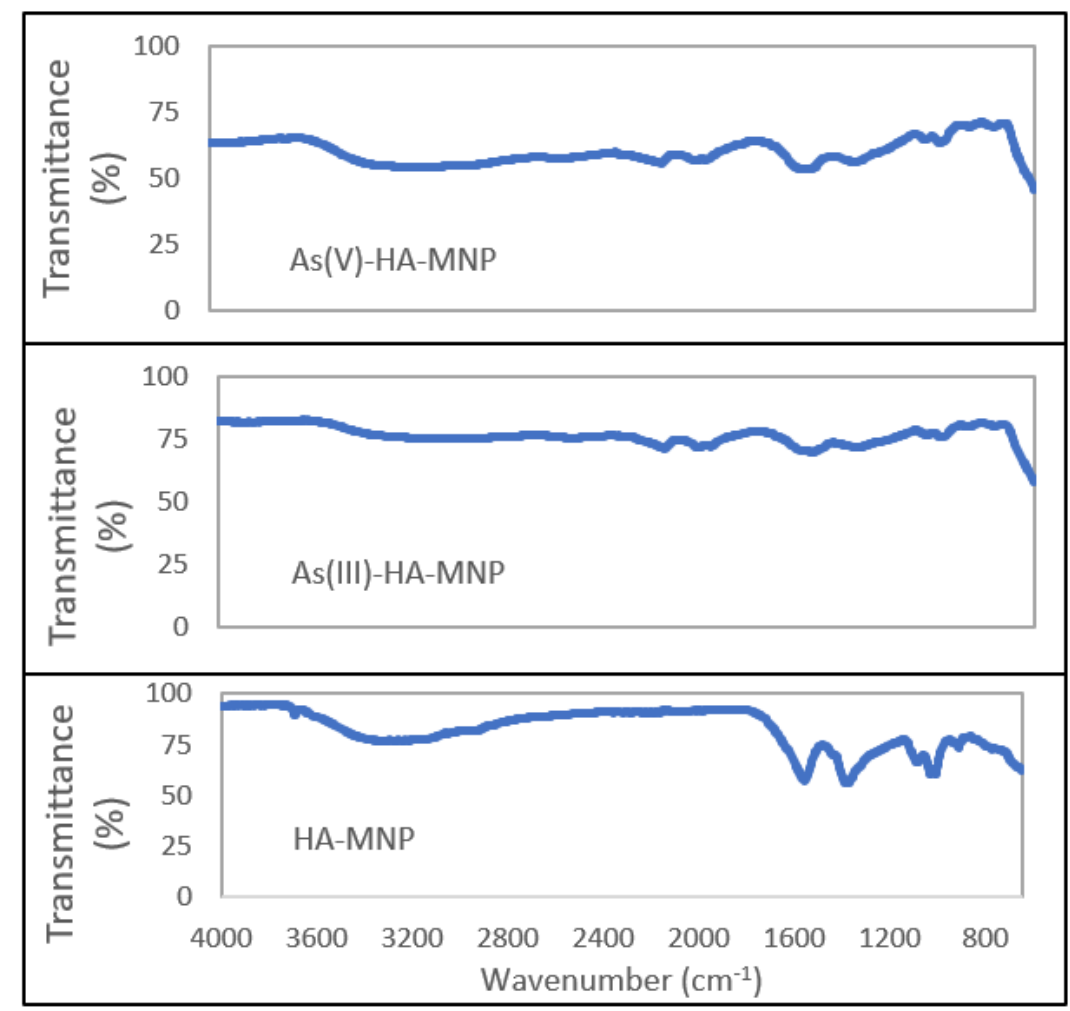

Figure B1: FTIR spectra of the synthesized HA-MNP before and after the adsorption of arsenic species

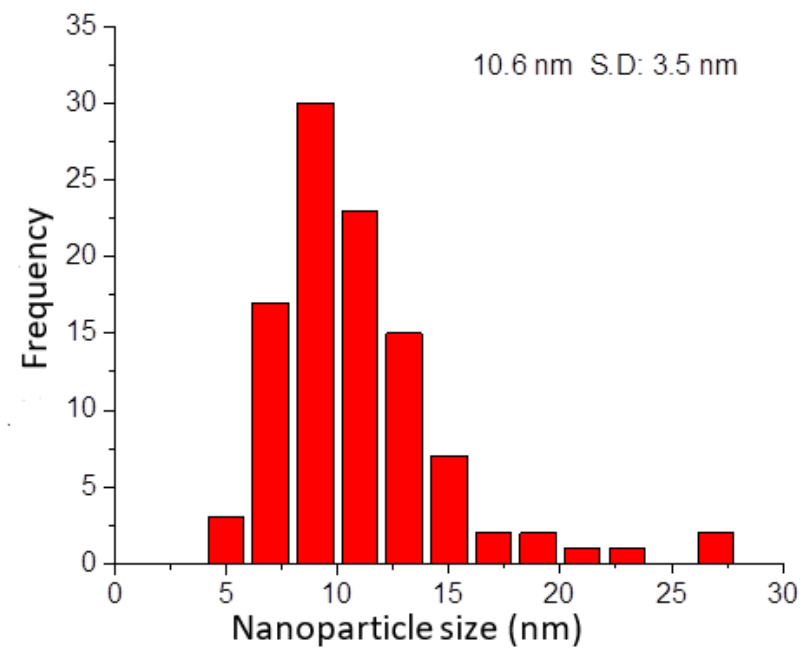

Figure B2: Size distribution of HA-MNP from TEM measurement 


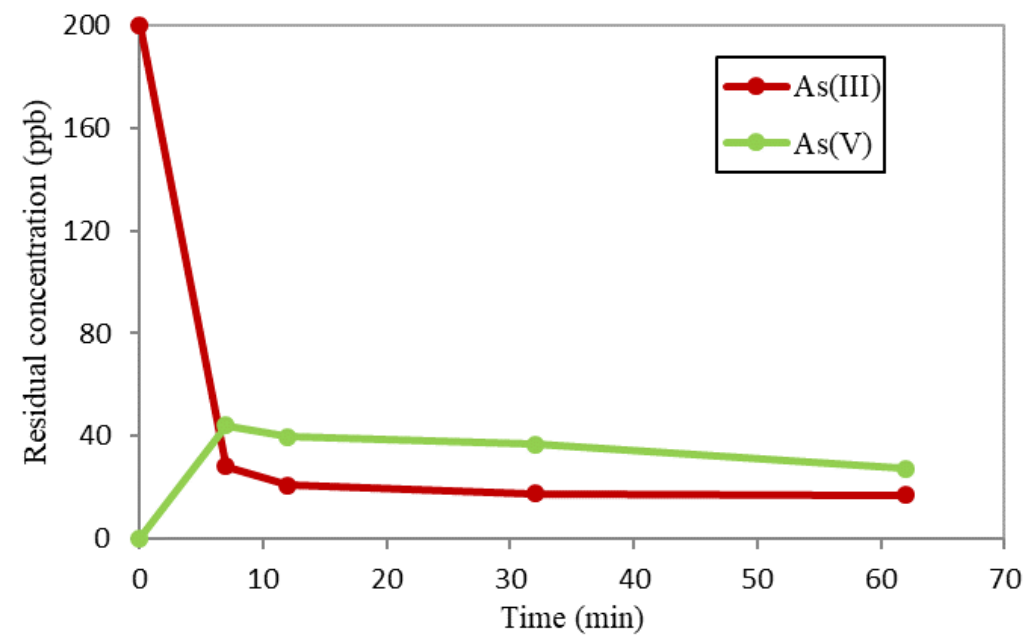

Figure B3: Adsorption and conversion of As(III) using HA-MNP and $\mathrm{O}_{2}$ under dark condition. Initial As(III) concentration $=200 \mathrm{ppb}, \mathrm{HA}-\mathrm{MNP}$ dose $=0.2 \mathrm{~g} / \mathrm{L}$
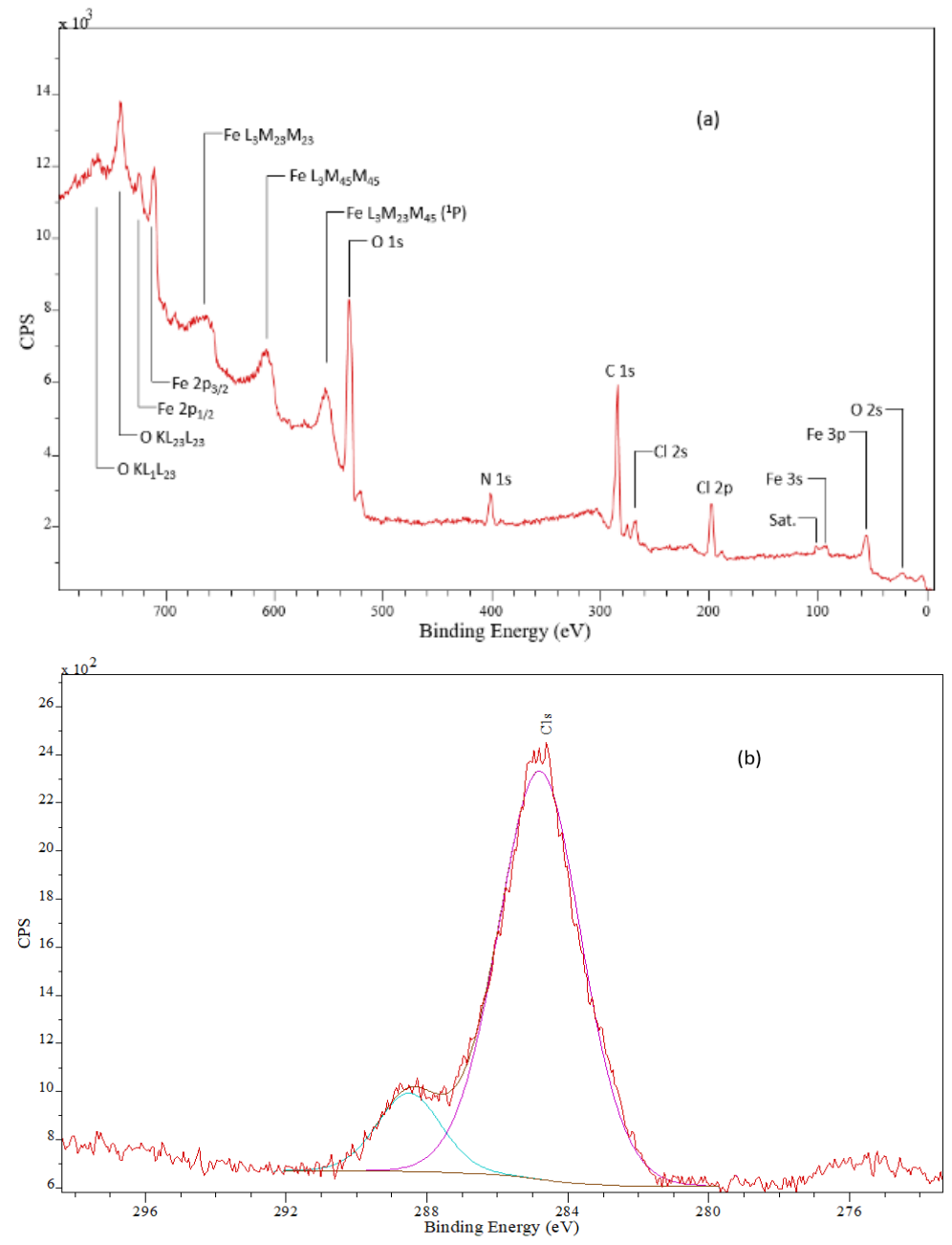

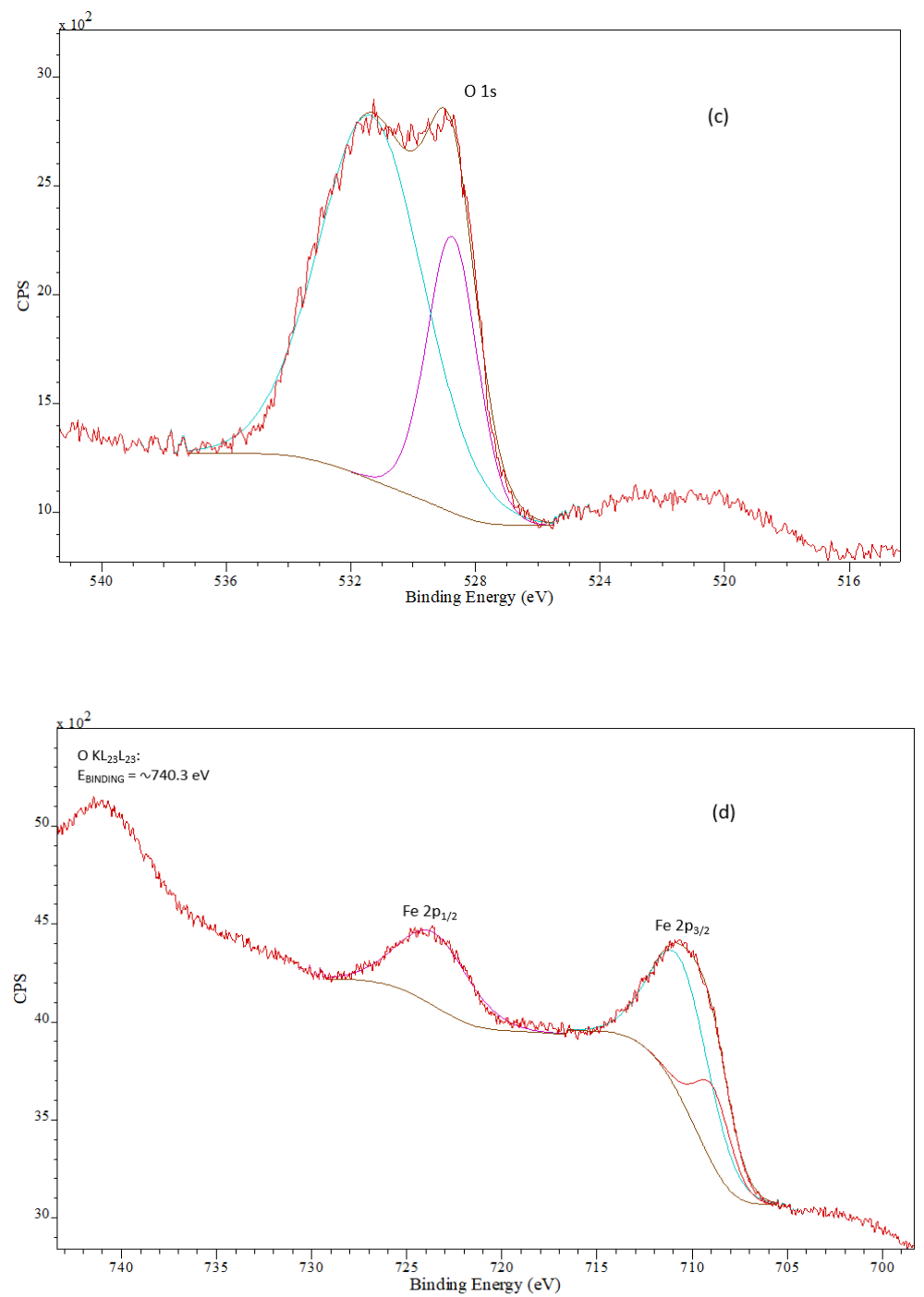

Figure B4: a) Wide scan XPS spectra of HA-MNP. Deconvolution of the XPS spectra of (b) $\mathrm{C} 1 \mathrm{~s}$, (c) $\mathrm{O} 1 \mathrm{~s}$ and (d) Fe $2 \mathrm{p}$ respectively 

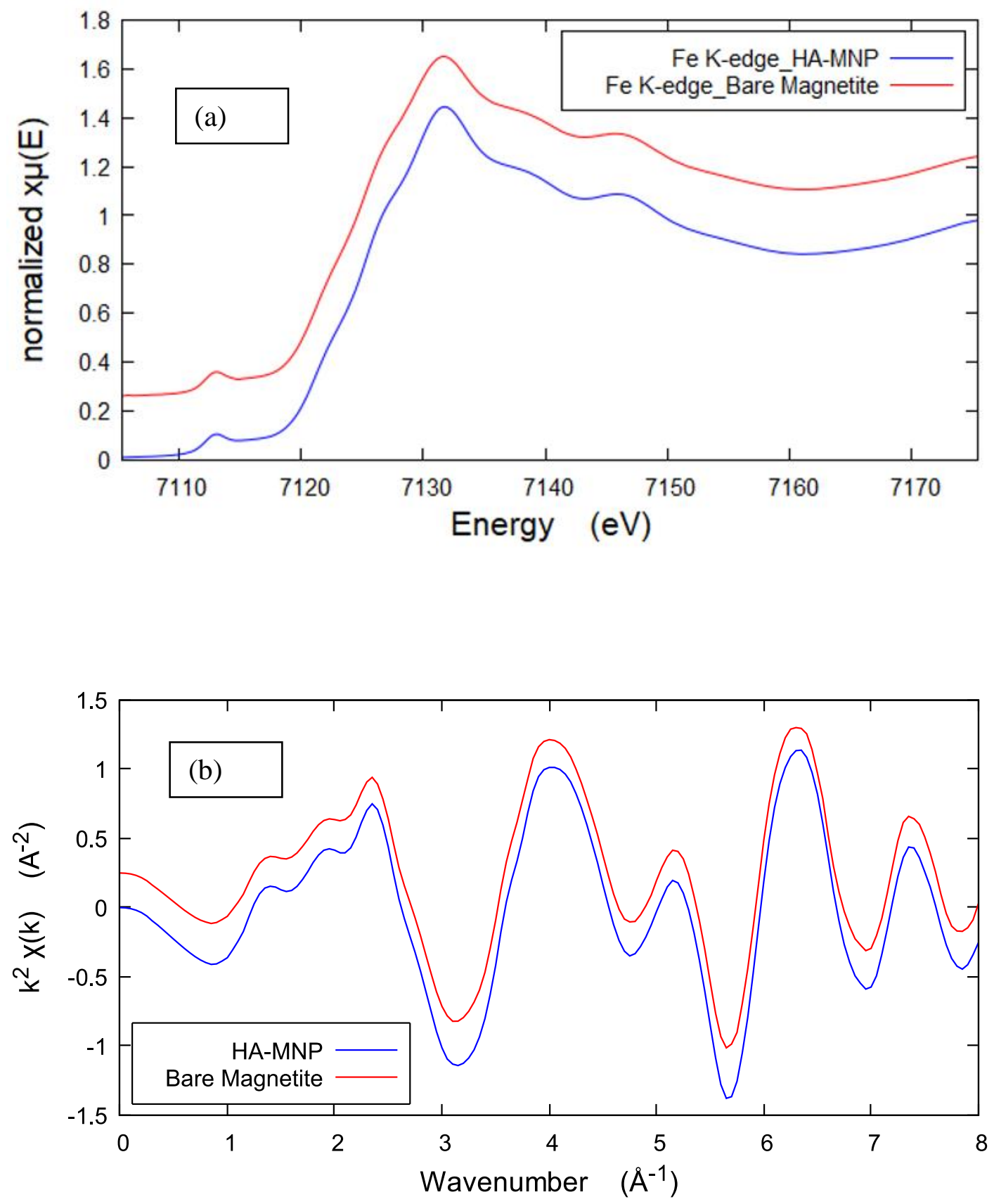

Figure B5: Fe K-edge (a) XANES and (b) EXAFS spectra of bare magnetite and HAMNP 

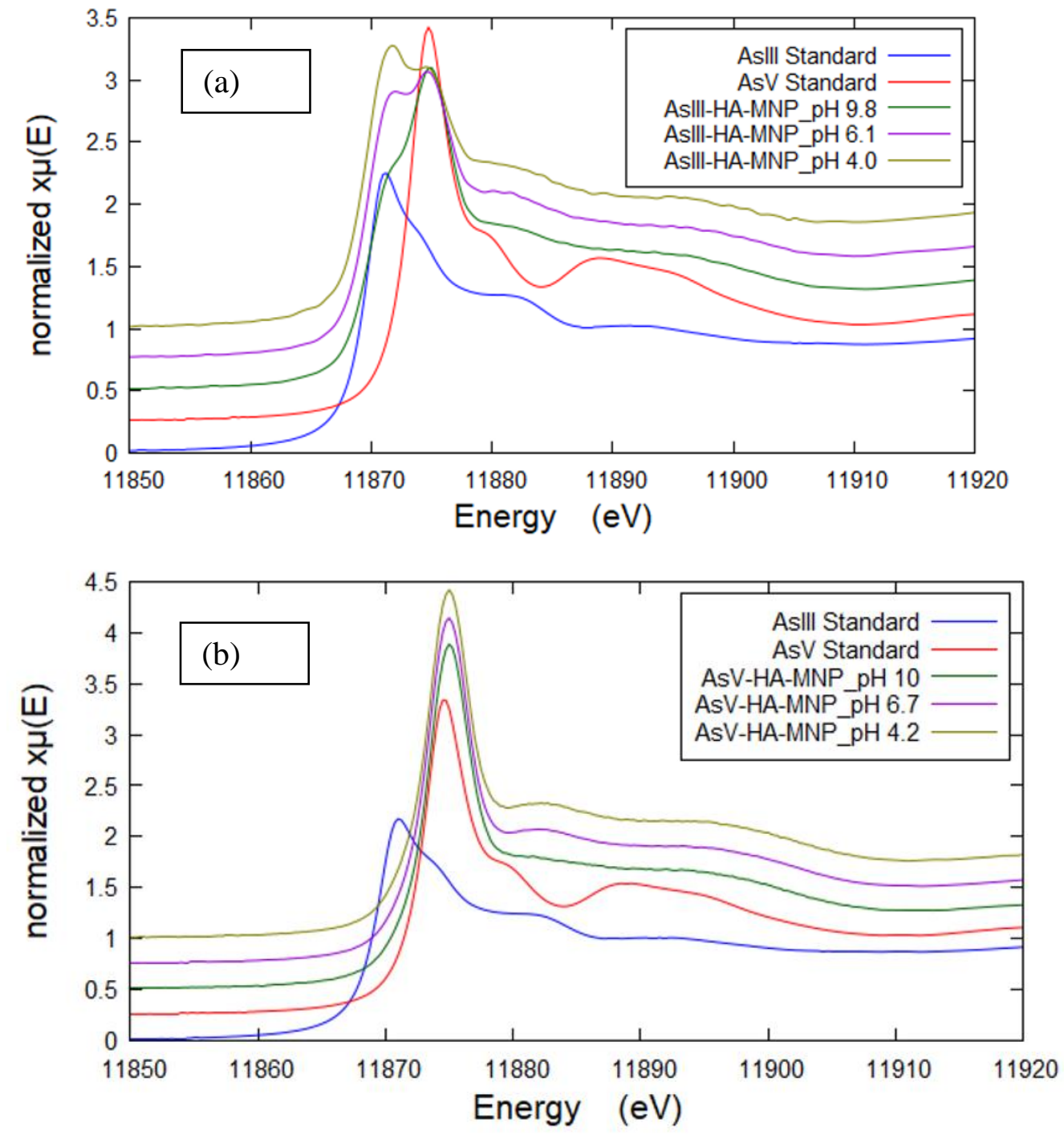

Figure B6: (a) Arsenic K-edge XANES spectra of As(III) standard, As(V) standard and As(III)-HA-MNP at different pH (b) arsenic K-edge XANES spectra of As(III) standard, $\mathrm{As}(\mathrm{V})$ standard and As(V)-HA-MNP at different $\mathrm{pH}$ 


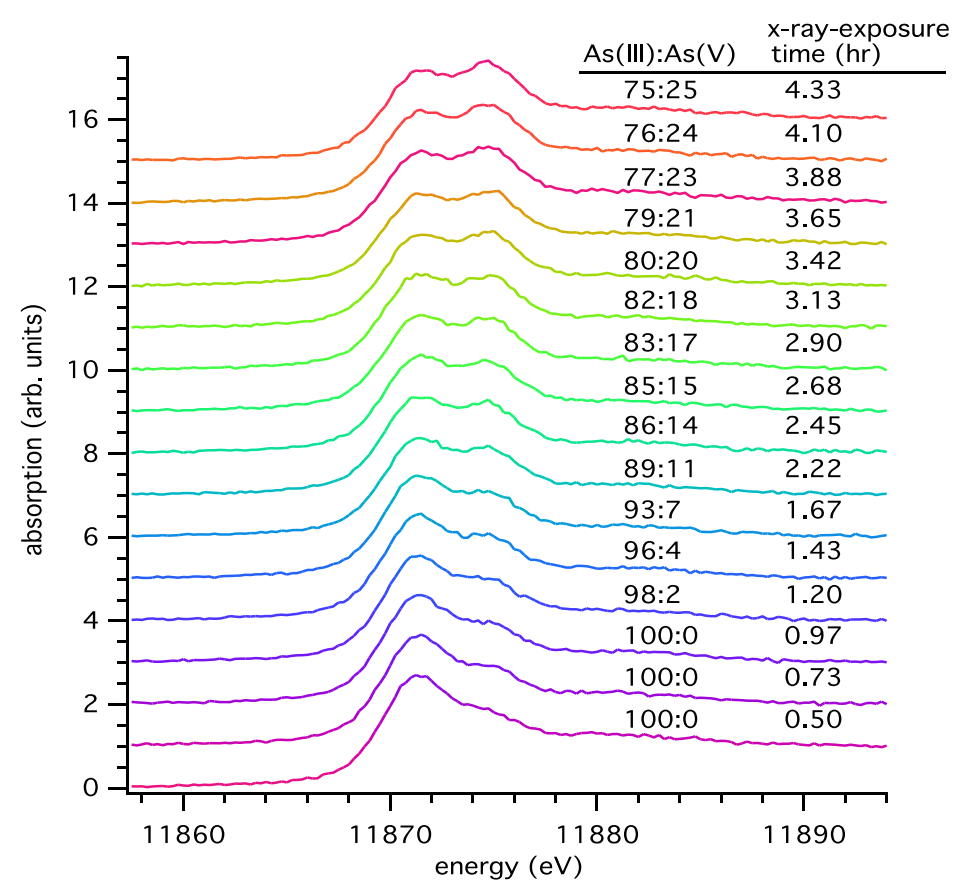

Figure B7: XANES spectra time profile of HA-MNP treated As(III) at pH 6.1

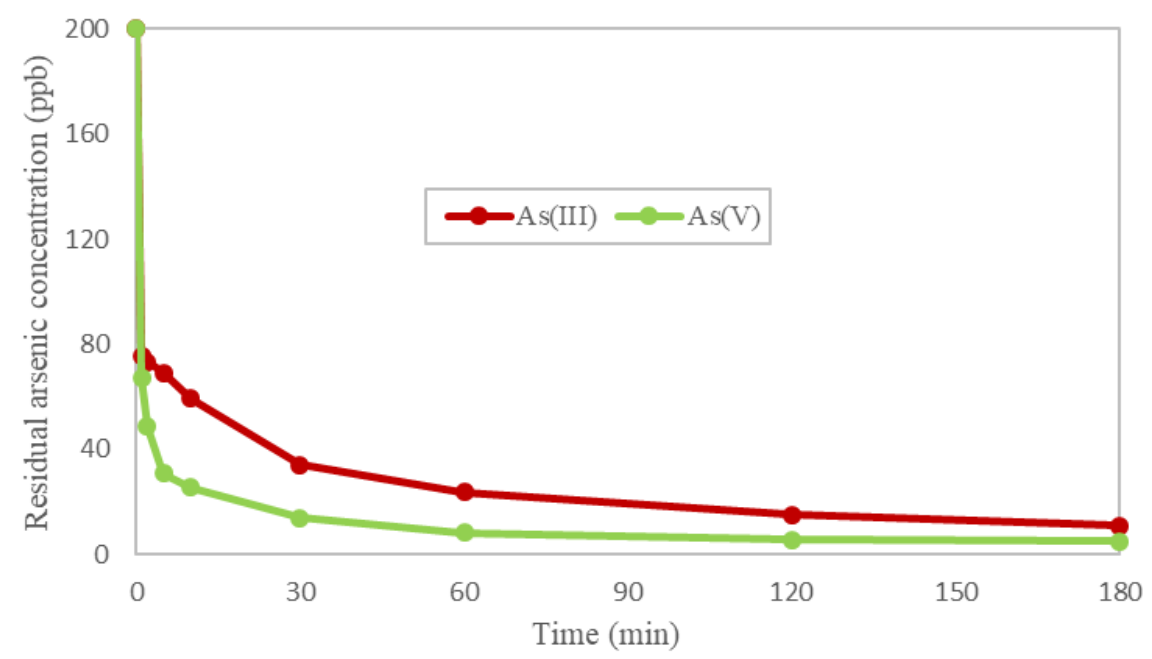

Figure B8: Competition between As(III) and As(V) for HA-MNP when present in the same solution. $[\mathrm{As}(\mathrm{III})]_{0}=200 \mathrm{ppb},[\mathrm{As}(\mathrm{V})]_{0}=200 \mathrm{ppb}, \mathrm{pH}=6.6, \mathrm{HA}-\mathrm{MNP} \operatorname{dose}=0.2 \mathrm{~g} / \mathrm{L}$ 


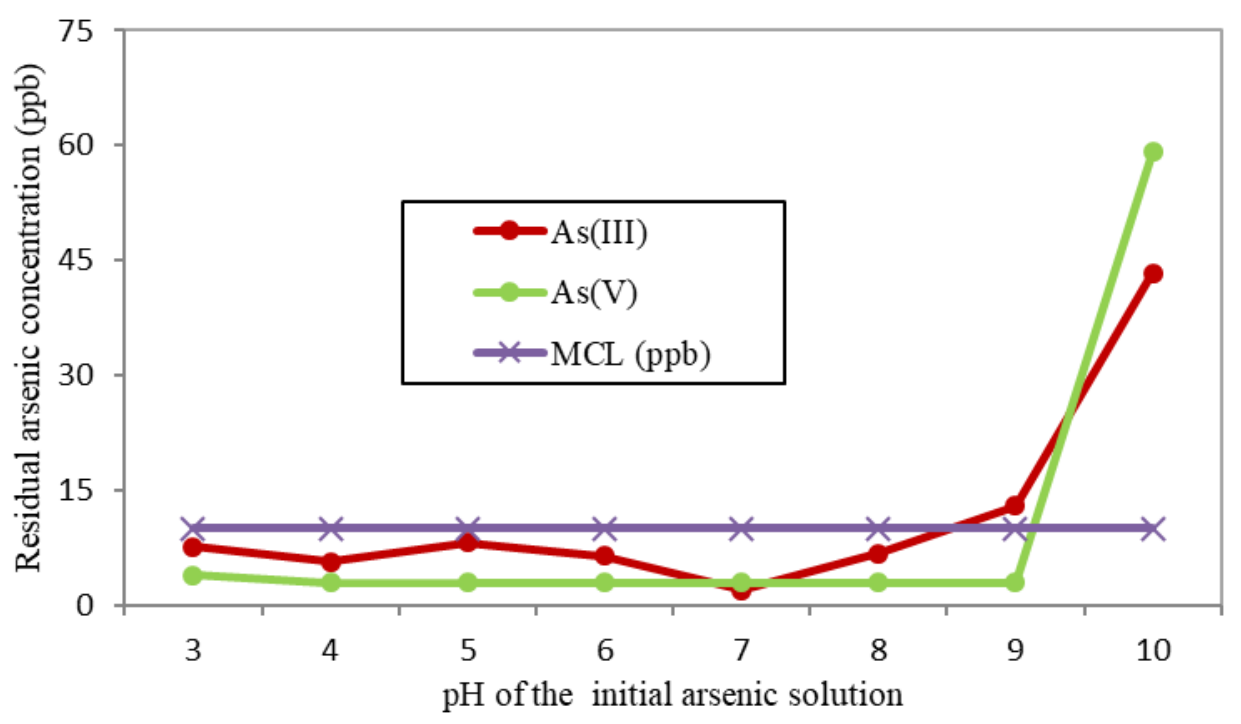

Figure B9: Effect of initial $\mathrm{pH}$ for the adsorption of As(III) and As(V) on HA-MNP. Initial As(III) concentration $=200 \mathrm{ppb}$, initial As(V) concentration $=200 \mathrm{ppb}$, HA-MNP dose $=$ $0.2 \mathrm{~g} / \mathrm{L}$, temperature $=25^{\circ} \mathrm{C}, \mathrm{MCL}$ stands for Maximum Contaminant Level (in drinking water)

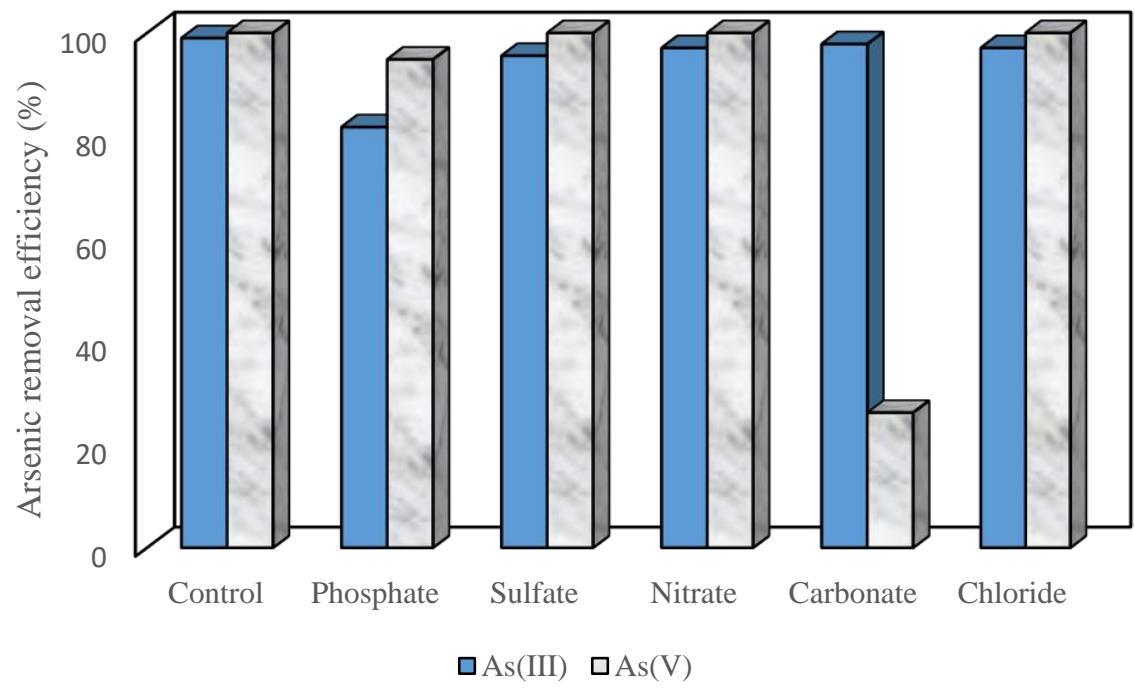

Figure B10: Effect of coexisting ions for the adsorption of arsenic species on HA-MNP. Initial As(III) concentration $=200 \mathrm{ppb}$, initial As(V) concentration $=200 \mathrm{ppb}, \mathrm{HA}-\mathrm{MNP}$ dose $=0.2 \mathrm{~g} / \mathrm{L}$, temperature $=25^{\circ} \mathrm{C}$ 
VITA

\section{MOHAMMAD MAMUNUR RASHID}

Born, Noakhali, Bangladesh

2000-2006

Bachelor of Science in Chemistry

University of Dhaka

Dhaka, Bangladesh

2007-2008

Customer Services Representative

Pacific Bangladesh Telecom Ltd

2008-2010

1) Laboratory Manager 2) EHS Officer

British American Tobacco

Dhaka, Bangladesh

2008-2013

MBA in Finance

Institute of Business Administration

University of Dhaka

Dhaka, Bangladesh

2012-2013

Executive- QMS \& EHS

Rahimafrooz Accumulators Ltd

Dhaka, Bangladesh

2013-present

Doctoral Candidate in Chemistry

Florida International University

Miami, Florida, USA

\section{PUBLICATIONS AND PRESENTATIONS}

S Zheng, W Jiang, M Rashid, Y Cai, DD Dionysiou, KE O'Shea. Selective reduction of $\mathrm{Cr}(\mathrm{VI})$ in chromium, copper and arsenic (CCA) mixed waste streams using $\mathrm{UV} / \mathrm{TiO}_{2}$ photocatalysis. Molecules, 2015, 20, 2622-2635

M Rashid, NT Price, MÁG Pinilla, KE O'Shea. Effective removal of phosphate from water using humic acid coated magnetic iron oxide nanoparticles. Water Research, 2017, 123, $353-360$

M Rashid, G Sterbinsky, MÁG Pinilla, Y Cai, KE O'Shea. Kinetic and mechanistic evaluation of inorganic arsenic species adsorption onto humic acid grafted magnetite nanoparticles. Journal of Physical Chemistry C, 2018

MM Rashid, Y Cai, KE O'Shea. Removal of arsenite from water by adsorption onto humic acid coated magnetite nanoparticles. 251st National American chemical society meeting, California, March 13-17, 2016 
MM Rashid, Y Cai, KE O'Shea. Efficient removal of toxic arsenic from water by using environment friendly humic acid coated magnetite nanoparticles. Graduate student appreciation week, FlU, March 28-29, 2016

MM Rashid, Y Cai, KE O'Shea. Environment friendly magnetic nanoparticles: An application to remove toxic arsenic from groundwater. Statewide graduate student research symposium, University of Florida, April 22, 2016

M Rashid, Y Cai, KE O'Shea. Removal of toxic arsenic species from water by using natural organic matter coated magnetic nanoparticles. $92^{\text {nd }}$ Florida annual meeting and exposition, Tampa, May 5-7, 2016

M Rashid, KE O'Shea. Removal of toxic arsenic and selenium species from water by using humic acid coated magnetic iron oxide nanoparticles. $9^{\text {th }}$ annual nanoscience technology symposium, University of Central Florida, September 25-26, 2016

M Rashid, KE O'Shea. Efficient removal of toxic selenium from water by using environment friendly magnetic nanoparticles. Graduate student appreciation week, FlU, March 27-28, 2017

M Rashid, Y Cai, G Sterbinsky, KE O'Shea. Application of natural organic matter coated magnetic iron oxide nanoparticles for the remediation of arsenic and selenium. 253rd National American chemical society meeting, California, April 2-6, 2017

M Rashid, KE O'Shea. Generation of ROS by the engineered nanoparticles of humic acid grafted iron oxide for the potential remediation of toxic arsenic from water. $23^{r d}$ international conference on advanced oxidation technologies for treatment of air, water and soil, Florida, November 13-16, 2017

MM Rashid, KE O'Shea. Study of the photochemical and adsorptive properties of NOM grafted iron oxide nanoparticles for the potential remediation of toxic arsenic from water. $255^{\text {th }}$ National American chemical society meeting, Louisiana, March 18-22, 2018 